\title{
Partitioning above and below ground interactions and their effects on juvenile Dacrycarpus dacrydioides (kahikatea) and Podocarpus totara (totara).
}

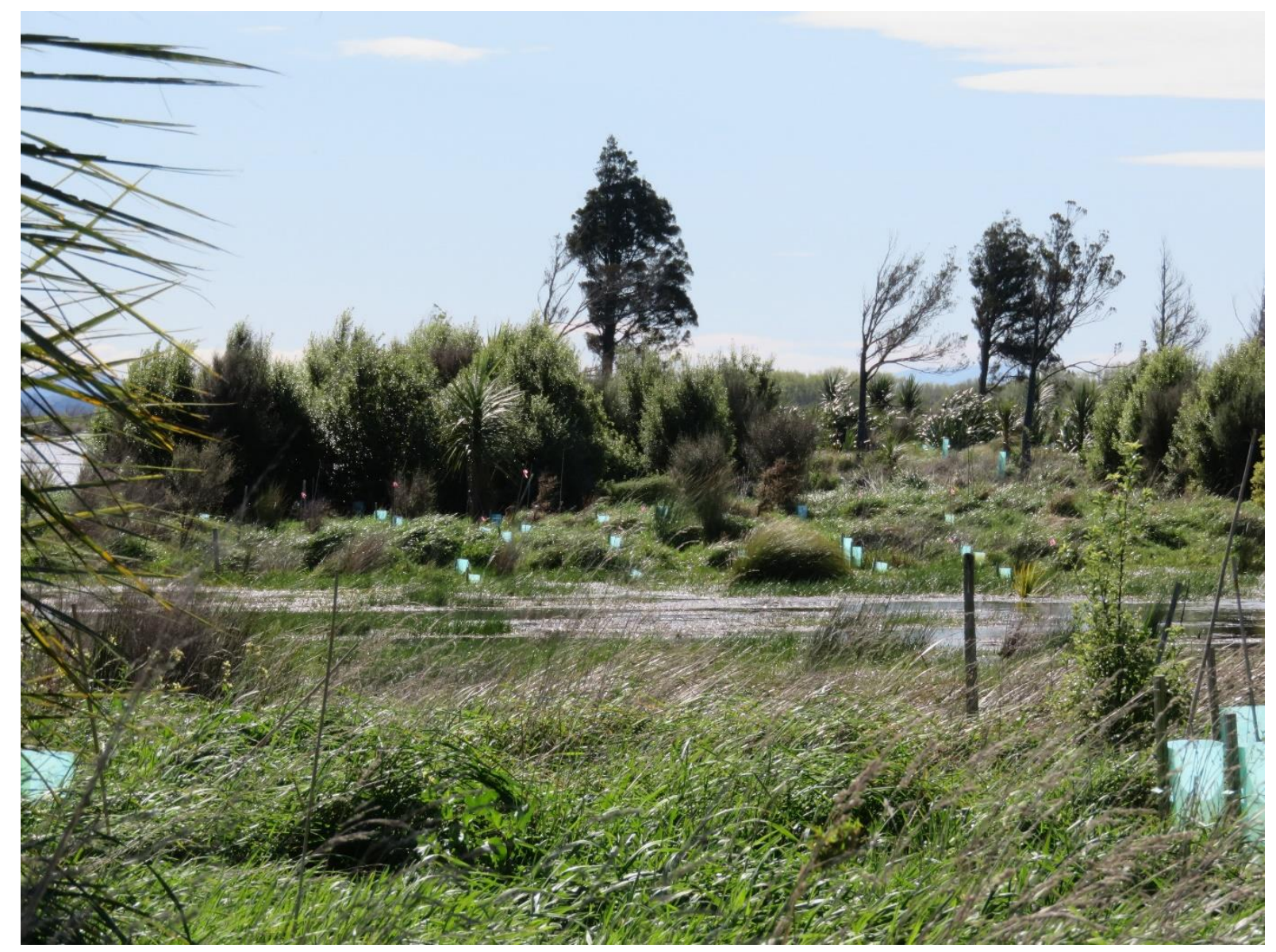

By

Garth Fabbro

A thesis submitted for the partial fulfilment for the degree of Master of Science in Ecology and Biodiversity

Victoria University of Wellington 


\section{$\underline{\text { Abstract }}$}

Competitive and facilitative interactions play an important role in determining plant community structure and development. Historically, competitive interactions have been considered to be more prevalent in nature. However, in the past few decades strong facilitative interactions have been identified as being more important than competition in certain environments. Recent evidence has also suggested that interactions occurring in the above and below ground environments may be unevenly contributing to the net interaction effects between a target plant and nurses species. This study partitions the above and below ground interactions and determines their strength and directions in order to help better understand their relative importance to plant community dynamics.

In Chapter 2 I develop species specific allometric models which aim to accurately estimate the total above- and below- ground biomass of individual $D$. dacrydioides and $P$. totara juveniles using measurements which are easily and non-destructively obtained in the field. The best model for each species is then used to construct total above and below ground biomass estimates for use in Chapter 3. Eight models using stem height, diameter, and volume either alone or in combination are examined for their predictive power and tested for their goodness of fit. Models using diameter alone are found to be less powerful in predicting total tree biomass, while models containing height either alone or in combination with diameter are more powerful. The absolute best model for predicting $D$. dacrydioides total biomass was $\mathrm{B}_{\text {TOTAL }}=0.0099\left(\text { Height }^{2}\right)^{0.8749}$, whereas the absolute best model for $P$. totara was $\mathrm{B}_{\mathrm{TOTAL}}=0.2635\left((\text { Height*Diameter })^{2}\right)^{0.5695}$.

In Chapter 3 I use the Relative Interaction Index (RII) to determine the strength and direction of the net interactions affecting $D$. dacrydioides and $P$. totara juveniles. To partition the above ground interactions, I examined the effects of a conspecific or interspecific neighbour. I found that my two study species $D$. dacrydioides and $P$. totara showed different responses to the treatments that they received. $D$. dacrydioides showed net facilitation and gained biomass when it had access to the mycorrhizal network and a neighbour. Whereas, P. totara showed net neutral interactions and did not gain biomass. $P$. totara also showed net competition when it did not have access to the mycorrhizal network and was grown next to neighbours. The role of above ground interactions was found to be less important than below ground interactions, overall. In general, these results mean that $D$. dacrydioides juveniles 
should be expected to have higher growth, reproductive, and survival rates when grown next to nurse species in comparison to $P$. totara.

Chapter 4 details the significance of this study for the restoration of Wairio wetland, and wetlands in general. Given the result in chapter 3 and the current restoration method at Wairio wetland, this study suggests that it may be worth exploring the benefit of planting new P. totara juveniles farther away from older woody species in order to avoid root competition. 


\section{Acknowledgements}

My sincere and deepest thanks go out to my supervisor Dr Julie Deslippe for all the help, support and sound advice she has provided me with over the duration of this thesis. Thank you to all the people who volunteered their time to help me plant and tend the trees during those rainy, windy, cold days; namely Dr Stephen Hartley, Manon Hulley, Aurore Fanal, and Matt Biovin. I would also like to acknowledge Ducks Unlimited and Jim Law for supplying the plants used in this study. To my work bosses Clare Obrien, and Maryanne Mckennie, thank you so much for allowing me such flexible work hours while I have been studying. I would also like to thank Chris Thorn of the technical team for her fast and efficient response in organising field and lab equipment. Finally, I would like to thank my long-suffering girlfriend Kassie Sydow for putting up with me while I have been studying, and especially for the food and encouragement she provided. 


\section{$\underline{\text { Lists }}$}

\section{List of figures}

Figure 1. Graphical representation of the relative intensity of facilitative and competitive interactions along an environmental stress gradient

Figure 2. Mechanisms of nutrient acquisition of a root from the surrounding soil.

Figure 3. Photo of the roots of a Podocarpus totara juvenile.

Figure 4. Map of Stage 3 at Wairio wetland

Figure 5. Stylized representation of a plot

Figure 6. Photo of stem height and diameter measurements being taken

Figure $7 . \quad$ Photos of root cleaning

Figure 8. Bar plot of relative height gain w/ and w/o grotectors

Figure 9. Regression plots of log transformed biomass data for D. dacrydioides

Figure 10. Regression plots of log transformed biomass data for P. totara

Figure 11. Graph of confidence intervals for the prediction of D. dacrydioides validation sample

Figure 12. Graph of confidence intervals for the prediction of $P$. totara validation sample

Figure 13. Map of lower North island and Wairio

Figure 14. Stylized representation of a plot

Figure 15. Photos of planted plots

Figure 16. Diagram of nearest neighbour measurements

Figure 17. Diagram of planting treatments

Figure 18. Diagram showing different combinations for calculating RII

Figure 19. Plot of RII data

Figure 20. Bar plot of mean total biomass data for D. dacrydioides

Figure 21. Bar plot of mean total biomass data for $P$. totara

Figure 22. Bar plot of pooled mean total biomass data for D. dacrydioides and P. totara 


\section{List of tables}

Table 1. Table of generic candidate models

Table 2. Characteristics of harvested juveniles

Table 3. Table of allometric equations for predicting $D$. dacrydioides biomass

Table 4. Table of allometric equations for predicting $P$. totara biomass

Table 5. Table of Goodness of fit statistics for D. dacrydioides

Table 6. Table of Goodness of fit statistics for P. totara

Table 7. Classification of neighbouring pairs

Table 8. Summary of how planting technique relates to below ground pathway access

Table $9 . \quad$ Summary of mortality data

\section{List of abbreviations}

SGH Stress Gradient Hypothesis

SS. Soil Solution

MN Mycorrhizal Network

RG Root Graft

Con Conspecific species

Inter Interspecific species

None No neighbour

RII Relative Interaction Index

w/o Without

w/ With

\section{List of species used in thesis}

\begin{tabular}{lll}
\hline Dacrycarpus dacrydioides & - & kahikatea \\
Podocarpus totara & - & totara \\
Cordyline australis & - & cabbage tree \\
Olearia virgata & - & twiggy tree daisy \\
Leptospermum scoparium & - & manuka \\
Pittosporum tenuifolium & - & kohūhū
\end{tabular}




\section{Table of Contents}

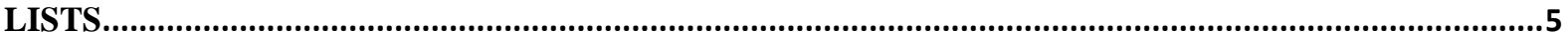

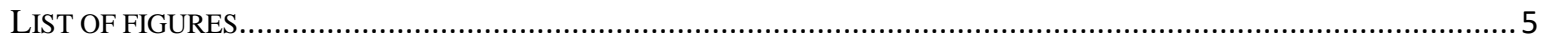

LIST OF TABLES

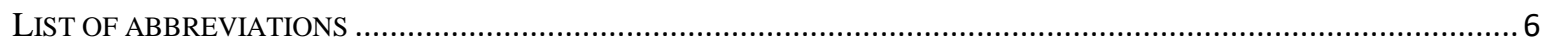

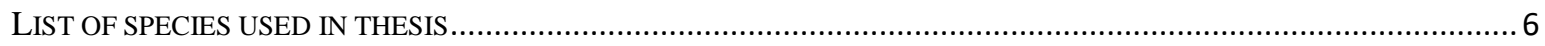

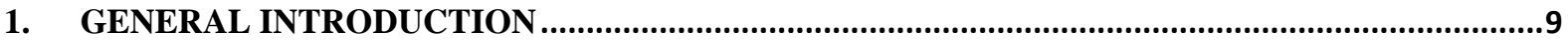

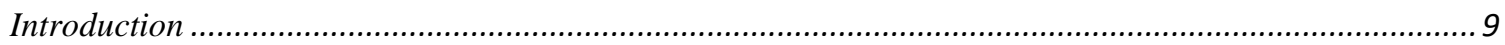

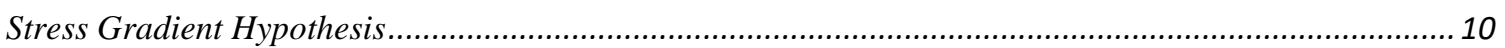

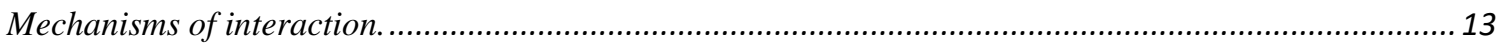

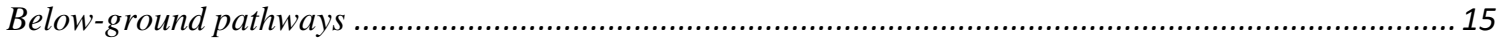

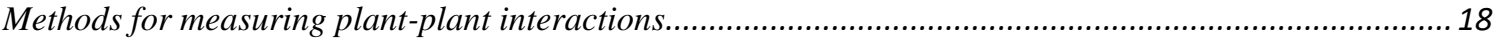

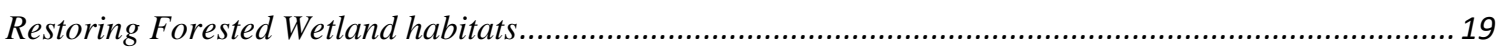

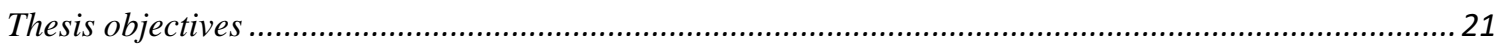

2. DEVELOPMENT OF ALLOMETRIC EQUATIONS FOR ESTIMATING THE BIOMASS OF $D$.

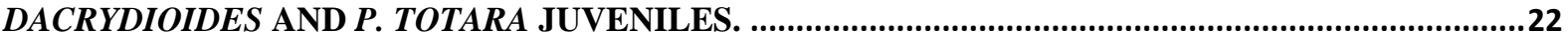

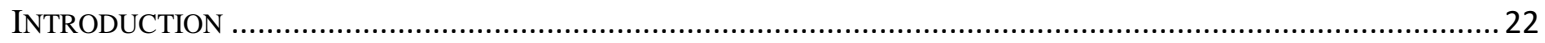

METHODS...

Study site

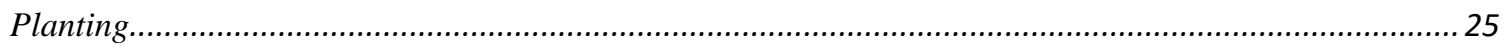

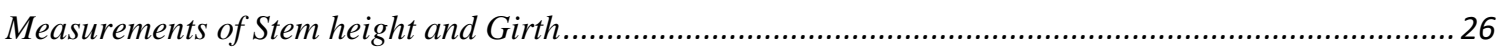

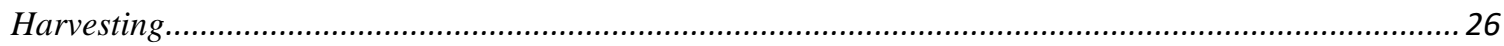

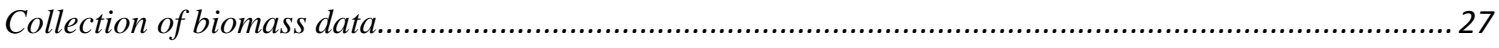

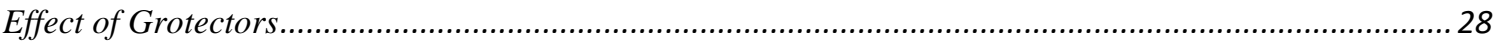

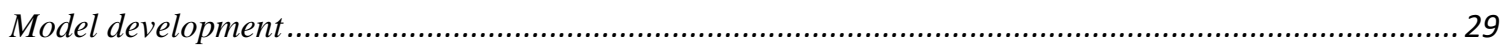

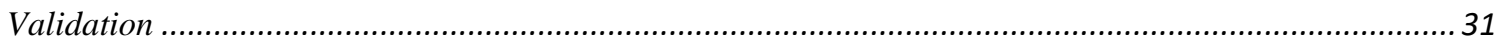

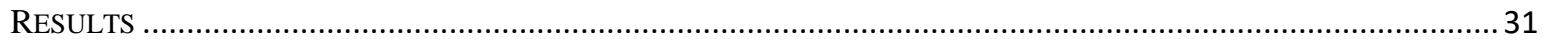

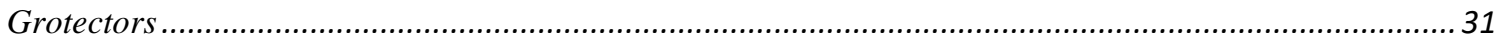

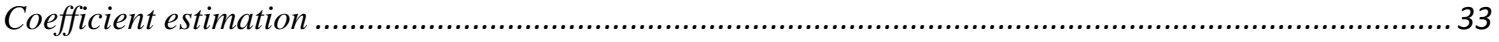

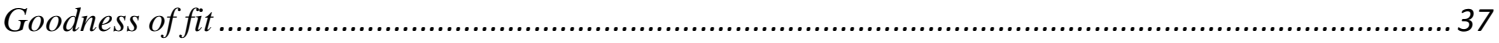

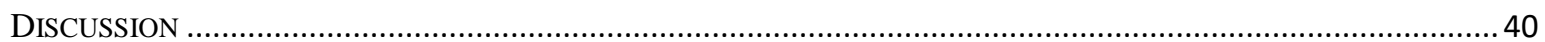

3. PARTITIONING ABOVE AND BELOW GROUND INTERACTIONS AND THEIR EFFECTS ON

D. DACRYDIOIDES AND P. TOTARA JUVENILES.............................................................................42

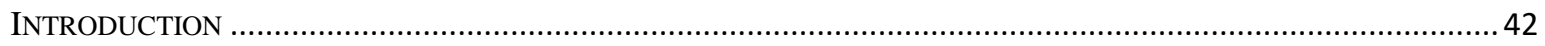

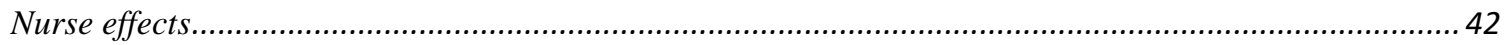

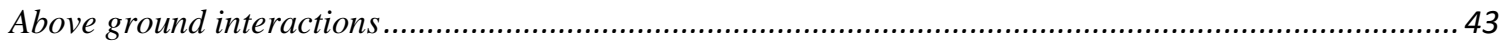

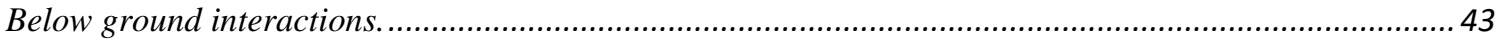

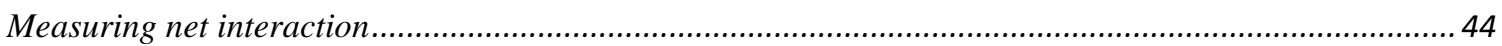




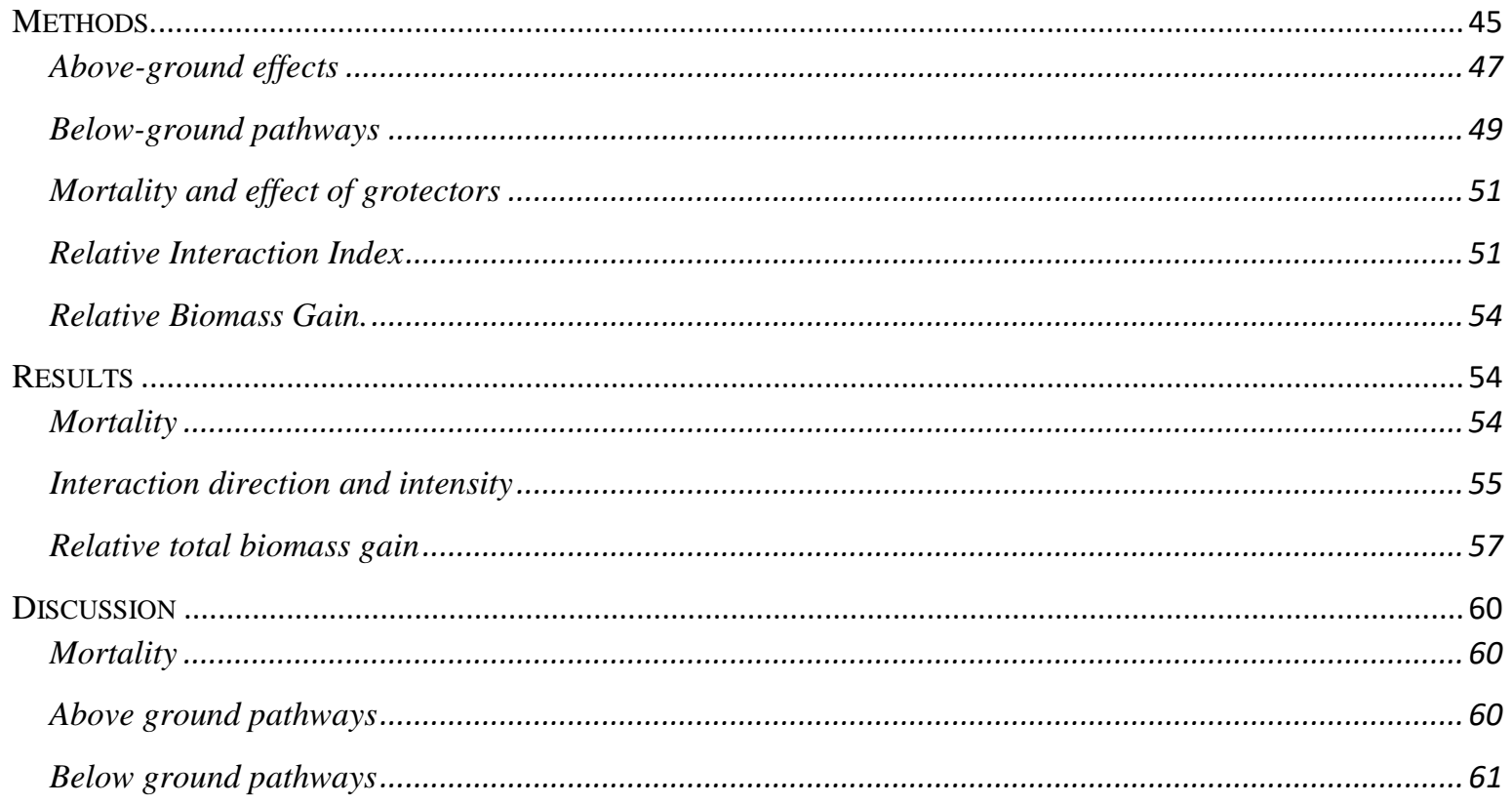

4. IMPLICATIONS FOR THE REFORESTATION OF A NEW ZEALAND WETLAND.................63

INTRODUCTION 


\section{General Introduction}

\section{Introduction}

Understanding and quantifying the mechanisms that influence the organization of plant communities is a central tenet in ecology. The common ecological usage for the term 'community' describes an assemblage of two or more species coexisting within a defined geographical area and timeframe (Lidicker 2008). Members of an ecological community are networked to one another through variety of complex interactions, such that the presence of an individual may directly or indirectly influence the success or failure of another individual's survival and growth within the community. The relative importance and intensity of these constant interactions are widely considered to be a fundamental driving force in shaping plant community structure and diversity (Holmgren et al. 1997, Bertness et al. 1999, Menge 2000, Mougi and Kondoh 2012).

Ecological interactions between individuals can be categorized in several different ways; Intra-specific, and inter-specific interactions occur between members of the same species, and members of two or more different species, respectively; competitive interactions where one individual has a negative effect on the another individual, and facilitative interactions where the effect is positive. Callaway (2007) in his excellent treatise on plant community interactions considers facilitative interactions to be where the presence of a plant species is beneficial to fitness, with positive changes to growth, reproduction, and survival of another species in its proximity. By comparison, competitive interactions are detrimental and will reduce survival, growth and fitness. This thesis adopts Callaway's definitions, with the caveat that changes in reproductive fitness are not considered here. This caveat is necessary as the tree species studied are juveniles, and not reproductively mature.

Competitive interactions between plants occur when individuals vie for a shared and limited resource. Typically, light, nutrients or water are limiting resources in plant communities with the competitively inferior individuals access to the resource being inhibited or reduced, resulting in a negative effect on growth and survival (Craine and Dybzinski 2013).

Competition is expected to be most intense between species which share a niche, particularly between conspecifics as niche overlap will be equivalent (MacArthur and Levins 1967). Conversely, competition is expected to be lower when niche dissimilarity is greatest. Perhaps the most widely known example of facilitative interactions between plants is the 'nurse' plant 
phenomenon. Nurse plants are older, more established plants that alter the surrounding environment to the benefit of a younger and often smaller neighbour. These so called 'nurse effects' can increase the size of a plant's realized niche beyond the range of its fundamental niche, allowing them to occupy locations which would normally be inhospitable in the absence of their neighbour (Bruno et al. 2003).

\section{Stress Gradient Hypothesis}

Many of the early pioneers of plant successional theory acknowledged that both facilitative and competitive interactions mediated plant community structure (Clements 1916, Gleason 1926, Whittaker 1956). Yet historically, competitive interactions have dominated the scientific literature, driven by popular models on community organization which stressed the role of competition (Grime 1973, Tilman 1982). Evidence for the importance of strong facilitative interactions organizing plant communities began to accumulate from studies in environments which were considered to be physiologically stressful for plants, such as arid, alpine, and intertidal zones (Franco and Nobel 1989, Bertness and Shumway 1993, Callaway 2007). In order to provide a theoretical background for the observed prevalence of facilitative interactions in stressful environments, Bertness and Callaway (1994) developed a model, in which the frequency of competitive and facilitative interactions observed changed along gradients of abiotic stress. The theoretical underpinning of the model is derived from the theories of competitive strategies; in which species must pre-empt resource limitation by expending energy in order to gain each resource (Grime 1977). In relatively benign environments, species can devote more energy towards competing for resources, as less energy is required to maintain physiological homeostasis. However, under harsh environmental conditions where physiological stress is increased, species cannot devote as much energy to competing for resources. Hence there are fewer or less intense competitive interactions in stressful environments and neighbour effects are more likely to be facilitative (Bertness and Shumway 1993). In essence, the model postulates that along an increasingly physiologically stressful gradient, or gradients of increasing consumer pressure, there will be a change from primarily competitive interactions to increasingly facilitative. The predictions generated by the model have been formally termed the "Stress Gradient Hypothesis" (SGH) and are generally well-supported by empirical evidence (Berkowitz et al. 1995a, Callaway et al. 2002, Gomez-Aparicio et al. 2004). 
However, the SGH model is not without criticism. Results from several studies reveal that, even within the same study system, there are differences in the frequency of facilitative and competitive interactions (Choler et al. 2001, Michalet et al. 2006, Butterfield et al. 2016). For instance, Tielbörger and Kadmon (2000) found that the interplay of facilitation and competition between a perennial nurse shrub and annual beneficiary species changed from predominantly negative to neutral, or from neutral to positive interactions when environmental conditions became less stressful, contrary to the predictions of SGH. Maestre et al. (2009) argues that the SGH model needs to be refined to account for the relative strength of interactions, rather than their frequency of occurrence. This is due to concerns that empirical support for the original SGH model was collected from studies which investigated only a single pair of species (a nurse species and its beneficiary or beneficiaries), or a few pairs of different species. Moreover, many studies examine gradients in stress over large spatial scales rather than experimentally manipulating stress at a local level. They considered experiments conducted in this way to have a high degree of risk in being confounded by local variations within species (Maestre et al. (2009). As a refinement to the SGH, Maestre et al. (2009) proposed a new model where facilitative intensity is predicted to be strongest at intermediate to high levels of stress, whereas, net competitive intensity will be greater than or equal to facilitation at low and extreme levels of stress (Figure 1).

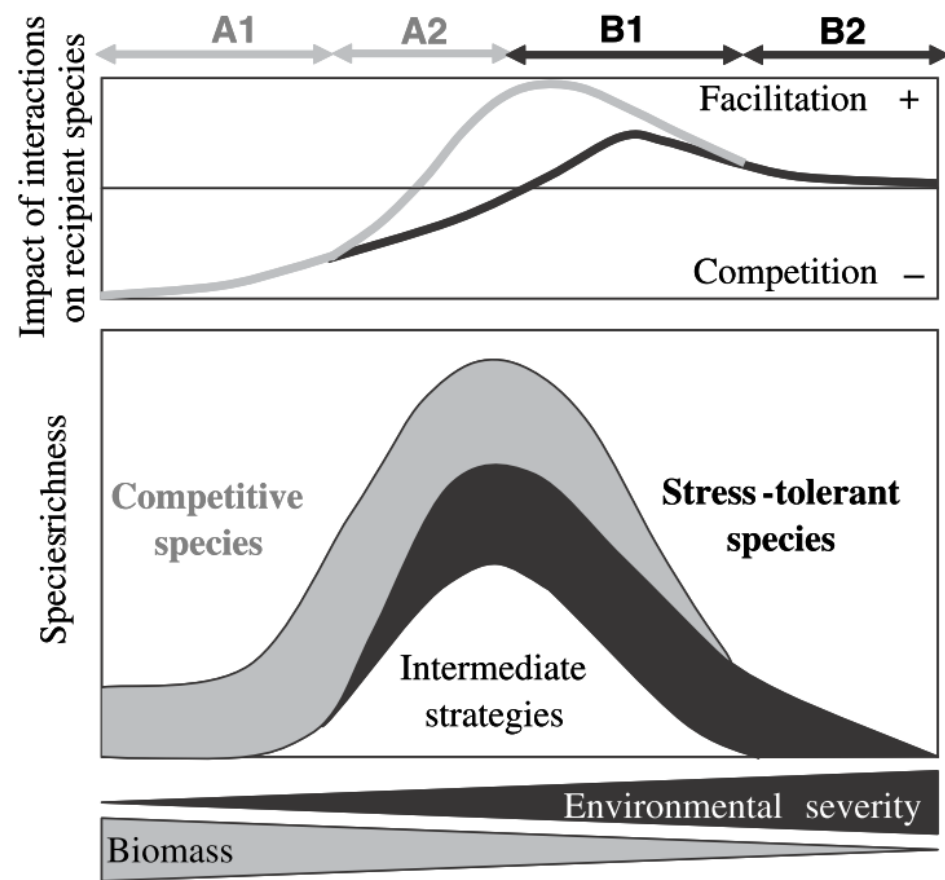

Figure 1. Graphical representation of the relative intensity of facilitative and competitive interactions along an environmental stress gradient. Adapted from (Michalet et al. 2006) 
Evidently, the ecological literature is full of examples where the results from empirical studies have not conformed to the specific predictions of the SGH, revealing a high degree of variability in the response of plant communities to stress. Recent research on facilitation has tended to be directed towards decoupling the ultimate causes determining interaction intensity. However, many facilitative interactions have a high degree of specificity between a nurse species and a small number of beneficiary species, whereas only a few interactions occur randomly between all species (Callaway 1998). For example, Mesquita et al. (2001) investigated secondary succession of abandoned pastures and cut forest, using two different pioneer nurse species, of the genus Cecropia and Vismia. They found that nurse species identity was a strong determinant of the identity and composition of beneficiaries. A similar specificity was observed in an examination of the interaction between the identity of a nurse species and the relative ontogeny of the beneficiary species (Paterno et al. 2016). They reported that beneficiary identity changed both with nurse species identity as well as with ontogenetic shifts. During germination of beneficiary species, all nurse species had a positive effect on growth. In summary, the strength and direction of plant-plant interactions is often dependent on species identity, and this idiosyncrasy currently limits the development of an improved general theory of species interactions over stress gradients.

The relative importance of interactions in structuring plant communities has also been reported as varying temporally and spatially, and may in fact be dependent on factors such as age, traits possessed by species, the distribution of resources within the habitat, and spatial and temporal variation in environmental conditions (Butterfield 2009). For example, Johnson et al. (1997) found that the interaction between a plant and its symbiotic relationship with a mycorrhizal fungi varied depending on environmental conditions and the developmental stage of the plant. Interactions changed from being overall facilitative in nutrient-poor soils, to overall parasitic in nutrient rich soils. Likewise, mycorrhizae had negative effects on the germination and early growth of seedlings by sequestering carbon from seed reserves normally assigned for use in seedling development. There is also evidence to suggest that the strength of facilitative interactions varies depending on the age and traits of nurse plants and their beneficiaries. Stands of Olneya tesota trees promoted species diversity depending on the size of the O. tesota canopy, whether beneficiary plants were perennials or ephermal, as well as the degree of environmental stress (Tewksbury and Lloyd 2001).

Recent empirical evidence has also revealed that competitive and facilitative interactions may not be symmetrical above and below ground (Zhang et al. 2013). For example, in an 
experimental test of the SGH using a 'foundation' tree Pinus edulis and the shrub Fallugia paradoxia, Sthultz et al. (2007) found that the intensity of interactions depended on whether or not they were partitioned into 'above' or 'below' ground, or grouped as 'above \& below' ground. They noted that interaction intensity did conform to the predictions of SGH when both above and below interactions were grouped, however, when analysed individually they found that both above and below ground interactions were competitive, but facilitative interaction only occurred above ground. In another experimental test of how the relative intensity and direction of above and below ground interactions affected communities, Lamb et al. (2009) reported the intensity of root competition being greater than shoot competition, yet while root competition had negligible effects on community structure, shoot competition effects on community structure were significant. Differences in the strength and symmetry of above and belowground interactions are relatively poorly studied. Investigating the relative contributions of above and below ground interactions to net interaction effects could better help integrate both the above and below ground environment into our understanding of community dynamics and secondary succession.

\section{Mechanisms of interaction.}

Plant-interactions are mediated by abiotic and biotic mechanisms. Abiotic mechanisms either increase or reduce physiological stress by altering environmental conditions, such as soil moisture (Callaway and King 1996, Caldwell et al. 1998), soil nutrients (Vetaas 1992), temperature (Callaway and King 1996), light (Flores and Jurado 2003), wind (Gerdol et al. 2000), and oxygen levels in soils (Drew 1983). Whereas, biotic mechanisms do so through the attraction of pollinators and seed dispersers (Sieber et al. 2011), granting protection from herbivores (Louthan et al. 2014), root grafting (Bormann and Graham 1959, Graham 1960, Tarroux and DesRochers 2011), and altering the composition of soil micro-organism and mycorrhizal communities (Johnson et al. 1992, Rodriguez-Echeverria et al. 2016).

The modes by which plants interact with one another are generally well understood mechanistically and empirical evidence of their facilitative affects are common within the literature. For example, Sieber et al. (2011) investigated whether the overall net effect of aggregations of plants on pollination in an alpine environment was positive (i.e. facilitative) or negative (i.e. competitive). They varied the relative frequency of two species of cushion plants E. nanum and Saxifraga within 60 plots located in the Swiss Alps. They found that plots with a higher proportion of Saxifraga were visited by insect pollinators more often than 
those with a greater proportion of E. nanum. However, within plots that contained both Saxfraga and E. nanum the visitation frequency of pollinators to each of the species was not significantly different. This suggests that Saxifraga is attracting pollinators at a greater rate than E. nanum at a distance, but once the pollinator arrives to a patch pollination of E. nanum is facilitated by Saxifraga, likely increasing its reproductive output.

Rodriguez-Echeverria et al. (2013) investigated the effects of soil biota on the growth, reproduction and abundance of 14 different species grown in soils either inoculated with the surrounding soil of a nurse plant, or from soil within an open space. They found that inoculation with soil (containing viable microbes) from beneath nurse plant species had a significantly positive effect on the growth response of seedlings. Different soil biota were also observed to have formed associations with distinct plant species, suggesting that there may be a degree of specificity between associations. The occurrence of plant species-specific microbial assemblages implies that one mechanism by which nurse plants may benefit neighbours is through the cultivation of a beneficial rhizosphere microbial community.

Studies which have measured either competitive or facilitative interactions only are far more prevalent within the literature, yet the two are not mutually exclusive and both forces act simultaneously within plant communities (Agrawal et al. 2007, Callaway 2007). However, it is important to remember that the overall net effect of competitive and facilitative interactions when qualifying plant-plant interaction is what matters. Franco and Nobel (1989) observed that $89 \%$ of Carnegiea gigantea cactus seedlings found at two separate locations in the Sonoran Desert were established under the canopy of two species of shrub. Under the shrub canopies available light for photosynthesis was reduced by $77 \%$ resulting in a predicted loss in photosynthetic efficiency by $\sim 90 \%$ compared to seedlings which had direct light. However, soil nitrogen content beneath the shrubs was up to $60 \%$ higher than in open areas. Nitrogen is a limiting resource for $C$. gigantean seedlings with just a $0.03-0.05 \%$ increase in concentration providing a dry-weight gain of $\sim 60 \%$. Therefore, the increased access to nitrogen under the shrub canopies outweighed the negative effect of a decrease in available light resulting in a net benefit to $C$. gigantea seedlings and presumably explaining their increased establishment under shrub canopies. 


\section{Below-ground pathways}

A major aspect of plant facilitation is the sharing of resources between two or more individuals using below-ground nutrient transfer pathways. Plants require 14 essential mineral nutrients, along with $\mathrm{CO}_{2}$, and water to carry out photosynthetic processes (Marschner and Rimmington 1988). The access that an individual may have to these resources can be limited or sporadic due to variation in the distribution of mineral nutrients and water both temporally, and spatially. Facilitative interactions occurring below-ground between plants may help ameliorate the effects of resource poor soils by the recycling of the mineral nutrients, or the transferal of nutrients between individuals from areas of high resource availability to the areas of low availability. It is generally accepted that there are three primary mechanisms of below ground nutrient transfer and acquisition amongst plants. (1) Through the soil solution (SS); (2) Mycorrhizal Networks (MN); (3) by the formation of Root Grafts (RG) (Hunter and Aarssen 1988).

\section{(1) Soil solution}

Plants can receive resources directly from the soil solution via root interception, diffusion, and mass flow. Most of the nutrient uptake by roots is due to the effects of mass flow and then diffusion, root interception is the least important driver of nutrient uptake from the soil solution with less than 3\% being attributed to this mechanism (Marschner and Rengel 2012).

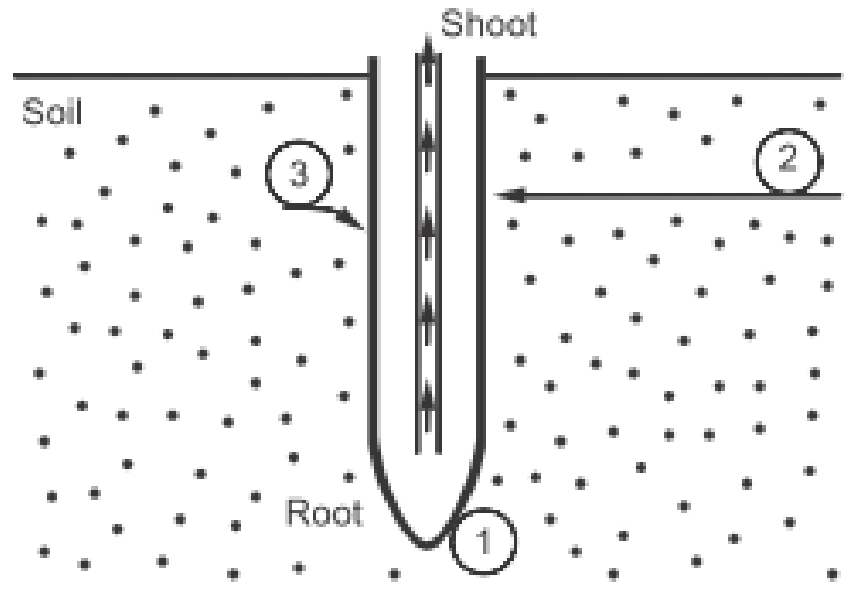

Figure 2. Mechanisms of nutrient acquisition of a root from the surrounding soil. (1) Root interception, (2) Mass flow, and (3) Diffusion. Adapted from (Marschner and Rimmington 1988).

Root interception (Figure 2.1) happens as a root grows through the soil and absorbs nutrient that it comes into direct contact with. Mass flow (Figure 2.2) is caused by the transpiration of water from the leaves, and the absorption of water by the roots. As the water exits the leaves 
it creates a suction which draws water up through the xylem, producing a water potential gradient between the soil and the root surface. Soluble nutrients dissolved in the soil are drawn along with water and absorbed across the root surface. The diffusion of nutrients (Figure 2.3) occurs over relatively short distances, when root uptake establishes a concentration gradient for a given nutrient, known as the 'zone of depletion'. Within the zone of depletion, the rate of diffusion depends on two factors, the rate of nutrient uptake, and the mobility of the nutrients in the surrounding soil.

Plants can indirectly affect other plant individuals growing in proximity by conditioning the surrounding soil by altering the biota and nutrient composition. While these 'plant-soil feedbacks' can be either positive or negative, factitive plant-soil feedbacks are considered to be important drivers of plant succession (Bever 2003). For example, a number of wetland plants have evolved aerenchymatous root tissue which allows them to release oxygen into the surrounding soil for their benefit and, indirectly, that of neighbouring plants (Cook et al. 1980, Stephens et al. 2005). In both field and glass house experiments Callaway and King (1996) found that the aerenchymatous plant Typha litifolia was able to increase the dissolved oxygen content in waterlogged soils by a factor of ten, at an optimal temperatures. This increase in dissolved oxygen then increased the capacity for two species of nonaernchymatous plants to occupy and grow in the soils.

\section{(2) Mycorrhizal networks}

Mycorrhizal Networks (MN) are a highly evolved association between a fungus and a plant, with $70-90 \%$ the world's vascular plant species forming symbiotic relationships with mycorrhizal fungi. Indeed, up to $20 \%$ of photosynthates produced by plants are estimated to be given to the mycorrhiza in exchange for nutrients (Pfeffer et al. 1999). Some woody plant species, including the two focal species of this thesis Dacrycarpus dacrydioides and Podocarpus totara, produce specialized root structures called "nodules" which house arbuscular mycorrhizal fungi (Figure 3.). 


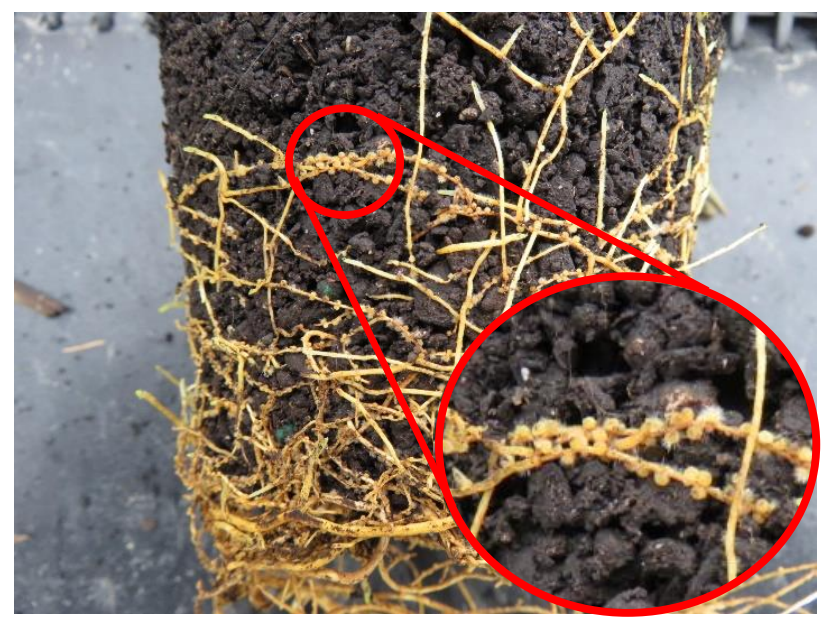

Figure 3 Photo of the roots of a Podocarpus totara juvenile showing a magnified view of the nodules borne on the roots.

In its simplest form, a mycorrhizal networks occurs when a single fungal individual colonizes the roots of two or more plant individuals, linking them together by its hyphal network.

(Simard et al. 2012). The fungal mycelia are able to acquire nutrients and water more efficiently due to the increased surface area created by the hyphal network in comparison to the plant roots. Complex mycorrhizal networks may facilitate the growth and survival of a community of plants by the reciprocal transfer of mineral nutrients acquired by the fungi in exchange for organic carbon created by the plants (Smith and Read 2010, Simard et al. 2012). Evidence also suggest that mycorrhizal networks may even facilitate the exchange of carbon between plants along a 'source/sink' gradient. Lerat et al. (2002) labelled the leaves of Erthronium americanum juveniles planted next to Acer saccharum and Betula alleghaniensis juvenileswith radioactive ${ }^{14} \mathrm{CO}_{2}$. E. americanum and A. saccharum are both Arbuscular mycorrhizal (AM), whereas B. alleghaniensis is ectomycorrhizal. They found that after seven days the concentration of radioactive ${ }^{14} \mathrm{C}$ was 13 times greater in $A$. saccharum than in $B$. allehaniensis. Suggesting that ${ }^{14} \mathrm{C}$ was being directly transferred to A. saccharum, rather than being taken up indirectly. Further, the concentration of ${ }^{14} \mathrm{C}$ in $A$. saccharum was negatively associated with the concentration of in ${ }^{14} \mathrm{C}$ stored in E. amercanum. An experiment conducted six months later, found that the ${ }^{14} \mathrm{C}$ was concentrated in the root system of $E$. americanum rather than in the leaves where it had been originally labelled, indicating that it was likely being passed between the two AM tree species by the arbuscular mycorrhizae located in the roots. 


\section{(3) Root Grafts}

Conspecific plants may also form root grafts, creating a direct link between two or more trees by which nutrients and organic carbon may be transported (Fraser et al. 2006). Root-grafting may occur when the roots of two individuals cross, as the roots increase in diameter, the vascular system can fuse at certain points creating a potential pathway for the transfer of resources among plants (Bormann 1966). With a few exceptions of closely related trees, rootgrafts have only been known to form between conspecific partners. In a field study of Pinus banksiana, Tarroux and DesRochers (2011) examined how radial growth rates were affected by the formation of natural root grafts. They found that during the formation of root grafts, radial growth rates were supressed compared to trees which were not forming root grafts. However, after graft formation was completed, radial growth rates were greater than those trees which were still undergoing root graft formation, and those that had not root grafts. They concluded that that while root grafts are initially energetically costly, once completed there is a significant benefit to partner trees.

\section{Methods for measuring plant-plant interactions}

Studies measuring ecological interactions often divide interactions in to two different aspects; direction and intensity. The direction of an interaction relates to whether an interactions is net facilitative, competitive or neutral, whereas, intensity describes how strong the interaction is (Pringle 2016).

Interaction indices seek to quantify the effect of interacting plant species by comparing a metric such as the growth of a targeted individual in the presence of neighbours, to the growth of individuals without neighbours. Over the past three decades, four approaches have commonly been used by studies measuring interactions; RCI - Relative Competition Index (Wilson and Keddy 1986), RNE - Relative Neighbour Effects (Markham and Chanway 1996), lnRR - Log Response Ratio (Hedges et al. 1999), and RII - Relative Interaction Index (Armas et al. 2004). Most of these have been developed after, or derived from, models which are used for assessing competitive interactions. The Relative Interaction Index is uniquely useful in that its index is symmetrical and can be used to show the direction and intensity of interactions, to provide insight in to whether interactions are net facilitative or net competitive. When calculated, RII will take on a value between 1 and -1 . If RII is $>0$ the net interaction effect is facilitative, if RII is $<0$ the net effect interaction effect is competitive, and when RII is $=0$ then the net interaction effect is neutral. Higher absolute values of RII will 
indicate greater interaction intensity. For instance, if RII is calculated for two individual plants resulting in values of -0.63 and 0.26 , it is considered to be a net competitive effect and net facilitative effect respectively. However, the competitive effect is also more intense $(0.63$ absolute) compared to the facilitative effect on the other plant ( 0.26 absolute).

In order to quantify and qualify plant-plant interactions in large field studies it is frequently necessary to find efficient methods to measure survival and growth. However, directly measuring above and belowground biomass for hundreds or even thousands of individual plants is often too resource and time intensive to be practical in most studies. Hence, the development of predictive models based on allometry are used to provide estimates of total plant biomass from easily measured metrics of plant size (e.g. height and diameter) (Picard et al. 2012). For example, Sato et al. (2015) wished to develop a series of allometric equations to help capture regional above-ground tree biomass data from tropical forests in Paraguay. They used DBH, height, and biomass measurements from a small sample of destructively harvested trees to construct three equations for their different ecosystem types which could predict regional biomass with a reported accuracy of $>96 \%$. While not being as accurate as directly measuring individuals, allometric equations provide a compromise between reduced effort and resources spent taking direct measurements, and reduced accuracy of those measurements, which may be desirable for studies which wish to measure large amounts of individuals

\section{Restoring Forested Wetland habitats}

Given the history of the development of the SGH in ecology, to date most studies of facilitative interactions have been conducted in areas of low water potential, namely arid environments or intertidal zones. By comparison, areas of high water potential stress, such wetlands, have received very little study in the context of facilitative plant interactions, despite that inundation stress is well documented (Kozlowski 1984, Visser et al. 2003). In comparison to arid environments, wetland ecosystems are characterized by the movement, distribution, and quality of large quantities of fresh water either on the surface or within the rhizosphere (Mitsch and Gosselink 2007). The effect of standing water and waterlogged soils on plants is well established. In well drained soils oxygen moves via diffusion caused by the respiration of roots and soil micro-organisms, from the atmosphere into pores within the soil substrate at a rate of $17 \mathrm{Lm}^{-2}$ per day (Drew 1983). However, when flooding occurs, the water on the surface forms a barrier between the atmosphere and the soil reducing the rate of 
diffusion by a magnitude of four (Gambrell and Patrick Jr 1978). The rate of biological respiration then depletes the amount of available oxygen faster than the rate of diffusion through the water to the soil. These conditions can cause physiological stress to plants by creating anaerobic conditions which prevent the root system from accessing oxygen in the quantities it needs to perform respiration. If these conditions persist without amelioration, fermentation rather than respiration occurs resulting in a reduced growth rate, less ATP produced, and the formation of ethanol as a by-product causing cell damage. Complete submergence of plants will also prevent transpiration and reduce photosynthesis by reducing the available light and preventing access to atmospheric $\mathrm{CO}_{2}$ (Blom and Voesenek 1996).

The influence and mechanisms of plant-plant interactions have been clearly established in the literature as having an influential role in the organization of plant communities. The development of the SGH provided a theoretical framework which presented researchers with a set of predictions which could be empirically tested. What is evident from the research conducted so far is that the intensity and direction of interactions are dependent on a wide array of environmental and biological mechanisms and may not be evenly distributed across the above and below ground environment. The intensity of interactions needs to be investigated by partitioning the effects from above and below ground interactions to more completely understand their effects on community dynamics.

Investigating how interactions between plants vary in intensity due to the changes in access to interactive mechanisms will not only add to our understanding of how plant communities are structured through interactions, but also help guide the restoration of degraded ecosystems. For example, traditional restoration techniques focus on reducing the impact of competitive interactions by removing existing vegetation through the applications of herbicides, or the mechanical removal of plants before planting has begun (Gomez-Aparicio 2009). These techniques could be detrimental to the survival of newly planted juveniles due to the removal of beneficial associations between existing biota and the juveniles, particularly if faciliatory effects are more important for survival and growth than competitive effects. Hence, understanding the importance and consequences of facilitative interactions for newly established plants will help increase the efficacy of future restoration projects. The success of restoration projects are intrinsically linked to a good understanding of plant-successional theory, as restoration is essentially the directed manipulation and acceleration of species composition in order to achieve a desired aesthetic or ecological outcome (Walker et al. 2007). In many cases, restoration projects seek to revert highly productive pastoral 
ecosystems with large amounts of nitrogen and phosphorus cycling, back to communities dominated by woody tree species with relatively lower nitrogen and phosphorus cycling. This study is conducted at Wairio, a wetland which was cleared and drained for conversion in to pastural agriculture. Wairio is currently being undergoing restoration by community groups with the goal of restoring the wetland to its historical Dacrycarpus dacrydioides (kahikatea) and Podocarpus totara (totara) and dominated forest. This provides an excellent opportunity to study the effects of plant-plant interactions on the establishment of these two species.

\section{Thesis objectives}

The objectives of this thesis are to quantify the plant-plant interactions for juvenile podocarp tree species planted as part of the reforestation of a degraded wetland site. It will do this by: (1) Developing allometric equations for estimating the total biomass of $D$. dacrydioides and $P$. totara juveniles; (2) Use the Relative Interaction Index to determine net interaction direction and intensity for a target, while manipulating above and below ground interactions; (3) Quantifying the effect of interactions on the biomass gain of $D$. dacrydioides and $P$. totara juveniles. The end goal being to partition the contribution of above ground and below ground interactions towards biomass gain in newly established juvenile trees. 


\section{Development of allometric equations for estimating the biomass of $D$. dacrydioides and $P$. totara juveniles.}

\section{$\underline{\text { Introduction }}$}

Biomass data for individual trees is used widely in research applications and forest management. Measurements of atmospheric carbon sequestration rates (Paul et al. 2013), primary productivity (Clark et al. 2001), forest inventories (Ketterings et al. 2001), and predictions on yield and grade of lumber (Briggs et al. 2007, Briggs 2010) all require the biomass of individual trees to be quantified. Tree biomass can be measured either by destructively harvesting the tree and measuring biomass directly, or non-destructively by taking measurements in the field and using allometric (biological scaling) relationships to predict the biomass. Direct measurements of biomass are inherently more accurate than predictions, however, direct measurements are often not feasible due to time or resource constraints. Therefore, the development of allometric equations is frequently necessary for measuring tree biomass in practice.

The aim of developing allometric models is to find a scaling relationship between a variable of interest and one or more other traits. Huxley (1924), when studying the growth of the larger chelae of Fiddler-crabs relative to their carapace found that the relationship between the growth rate of chelae and carapace could be mathematically expressed as the power function $Y=a \mathrm{X}^{\mathrm{b}}$ (originally written as $\mathrm{y}=b x^{k}$ ). Where $\mathrm{Y}$ is the variable of interest, $a$ is an allometric constant, $\mathrm{X}$ is a measure of a trait related to $\mathrm{Y}$, and $b$ is a scaling exponent. Thus, for any change in $\mathrm{X}, \mathrm{Y}$ will also scale at a ratio of $b$. When $b>1, \mathrm{Y}$ is increasing at a greater rate relative to the increase in $\mathrm{X}$. Conversely, when $b<1, \mathrm{Y}$ is increasing at a lesser rate relative to the increase in $X$.

In the context of my study, where I am developing models to predict biomass using stem diameter and height as explanatory variables, $\mathrm{Y}=$ total tree biomass, and $\mathrm{X}=$ one of the explanatory variables. The $Y=a \mathrm{X}^{\mathrm{b}}$ equations suggests that for a given change in the explanatory variable (diameter or height), total biomass would also change exponentially by b. 
Typically, models estimating tree biomass are developed with regression methods using a combination of trunk diameter and height as the explanatory variable, as this data is relatively easy to collect non-destructively in the field (Picard et al. 2012). Primarily, allometric equations developed for adult trees are more common because growth patterns tend to be more conserved between individuals as they age (Mencuccini et al. 2005, Herault et al. 2011), thereby making it easier to develop models which accurately predict biomass for different individuals or stands of trees. Allometric models for adult trees are also more common due to having a greater contribution to the net primary productivity of an ecosystem (Zhou et al. 2006, Wang et al. 2018), and being more economically valuable in terms of quality and yield of timber (Mathews et al. 2016). However, most studies developing biomass models for trees have calculated allometric equations only for the above-ground portion of adult trees. Modelling of adult below ground root systems generally uses a shoot to root ratio to estimate below ground biomass, or it is ignored because of the difficulty associated with excavating the extensive root system of adult trees without using destructive methods (e.g sluicing) (Nam et al. 2016).

For my study I required accurate estimates of $D$. dacrydioides and $P$. totara total tree biomass (above + below ground biomass) for use in chapter 3. A review of the literature found no published models for estimating biomass in $D$. dacrydioides and P. totara juveniles. It was therefor necessary to develop my own. In this chapter I develop species specific models for each of $D$. dacrydioides and $P$. totara by using stem diameter and stem height as explanatory variables, and then test their efficacy to predict total tree biomass accurately. 


\section{Methods}

Study site

Plant material for this study was collected from a 5ha research and restoration site at 'Stage 3' of Wairio wetland, on the south-eastern shore of Lake Wairarapa in the southern part of New Zealand's North Island (41¹4'37.9"S 175¹5'38.6"E) (Figure4).

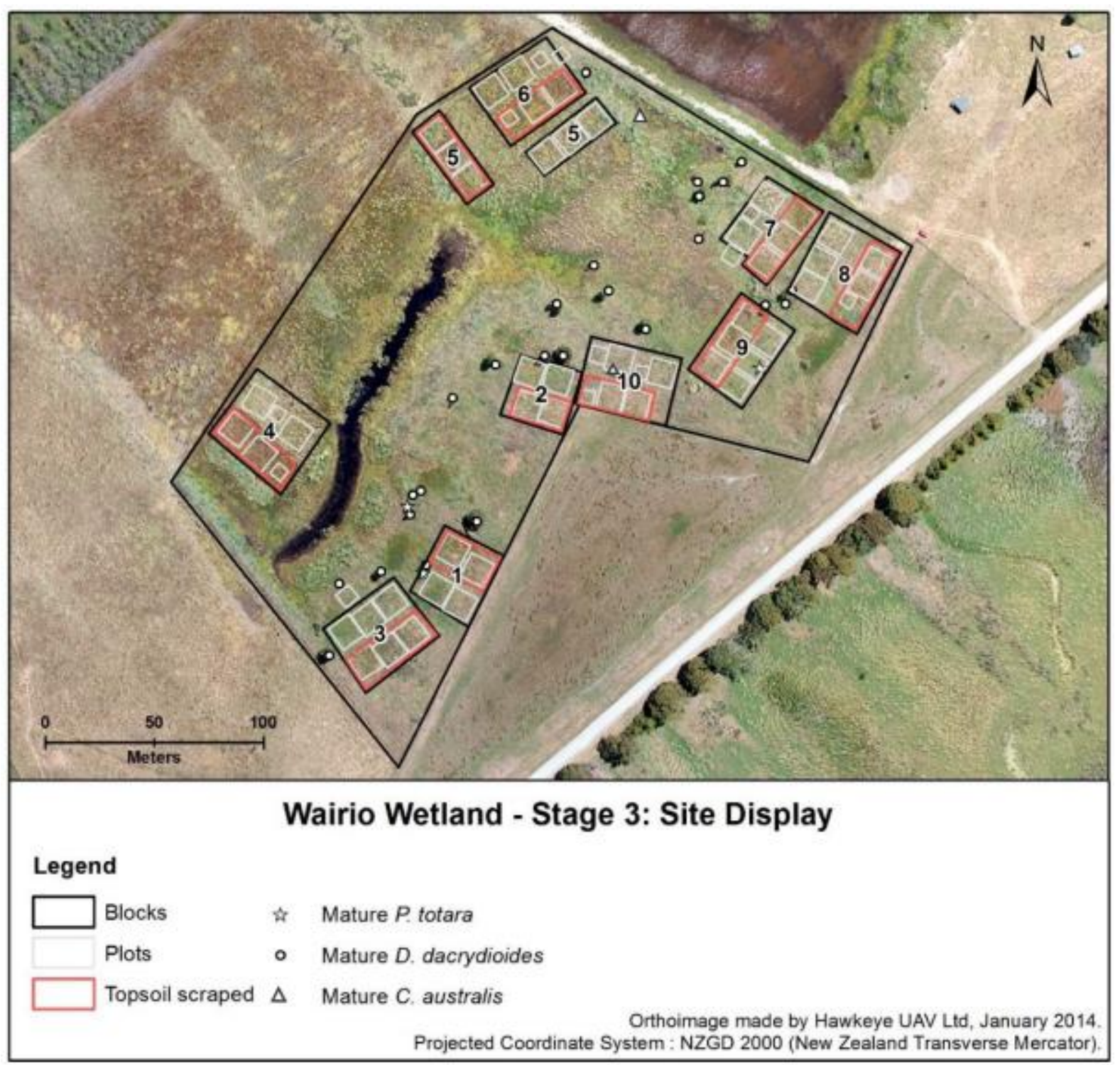

Figure 4. Map of Stage 3 at Wairio wetland. Blocks 3, 7, and 10 were used. Adapted from (Fanal 2017) 


\section{Planting}

In July 2011, several blocks of native trees were planted in 'Stage 3' (Figure 4) by Victoria University of Wellington for the purpose of conducting research into wetland restoration (Gillon 2014). These blocks were comprised of multiple plots containing either; (1) a mix of Dacrycarpus dacrydioides (kahikatea), Podocarpus totara (totara), Cordyline australis (cabbage tree), and Olearia virgata (twiggy tree daisy); or (2) two species of 'nurse plants', Leptospermum scoparium (manuka), and Pittosporum tenuifolium (kohūhū). Additionally, during July 2016, 14 D. dacrydioides and 14 P. totara juveniles were randomly distributed and planted into gaps within the five-year-old plots of blocks 3, 7, and 10 (Figure 4-5), as well as establishing new plots containing only the newly planted juveniles and none of the trees planted in 2011 . The newly planted $D$. dacrydioides and $P$. totara juveniles had been grown from seed by the Norfolk Road nursery and were $\sim 24$ months old at the time of planting (Pers. Comms). Each juvenile was planted either; (1) directly into the ground, (2) with a grotector, (3) inside a mesh bag and then into the ground, (4) with a grotector and a mesh bag, (5) inside a net pot and mesh bag, (6) with a grotector, net pot, and a mesh bag. These treatments are designed to manipulate soil and aerial conditions and are described in detail in Chapter 3 of this thesis.

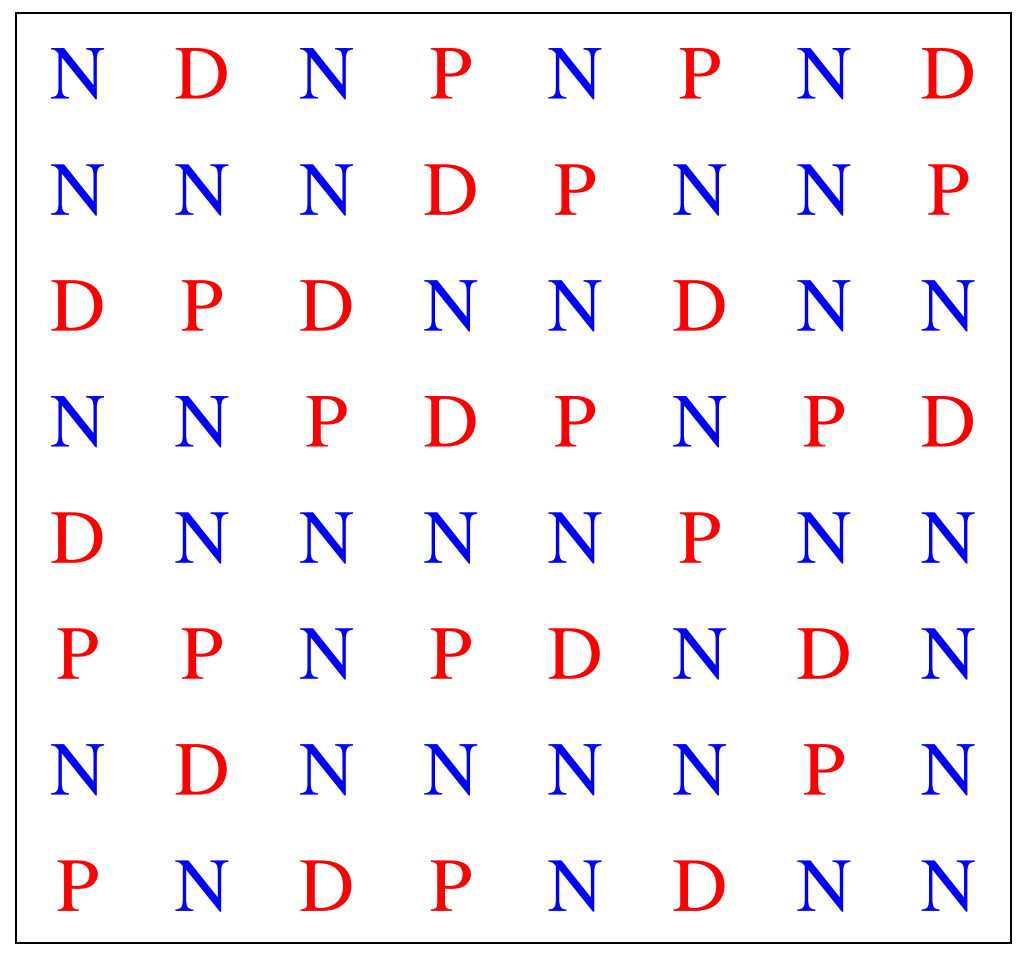

Figure 5. Stylized representation of a plot with $D$. dacrydioides (red D, $\mathrm{n}=14$ ) and P. totara (red $\mathrm{P}, \mathrm{n}=14$ ) planted in to gaps left within a plot of surviving nurse species (blue N) planted in 2011. 

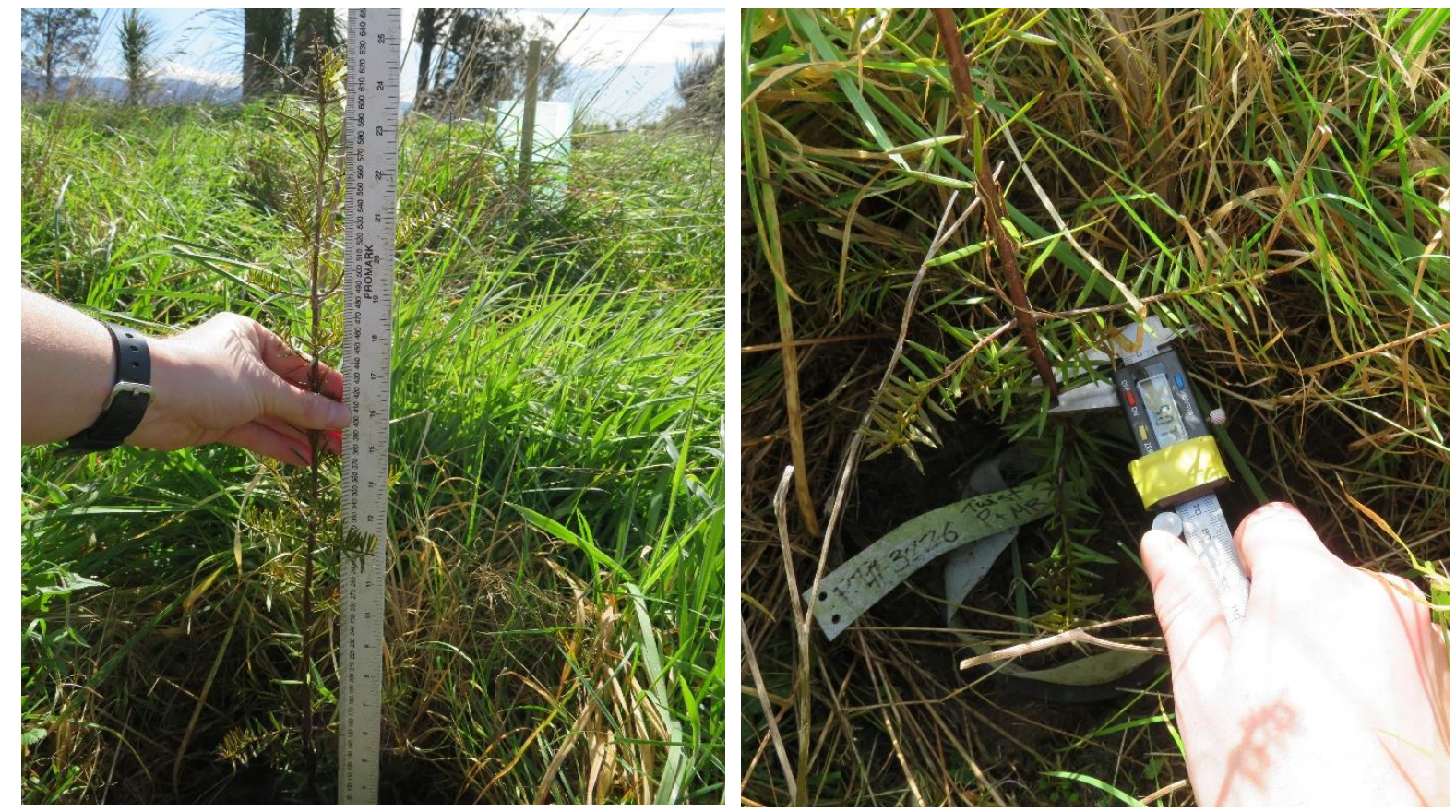

Figure 6. Juvenile stem height was measured from the root collar to the apical meristem. Stem diameter was measured at $10 \mathrm{~cm}$ above the root collar.

Stem height and diameter was collected for each individual $D$. dacrydioides and $P$. totara juvenile at the time of planting and again after the one-year growth period. Stem height was measured from the root collar up to the apical meristem using a $1 \mathrm{~m}$ ruler. Stem diameter was measured at $10 \mathrm{~cm}$ above the root collar using a set of Mako Digital Callipers.

\section{Harvesting}

In late September 2017, after 14 months of growth, 60 D. dacrydioides $(\mathrm{n}=30)$ and P. totara $(n=30)$ juveniles were destructively harvested for the purpose of developing allometric equations for estimating juvenile biomass. The juveniles were harvested from plots within blocks 3, 7, and 10 (Figure 6). Five D. dacrydioides and P. totara juveniles for each treatment type (see Chapter 3) were randomly selected from the plots, with no juvenile receiving the same treatment being selected from each plot more than once to diversify the range of local conditions affecting the juvenile. However, due to the high degree of flooding and mortality within block 3, juveniles from blocks 7 and 10 occurred more frequently within the sample.

Sampled juveniles were removed from the ground by excavating around the juvenile at a radius of $60 \mathrm{~cm}$, and then undercutting the juvenile to a depth of $30 \mathrm{~cm}$. These dimensions 
were estimated to be sufficient in removing the plant from the surrounding soil and keeping the root mass intact without causing damage to the roots.

Loose soil was removed from the remaining root mass by gentle agitation, any severed root segments were collected. A visual inspection of the root system and hole was then conducted to determine if any root-grafting had occurred between the juvenile and its neighbours. The roots of $D$. dacrydioides and $P$. totara juveniles can be distinguished from those of other plants in the community by the presence of conspicuous root nodules, and distinct colours. $D$. dacrydioides roots are a dark red and $P$. totara roots are a golden-yellow (Figure 7.). In comparison, other local species roots were white to light brown in colour. Those juveniles grown within mesh bags had the bag inspected for signs of root penetration, or any tearing of the bag. Only two bags containing $P$. totara were found to be compromised, but the roots had not yet grown outside of the bag, so it was assumed that no root-grafting could have occurred. Each excavated juvenile was then placed into a plastic bag, which was then sealed and placed on ice for transportation. The samples were transferred to a refrigerator within at least 8 hours of being excavated.

\section{Collection of biomass data}

Once in the lab, the juvenile was removed from its bag and placed it in a deep tray. The aboveground biomass was severed from the belowground biomass by clipping at the root collar. Foreign vegetation and soil debris were removed from the above ground parts by gently washing under slow running tap water. The root mass was cleaned by first removing loose dirt by gently agitating the root mass over the deep tray. Foreign roots and other objects where then removed with a pair of forceps and the root mass submerged in a bucket of water for 20 minutes to loosen any dirt and vegetation on the roots further. During the 20-minute period, a search for loose roots in the dirt removed from the root mass was conducted. 20 minutes was considered enough time to find the majority of lost roots while keeping search effort equivalent between the plants. The root mass was removed from the water and cleaned with the forceps again. The dirty water was then sieved to $1.18 \mathrm{~mm}$ and $420 \mu \mathrm{m}$ and remaining roots collected. Clean above and belowground biomass was placed separately into paper bags and dried at $65^{\circ} \mathrm{C}$ for 48 hours in a drying oven. All samples were cleaned and placed in to the drying oven within 48 hours of harvest. Once dry, stem and root masses were weighed separately on a METTLER PJ300 scale, with $0.001 \mathrm{~g}$ precision. The above and 
belowground biomass data were summed together as a measure of total dry weight biomass per juvenile.

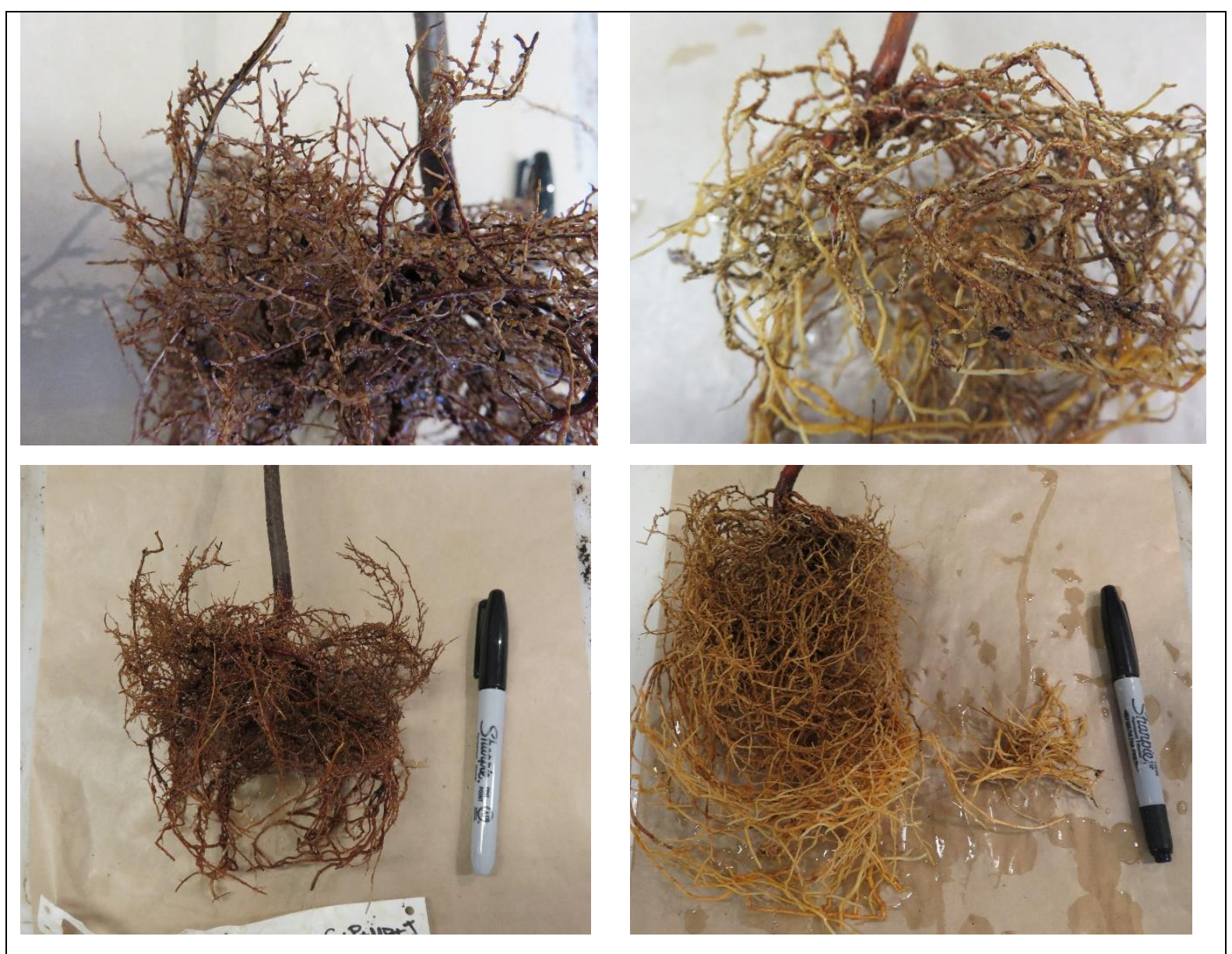

Figure 7. Photos showing the roots of D. dacrydioides (left side) and P. totara (right side) after harvesting and cleaning. Sharpie pen is used for scale.

\section{Effect of Grotectors}

For each species, 30 trees were stratified into two even groups consisting of those grown with grotectors $(n=15)$ and those grown without $(n=15) .10$ trees from each group were randomly selected for the development of the allometric model. The remaining 10 trees were then set aside as a subsample for later use in validating the model.

The intent in splitting the trees in to the two groups of those with grotectors and those without was to investigate whether there were true differences in the growth of the trees due to the presence of a grotector. Observations from in the field suggested that the juvenile trees may be responding to the grotectors with increased vertical growth. Because this response could 
have the potential to alter the true relationship between height and biomass for juvenile trees, I examined whether grotectors effected relative height gain in the $D$. dacrydioides and $P$. totara juveniles over the one-year period. If no differences were found, the two groups could then be pooled together to develop a single model for each of the species from a larger sample size. Increasing the sample size is highly desirable as it will decrease sampling error, while also increasing the robustness and accuracy of the model in predicting biomass (Burnham and Anderson 2003, Sullivan et al. 2018).

Relative height gained was calculated as the difference between the final and initial heights measured, as a proportion of the initial height.

Relative Height Gain $=\frac{\text { Final height-Initial height }}{\text { Initial height }}$.

To test the assumptions of the normality of the distributions and homogeneity of variance between the groups a Shapiro-Wilk test, and a Bartlett test were conducted respectively. No departures from the assumptions were found.

\section{Model development}

No significant differences were found between the mean relative height gain of trees grown with a grotector and those without. Full results of the t-test are reported later in this chapter. Because there were no differences in height gain it was assumed that the grotectors had not impacted growth, and therefore biomass, to a significant extent. Hence, the decision was made to pool the two grotector groups together.

The allometric models for predicting tree biomass were developed using the structure described by Picard et al. (2012). A review of the scientific literature was conducted to obtain species and age specific allometric equations for testing. However, no equations were found for juvenile $D$. dacrydioides and $P$. totara in the published literature. Therefore, a suite of generic candidate models were selected. Three variables used singularly or in several different combinations were considered as predictors of juvenile tree total biomass; height alone, diameter alone, volume, height $\mathrm{x}$ diameter, diameter ${ }^{2}$, height ${ }^{2}$, (height $\mathrm{x}$ diameter $)^{2}$, and height + diameter (Table 1). These variables were selected due to the prevalence of their use in the development of allometric equations for juvenile tree species (Picard et al. 2012, Chapagain et al. 2014, Stankova et al. 2015), along with the ease at which these 
measurements could be taken. Stem volume was estimated from the volume of an elliptical cone, given by the formula $V=\frac{\pi d^{2} h}{6}$, where $d$ is the diameter of the main stem $10 \mathrm{~cm}$ above the root collar, and $h$ is the height from the root collar to the apical meristem. An elliptical cone was considered to be the shape which best fit the form of a D. dacrydioides or P. totara juvenile

Table 1. Generic candidate models chosen for the development of allometric equations for predicting the total biomass (g) of one-year old $D$. dacrydioides and $P$. totara juveniles. All predictor variables are measurements are of the main stem.

\begin{tabular}{l}
\hline \multicolumn{1}{c}{ Predictor variable $(X)$} \\
\hline Height \\
Diameter \\
Volume \\
Height $x$ Diameter \\
Diameter \\
Height $^{2}$ \\
(Height $x$ Diameter $^{2}$ \\
Height + Diameter
\end{tabular}

Predictor variables were first plotted against total biomass measurements to assess their relationships. All relationships were found to be non-linear, or at least became more linear once log-transformed. A single variable, power function using the general form $Y=a(X)^{b}+\varepsilon$ was selected and transformed using natural logarithm to linearize the response, giving the transformed model $\ln (Y)=\ln a+b \ln (X)+\varepsilon$. In both cases $Y$ is the total tree biomass, $X$ is the predictor variable, the coefficients $a$ and $b$ are a constant and the scaling factor respectively, and $\varepsilon$ is the error.

Ordinary Least Squares regression was used to obtain estimates of the $a$ and $b$ coefficients. The model was fitted by plotting tree biomass data against each of the predictor variables using the log-transformed data. The significance of the coefficients and the model was then analysed.

Back-transformation of the log-transformed model is required for the accurate translation of biomass estimates. However, back-transformation creates a bias in the prediction of the residual error for the model (Sprugel 1983, Burnham and Anderson 2003, Picard et al. 2012). Thus, it is necessary to correct for the bias using a correction factor (CF). To apply the correction, the correction factor for each model was calculated using the formula $C F=$ $\exp \left(\frac{\widehat{\sigma}^{2}}{2}\right)$ and multiplied the result by the model estimate (Sprugel 1983). The correction factor was then incorporated into the biomass estimate equation by multiplying the $a$ coefficient by CF. 


\section{Validation}

Each of the candidate models were compared to the independent subsample using the validation criteria set out in Picard et al. (2012), and Kozak and Kozak (2003). These criteria use the prediction statistics of average Bias (B), Root Mean-Squared Error (RMSE), the Coefficient of determination $\left(R^{2}\right.$ adj $)$, and the Akaike Information Criterion (AIC) to select the model which best predicts the observed total biomass of the subsample. Lower values of $B$, RMSE, and AIC, and higher values of $R^{2}$ adj are indicative of model which better predicts the variable of interest.

After validation the 10 data points of the independent subsamples were then plotted with the 95\% prediction and confidence intervals generated by the best models for each species in order to visualize the goodness of fit.

All statistical analyses and modelling was conducted using the ' $R$ ' Statistical Software program (R Development Core Team 2015). Tests were conducted at the $\alpha=0.05$ level of significance unless otherwise specified.

\section{$\underline{\text { Results }}$}

In total 30 individual juvenile trees of each species were harvested, 20 of which were used for the construction of the allometric equation for predicting biomass and 10 for validating the model. Stem height for $D$. dacrydioides ranged from between $41 \mathrm{~cm}$ tall to $106 \mathrm{~cm}$ tall, with a mean height of $77.5 \mathrm{~cm}$. P. totara stem height ranged from $47 \mathrm{~cm}$ to $101 \mathrm{~cm}$, with a mean height of $74.70 \mathrm{~cm}$.

\section{Grotectors}

The presence of grotectors on juveniles of both species had no effect on observed relative height gain (Figure 8). The mean increase in height of $D$. dacrydioides juveniles grown with grotectors as a proportion to their initial height was 0.27 , whereas the mean increase for those without grotectors was 0.29 . Statistical analysis showed that the two means were not statistically different $(t=-0.0238, d f=18, p$-value $=0.981) . P$. totara juvenile increased by a mean proportion of 0.24 of their initial height when with a grotectors, and 0.16 when without. However, the difference between the two means was also not statistically significant $(t=$ $1.2611, d f=18, p$-value $=0.226)$. 
Table 2. Characteristics of harvested juvenile trees used to develop the allometric equations. Measurements were taken after a one-year growth period. $n=20$ for each species.

\begin{tabular}{lcccc}
\hline Variable $(\mathrm{x})$ & Mean & Minimum & Maximum & Standard dev \\
\hline D. dacrydioides $\mathrm{n}=20$ & & & & \\
Stem height $(\mathrm{cm})$ & 77.5 & 41 & 106 & 19.22 \\
Stem diameter $(\mathrm{cm})$ & 0.79 & 0.5 & 1.2 & 0.15 \\
Stem volume $\left(\mathrm{cm}^{3}\right)$ & 27.02 & 6.68 & 67.86 & 14.82 \\
& & & & \\
P. totara $\mathrm{n}=20$ & & & & \\
Stem height $(\mathrm{cm})$ & 74.70 & 47 & 101 & 15.09 \\
Stem Diameter $(\mathrm{cm})$ & 0.54 & 0.4 & 0.8 & 0.11 \\
Stem volume $\left(\mathrm{cm}^{3}\right)$ & 11.82 & 4.52 & 24.8 & 5.38 \\
\hline
\end{tabular}
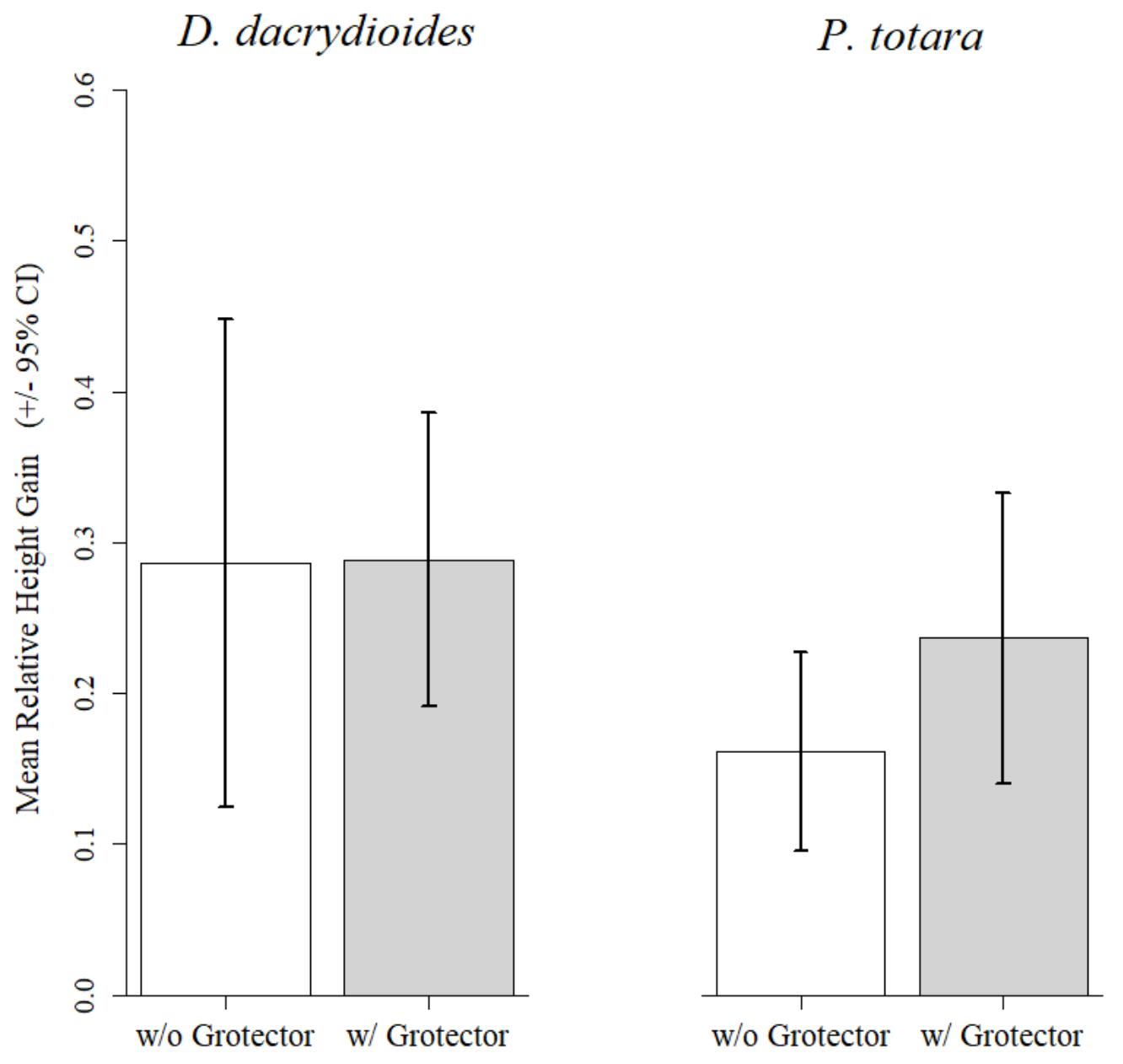

Figure 8. Mean (+/- 95\% Confidence Interval) relative height gain of juvenile $D$. dacrydioides $(\mathrm{n}=20)$ and $P$. totara $(\mathrm{n}=20)$ stems over a one-year growth period at Wairio wetland. Juveniles of both species were grown either with (w/), or without (w/o) a grotector, shown by the filled and unfilled bars respectively 


\section{Coefficient estimation}

The $a$ and $b$ coefficients estimated by ordinary least squares regression were highly significant across the 16 species specific models examined, with all $p$-values being $<0.05$ (Table 3, 4). For both species, the highest $\mathrm{R}^{2}$ values were found for models containing height (including stem volume which uses height in its calculation), and the lowest in the models using diameter alone. The $\mathrm{R}^{2}$ values for the $D$. dacrydioides and $P$. totara models using height ranged from 0.693 to 0.896 , and 0.473 to 0.71 respectively. In contrast, models using diameter measurements only were smaller, with values of 0.311 for $D$. dacrydioides and 0.244 for $P$. totara. These values suggest that estimated coefficients fit the observed data better when height was included in the model. Plots of the log-transformed data show that this is indeed the case for both D. dacrydioides (Figure 9. C \& E), and P. totara (Figure 10. C $\&$ E). Observed total biomass varied greatly around that which was predicted when using diameter alone, whereas, when using height either alone or in combination with other measurements the predicted values matched the observed more closely. 
Allometric models for $D$. dacrydioides biomass prediction
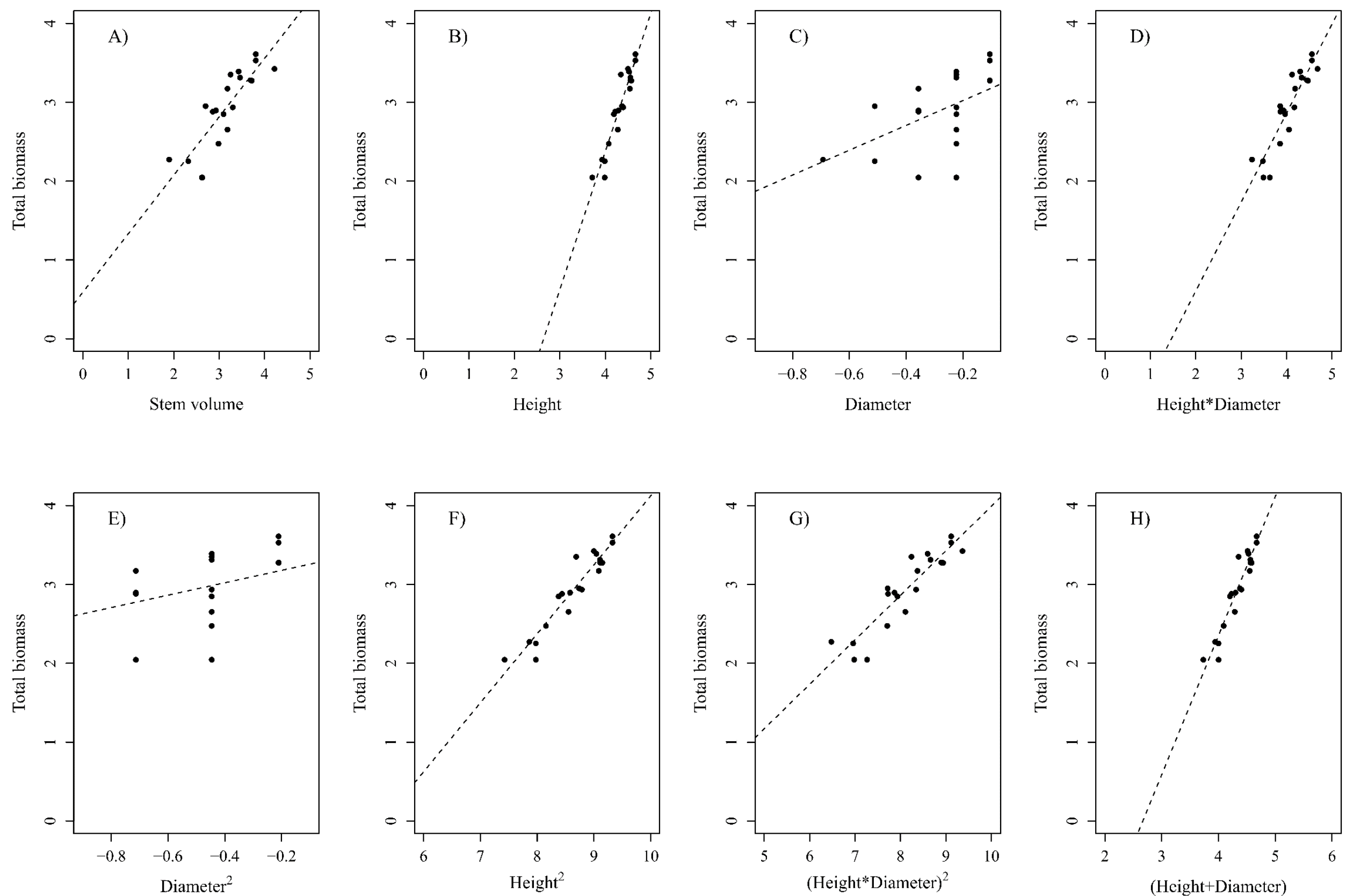

Figure 9. Plot (log transformed data) of predictor variable $(x)$ against the total biomass of one-year old $D$. dacrydioides juveniles. Height and Diameter were measured in centimetres. Total biomass was measured in grams. The line of best fit for each model is shown as a dashed line. All axes are on a log-scale. 
Allometric models for $P$. totara biomass prediction
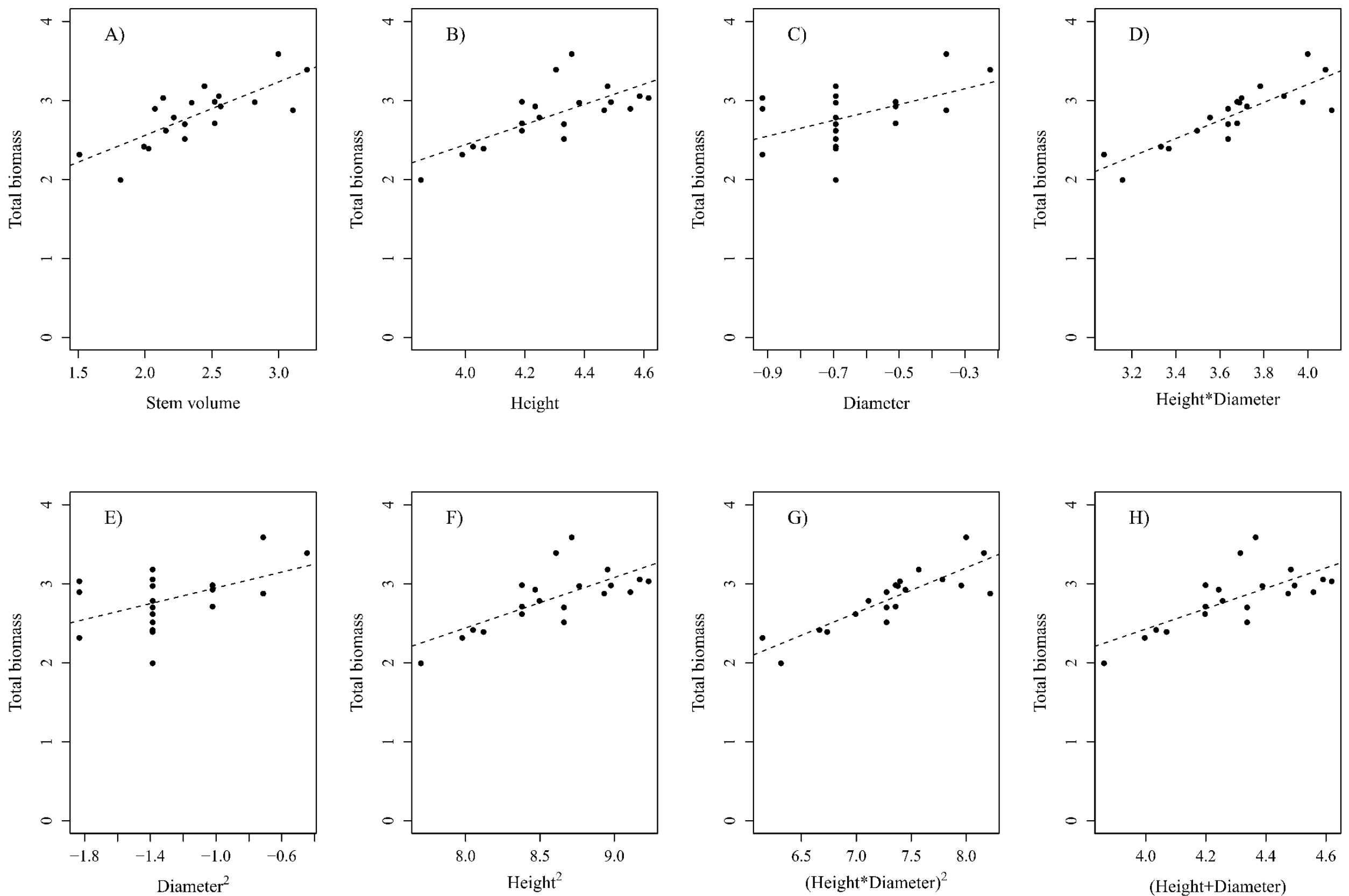

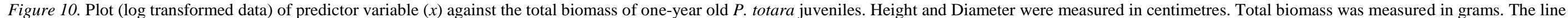
of best fit for each model is shown as a dashed line. All axes are on a log-scale. 
Table 3. Allometric equations for estimating the total biomass $(\mathrm{g})$ of one-year old $D$. dacrydioides juveniles $(\mathrm{n}=20)$.

D. dacrydioides

\begin{tabular}{|c|c|c|c|c|c|c|c|c|c|}
\hline & Regression Model & $a$ coef & $b$ coef & $F$ statistic & df & $\mathrm{p}$-value & $\mathrm{R}_{\text {adj }}^{2}$ & $\mathrm{CF}$ & Equation \\
\hline A) & $\ln \left(\mathrm{B}_{\mathrm{TOTAL}}\right)=\ln a+b \ln ($ Volume $)$ & 0.5916 & 0.7413 & 43.79 & 1,18 & $3.26 \mathrm{e}-06$ & 0.693 & 1.038 & $\mathrm{~B}_{\mathrm{TOTAL}}=1.8755(X)^{0.7413}$ \\
\hline B) & $\ln \left(\mathrm{B}_{\text {TOTAL }}\right)=\ln a+b \ln ($ Height $)$ & -4.6253 & 1.7497 & 162.2 & 1,18 & $1.929 \mathrm{e}-10$ & 0.895 & 1.013 & $\mathrm{~B}_{\text {TOTAL }}=0.0099(X)^{1.7497}$ \\
\hline C) & $\ln \left(\mathrm{B}_{\text {TOTAL }}\right)=\ln a+b \ln ($ Diameter $)$ & 3.3363 & 1.5733 & 9.582 & 1,18 & 0.006241 & 0.311 & 1.088 & $\mathrm{~B}_{\mathrm{TOTAL}}=30.589(X)^{1.5733}$ \\
\hline D) & $\ln \left(\mathrm{B}_{\mathrm{TOTAL}}\right)=\ln a+b \ln ($ Height $*$ Diameter $)$ & -1.6515 & 1.1285 & 87.71 & 1,18 & $2.43 \mathrm{e}-08$ & 0.82 & 1.022 & $\mathrm{~B}_{\text {TOTAL }}=0.196(X)^{1.1285}$ \\
\hline E) & $\ln \left(\mathrm{B}_{\text {TOTAL }}\right)=\ln a+b \ln \left(\right.$ Diameter $\left.^{2}\right)$ & 3.3363 & 0.7867 & 9.582 & 1,18 & 0.00624 & 0.311 & 1.088 & $\mathrm{~B}_{\mathrm{TOTAL}}=30.589(X)^{0.7867}$ \\
\hline F) & $\ln \left(\mathrm{B}_{\text {TOTAL }}\right)=\ln a+b \ln \left(\right.$ Height $\left.^{2}\right)$ & -4.6253 & 0.8749 & 162.2 & 1,18 & $1.929 \mathrm{e}-10$ & 0.895 & 1.013 & $\mathrm{~B}_{\text {TOTAL }}=0.0099(X)^{0.8749}$ \\
\hline G) & $\ln \left(\mathrm{B}_{\text {ТОТАL }}\right)=\ln a+b \ln (\text { Height } * \text { Diameter })^{2}$ & -1.6515 & 0.5643 & 87.71 & 1,18 & $2.426 \mathrm{e}-08$ & 0.82 & 1.022 & $\mathrm{~B}_{\mathrm{TOTAL}}=0.196(X)^{0.5643}$ \\
\hline H) & $\ln \left(\mathrm{B}_{\text {TOTAL }}\right)=\ln a+b \ln ($ Height + Diameter $)$ & -4.7058 & 1.7641 & 164.6 & 1,18 & $1.712 \mathrm{e}-10$ & 0.896 & 1.012 & $\mathrm{~B}_{\text {TOTAL }}=0.0092(X)^{1.7641}$ \\
\hline
\end{tabular}

Table 4. Allometric equations for estimating the total biomass (g) of one-year old $P$. totara juveniles $(\mathrm{n}=20)$.

P. totara

\begin{tabular}{|c|c|c|c|c|c|c|c|c|c|}
\hline & Regression Model & $a$ coef & $b$ coef & $F$ statistic & df & $p$-value & $R_{\text {adj }}^{2}$ & $\mathrm{CF}$ & Equation \\
\hline A) & $\ln \left(\mathrm{B}_{\text {TOTAL }}\right)=\ln a+b \ln ($ Volume $)$ & 1.2013 & 0.6779 & 26.73 & 1,18 & $6.43 \mathrm{e}-05$ & 0.575 & 1.031 & $\mathrm{~B}_{\mathrm{TOTAL}}=3.3446(X)^{0.6779}$ \\
\hline B) & $\ln \left(\mathrm{B}_{\mathrm{TOTAL}}\right)=\ln a+b \ln ($ Height $)$ & -2.6648 & 1.2763 & 18.07 & 1,18 & $0.481 \mathrm{e}-04$ & 0.473 & 1.038 & $\mathrm{~B}_{\mathrm{TOTAL}}=0.0723(X)^{1.2763}$ \\
\hline C) & $\ln \left(\mathrm{B}_{\text {TOTAL }}\right)=\ln a+b \ln ($ Diameter $)$ & 3.4473 & 0.9991 & 5.82 & 1,18 & 0.02673 & 0.202 & 1.058 & $\mathrm{~B}_{\text {TOTAL }}=33.2376(X)^{0.9991}$ \\
\hline D) & $\ln \left(\mathrm{B}_{\text {ТОТАL }}\right)=\ln a+b \ln ($ Height $*$ Diameter $)$ & -1.3544 & 1.1390 & 47.61 & 1,18 & $1.883 \mathrm{e}-06$ & 0.710 & 1.021 & $\mathrm{~B}_{\text {TOTAL }}=0.2635(X)^{1.139}$ \\
\hline E) & $\ln \left(\mathrm{B}_{\text {TOTAL }}\right)=\ln a+b \ln \left(\right.$ Diameter $\left.^{2}\right)$ & 3.4473 & 0.4996 & 5.82 & 1,18 & 0.02673 & 0.244 & 1.058 & $\mathrm{~B}_{\mathrm{TOTAL}}=33.2376(X)^{0.4996}$ \\
\hline F) & $\ln \left(\mathrm{B}_{\mathrm{TOTAL}}\right)=\ln a+b \ln \left(\right.$ Height $\left.^{2}\right)$ & -2.6648 & 0.6382 & 18.07 & 1,18 & $0.481 \mathrm{e}-04$ & 0.473 & 1.038 & $\mathrm{~B}_{\mathrm{TOTAL}}=0.0723(X)^{0.6382}$ \\
\hline G) & $\ln \left(\mathrm{B}_{\text {TОтАL }}\right)=\ln a+b \ln (\text { Height } * \text { Diameter })^{2}$ & -1.3544 & 0.5695 & 47.61 & 1,18 & $1.883 \mathrm{e}-06$ & 0.710 & 1.021 & $\mathrm{~B}_{\text {TOTAL }}=0.2635(X)^{0.5695}$ \\
\hline H) & $\ln \left(\mathrm{B}_{\text {ТОТАL }}\right)=\ln a+b \ln ($ Height + Diameter $)$ & -2.7349 & 1.2904 & 18.39 & 1,18 & $0.442 \mathrm{e}-04$ & 0.478 & 1.038 & $\mathrm{~B}_{\mathrm{TOTAL}}=0.0674(X)^{1.2904}$ \\
\hline
\end{tabular}


Table 5. Summary of the fit statistics used for validating the model estimates of the total biomass $(\mathrm{g})$ of the sub-sampled one-year old $D$. dacrydioides juveniles $(\mathrm{n}=10)$.

D. dacrydioides

\begin{tabular}{|c|c|c|c|c|c|}
\hline & Model & $B$ & $R M S E$ & $R_{a d j}^{2}$ & $A I C$ \\
\hline A) & $\mathrm{B}_{\text {TOTAL }}=1.8755(\text { Volume })^{0.7413}$ & 1.814 & 3.552 & 0.75 & 25.117 \\
\hline B) & $\mathrm{B}_{\text {TOTAL }}=0.0099(\text { Height })^{1.7497}$ & 1.018 & 2.862 & 0.838 & 20.8 \\
\hline C) & $\mathrm{B}_{\text {TOTAL }}=30.589(\text { Diameter })^{1.5733}$ & 1.379 & 4.666 & 0.568 & 30.573 \\
\hline D) & $\mathrm{B}_{\text {TOTAL }}=0.196(\text { Height } * \text { Diameter })^{1.1285}$ & 1.698 & 3.336 & 0.779 & 23.861 \\
\hline E) & $\mathrm{B}_{\text {TOTAL }}=30.589\left(\text { Diameter }^{2}\right)^{0.7867}$ & 2.545 & 5.309 & 0.441 & 33.156 \\
\hline F) & $\mathrm{B}_{\text {TOTAL }}=0.0099\left(\text { Height }^{2}\right)^{0.8749}$ & 1.01 & 2.86 & 0.838 & 20.783 \\
\hline G) & $\mathrm{B}_{\text {ТОТАL }}=0.196\left((\text { Height } * \text { Diameter })^{2}\right)^{0.5643}$ & 1.691 & 3.332 & 0.78 & 23.838 \\
\hline H) & $\mathrm{B}_{\mathrm{TOTAL}}=0.0092(\text { Height }+ \text { Diameter })^{1.7641}$ & 1.048 & 2.88 & 0.836 & 20.923 \\
\hline
\end{tabular}

Table 6. Summary of the fit statistics used for validating the model estimates of the total biomass $(\mathrm{g})$ of the sub-sampled one-year old $P$. totara juveniles $(\mathrm{n}=10)$.

\section{P. totara}

\begin{tabular}{|c|c|c|c|c|c|}
\hline & Model & $B$ & $R M S E$ & $R_{a d j}^{2}$ & $A I C$ \\
\hline A) & $\mathrm{B}_{\mathrm{TOTAL}}=3.3446(\text { Volume })^{0.6779}$ & -0.113 & 6.093 & 0.045 & 35.911 \\
\hline B) & $\mathrm{B}_{\text {TOTAL }}=0.0723(\text { Height })^{1.2763}$ & -0.436 & 4.164 & 0.554 & 28.3 \\
\hline C) & $\mathrm{B}_{\text {TOTAL }}=33.2376(\text { Diameter })^{0.9991}$ & 1.088 & 6.097 & 0.044 & 35.923 \\
\hline D) & $\mathrm{B}_{\text {TOTAL }}=0.2635(\text { Height } * \text { Diameter })^{1.139}$ & 0.536 & 3.294 & 0.721 & 23.611 \\
\hline E) & $\mathrm{B}_{\text {TOTAL }}=33.2376\left(\text { Diameter }^{2}\right)^{0.4996}$ & 1.089 & 6.097 & 0.044 & 35.924 \\
\hline F) & $\mathrm{B}_{\text {TOTAL }}=0.0723\left(\text { Height }^{2}\right)^{0.6382}$ & -0.444 & 4.165 & 0.554 & 28.305 \\
\hline G) & $\mathrm{B}_{\mathrm{TOTAL}}=0.2635\left((\text { Height } * \text { Diameter })^{2}\right)^{0.5695}$ & 0.519 & 3.29 & 0.722 & 23.585 \\
\hline H) & $\mathrm{B}_{\mathrm{TOTAL}}=0.0674(\text { Height }+ \text { Diameter })^{1.2904}$ & -0.438 & 4.151 & 0.557 & 28.236 \\
\hline
\end{tabular}

\section{Goodness of fit}

The goodness of fit statistics for each species-specific model are presented in Tables 5 and 6. Each species-specific model was evaluated on how well it predicted the biomass for the 10 trees in the subsample put aside for validation. For Bias and RMSE, values approaching 0 indicated a greater goodness of fit. For AIC, the lower a score is in comparison to the other model scores, the better the goodness of fit. Values of $\mathrm{R}^{2}$ adj approaching 1.00 suggest a better goodness of fit than lower values.

For $D$. dacrydioides, the model using the variable Height ${ }^{2}$ (model F) showed the best performance in terms of Bias (1.01), RMSE (2.86), $\mathrm{R}_{\text {adj }}$ (0.838), and AIC (20.783). 
However, models using Height, and Height + Diameter (models B \& H) had a similar goodness of fit statistics with Bias $=1.018, \mathrm{RMSE}=2.862, \mathrm{R}^{2}$ adj $=0.838$, and $\mathrm{AIC}=20.8$ and Bias $=1.048, \mathrm{RMSE}=2.88, \mathrm{R}_{\text {adj }}^{2}=0.836$, and AIC $=20.92$, respectively. Models for $D$. dacrydioides using diameter alone (models C \& E), or Volume (model A) always had the worst predictive ability.

P. totara total biomass was best predicted by the model using the variable $(\text { Height*Diameter })^{2}($ model G) with goodness of fit statistical values of Bias $=0.519$, RMSE $=3.29, \mathrm{R}^{2}$ adj $=0.722$, and AIC $=23.585$. The model using Height $*$ Diameter (model D) also had similar values, with Bias $=0.536, \mathrm{RMSE}=3.294, \mathrm{R}_{\text {adj }}^{2}=0.721$, and $\mathrm{AIC}=23.611$. The variables Volume, Diameter, and Diameter ${ }^{2}$ (models A, C, and E respectively) were all similarly bad at predicting $P$. totara juvenile biomass.

Multiple models had similar predictive abilities for both $D$. dacrydioides and P. totara. Burnham and Anderson (2003) suggest that AIC scores are the most useful indicator of which models have the best predictive power and that models that differ in AIC by less than ten units can be considered to have comparable predictive power. Models A, B, D, F, G, and H for D. dacrydioides, and models B, D, F, G, H for P. totara all have a $<10$ difference in AIC compared to the model with the absolute lowest score (Table 5-6). Nonetheless, to facilitate biomass estimation for $D$. dacrydioides and $P$. totara from my data an absolute best predictive model was chosen for each species; Model F for D. dacrydioides and model G for P. totara.

The predictive power of these two models are visualized in Figures 11 and 12, respectively. The grey shaded area of the plots shows where the true best-fit line for the population lies, estimated with $95 \%$ certainty. While the red dashed lines show the bounds of where $95 \%$ of the biomass values are for a tree at a certain height. Figure 11. shows that the model is able to predict all 10 juvenile $D$. dacrydioides biomasses with $95 \%$ confidence. The narrowness of the grey shaded area indicates that the predicted biomass means are similar to the true biomass mean for a certain height, although the accuracy of the prediction is reduced at the lower and high range of height data points. In comparison to the model for $D$. dacrydioides, the model for $P$. totara is slightly less powerful in its capacity to accurately predict the true biomass of a juvenile, particularly at the higher range of heights as indicated by the flaring of the grey area on the right of the plot (Figure 12.). However, it was still able to predict all 10 juvenile $P$. totara biomass with $95 \%$ confidence. 


\section{D. dacrydioides}

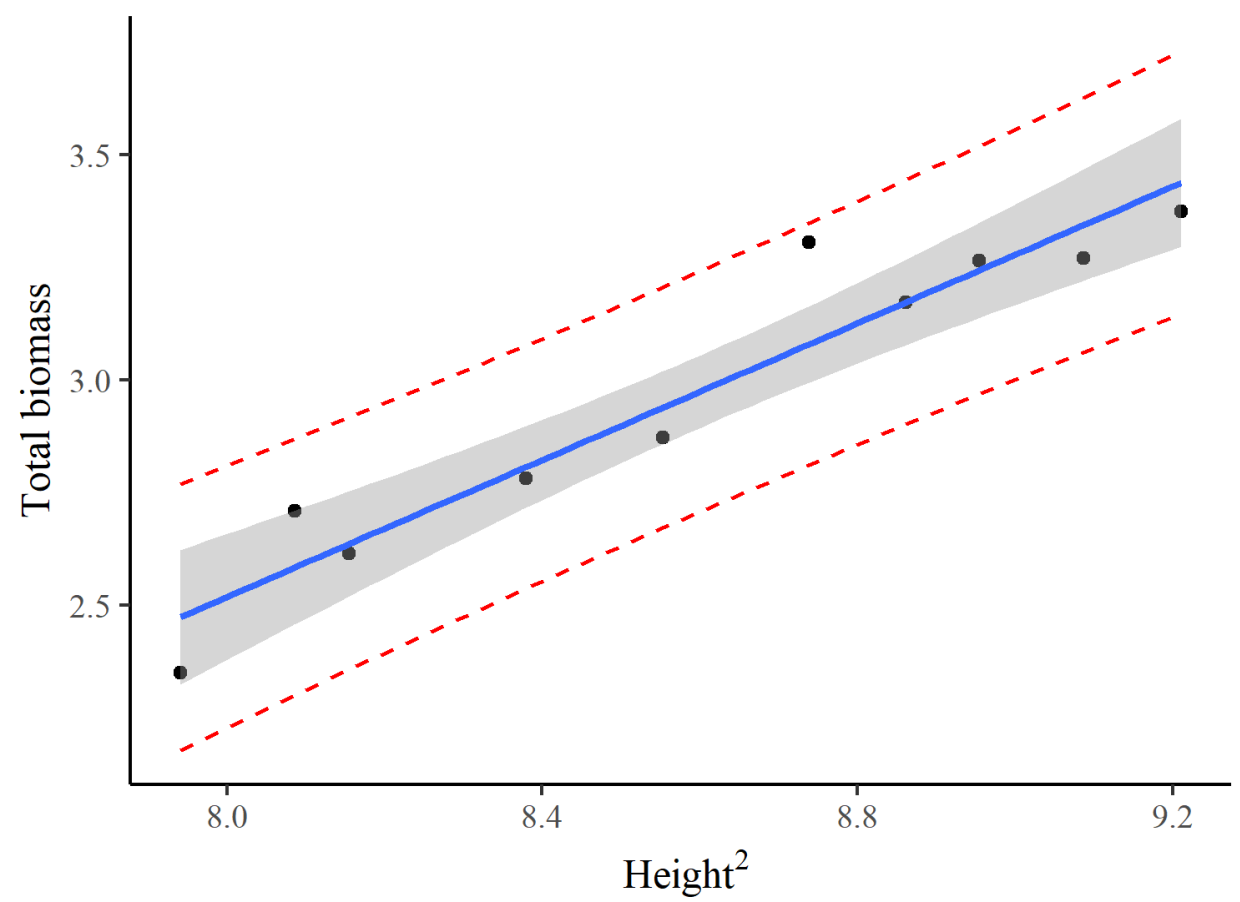

Figure 11. Plot (log transformed data) of the observed Total biomass against the observed Height ${ }^{2}$ of $D$. dacrydioides juveniles $(n=10)$ harvested after one-year of growth. The solid blue line is the prediction of the simple linear regression model of $\ln ($ Втотац $)$ against $\ln \left(\right.$ Height $\left.^{2}\right)$ The shaded area represents the 0.95 confidence interval for the prediction of a mean tree, while the dashed red line represents the 0.95 confidence interval for a tree selected at random

\section{P. totara}

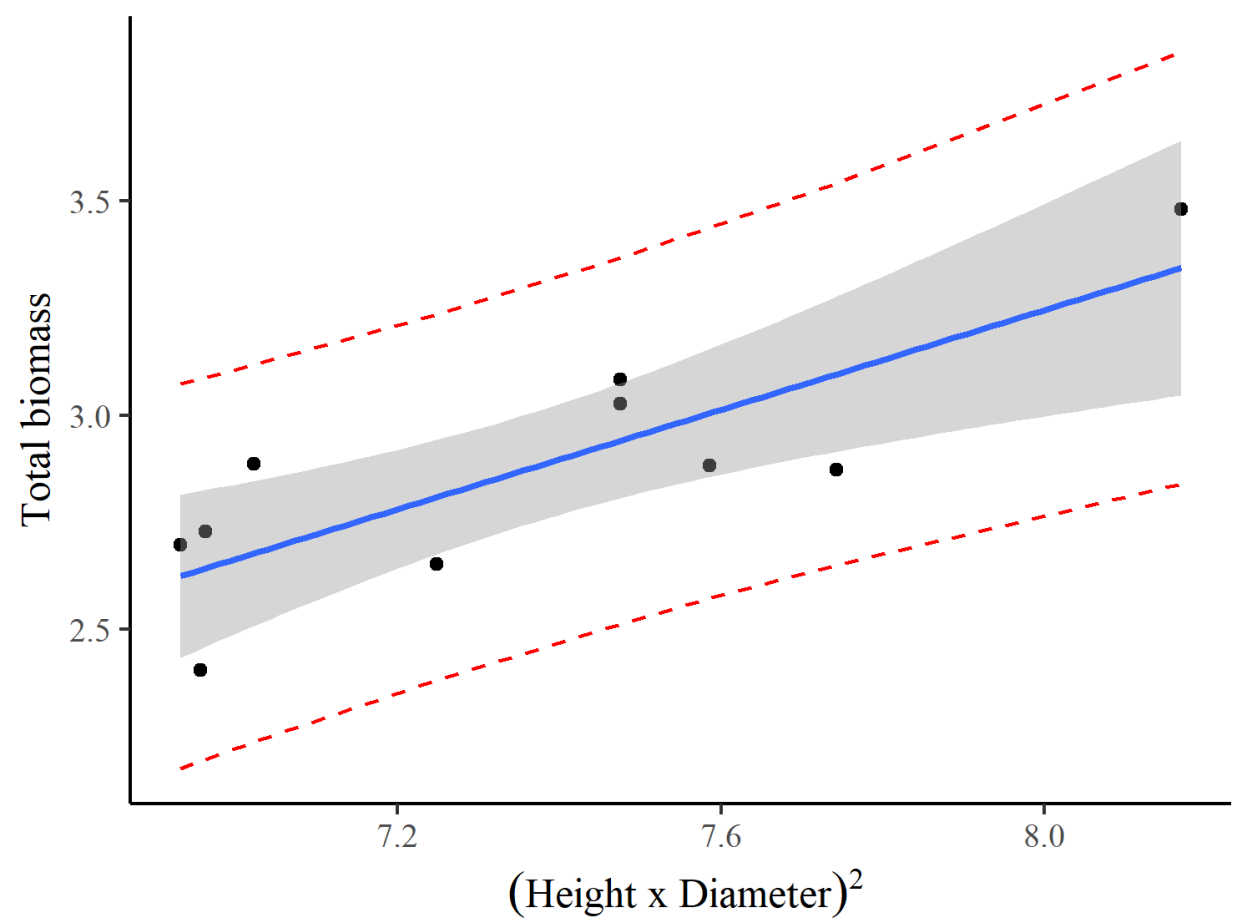

Figure 12. Plot (log transformed data) of the observed Total biomass against the observed (Height x Diameter) ${ }^{2}$ of $P$. totara juveniles $(n=10)$ harvested after one-year of growth. The solid blue line is the prediction of the simple linear regression model of $\ln \left(\mathrm{B}_{\text {TOTAL }}\right)$ against $\ln \left((\text { Height } x \text { Diameter })^{2}\right)$ The shaded area represents the 0.95 confidence interval for the prediction of a mean tree, while the dashed red line represents the 0.95 confidence interval for a tree selected at random. 


\section{$\underline{\text { Discussion }}$}

The main objective of this chapter was to develop species specific allometric models which would accurately estimate the total above- and below ground biomass of individual $D$. dacrydioides and $P$. totara juveniles using measurements of stem height, and stem diameter obtained non-destructively in the field. Eight models using stem height, diameter, and volume either alone or in combination where examined for their predictive power. I found that total biomass for $D$. dacrydioides was best predicted by the model $\mathrm{B}_{\mathrm{TOTAL}}=0.0099\left(\mathrm{Height}^{2}\right)^{0.8749}$, and $P$. totara by the model $\mathrm{B}_{\text {TOTAL }}=0.2635\left((\text { Height } * \text { Diameter })^{2}\right)^{0.5695}$. Models using diameter alone were found to be less powerful in predicting total tree biomass, while models containing height either alone or in combination with diameter were more powerful.

In comparison to other models present in the literature (Truax et al. 2014, Stankova et al. 2015, Fortier et al. 2017), I found that stem height was a better predictor of juvenile biomass than stem diameter. This is likely due to juveniles allocating resources to vertical growth rather than to girth until later in their ontogeny. Fanal (2017) also found that height was the best predictor in estimating the biomass of six-year old $D$. dacrydioides, while Beets et al. (2012) found diameter at breast height to be a better predictor for mature (>40yr) $D$. dacrydioides. Many forest trees have this growth form as it a necessary strategy in the competition for available light (Rozendaal et al. 2015). Later in its life the tree allocates more growth to increase girth to support its vascular system (Rozendaal et al. 2015). Diameter may also be the variable of preference in cases where it is unfeasible to accurately measure the height of an adult tree. Even though height may be the better predicter during model development.

Grotectors did not have a significant effect on the relative height gained over a one-year period for either $D$. dacrydioides or $P$. totara juveniles. Because grotectors had no effect on growth, trees planted with grotectors were pooled with those without grotectors to increase the sample size for development of the allometric equations. While this does increase the predictive power of the allometric models, it has the unintended consequence of masking the effect of the grotectors once biomass is estimated for the 168 trees that I will analyse in chapter 3. Possibly reducing my ability to detect biomass differences from above ground interaction. However, since there were no differences in height, and height was the best predictor of biomass it is likely that the grotectors would have been found to not have an effect on the biomass of juveniles in Chapter 3. 
The allometric models developed in this chapter are deemed suitable for the prediction of total tree biomass of $D$. dacrydioides and $P$. totara juveniles. However, this statement comes with the caveat that the allometric equations are likely highly species, location, age, and size specific since the models were developed from a sample of 20 trees. It is generally considered that a model becomes more applicable to use outside the context of the original data set the larger the sample size used in development (Picard et al. 2012).

Here I've developed species specific and age specific allometric equations which were necessary due to an absence of published allometric equations that fit my data well, given the young age and small diameter of the trees in my study. These models allow me to estimate biomass from measurements of only height and diameter for the 168 trees in my chapter 3. These models will be useful in the context of biomass or carbon budgeting and for those who wish to assess the growth of juvenile trees in the context of restoration planting at Wairio wetland. 


\section{Partitioning above and below ground interactions and their effects on D. dacrydioides and P. totara juveniles.}

\section{$\underline{\text { Introduction }}$}

Ecological interactions between neighbouring conspecific and interspecific plants play an important role in determining plant community development and composition (Connell and Slatyer 1977, Lortie et al. 2004). Competitive and facilitative interactions occur simultaneously between neighbouring plants, the net effect of which determines whether the presence of a neighbour is beneficial, detrimental, or neutral to an individual's survival or growth (Berkowitz et al. 1995b, Holmgren et al. 1997).

Historically, competitive interactions were considered to be more dominant than facilitative interactions (Grime 1973, Tilman 1982), mediating community composition through competitive exclusion. However, the facilitative effects of plants/plants interactions are known to ameliorate environmental and biological conditions allowing other species to broaden their niche and occupy habitats where they would nominally be excluded. These environment ameliorating trees are often termed nurse plants.

\section{Nurse effects}

Nurse effects are created by plants ameliorating local biotic and abiotic conditions to the benefit of their neighbours. These facilitative interactions between plants can increase the size of their realized niche beyond the range of the fundamental niche, allowing them to occupy locations which would normally be inhospitable in the absence of their neighbours (Bruno et al. 2003). Facilitative interactions may have a high degree of specificity between a nurse species and a small number of beneficiary species, whereas only a few interactions occur randomly between all species (Callaway 1998). For example, Mesquita et al. (2001) investigated secondary succession of abandoned pastures and cut forest, using two different pioneer nurse species, of the genus Cecropia and Vismia. They found that nurse species identity was a strong determinant of the identity and composition of beneficiaries. A similar specificity was observed in an examination of the interaction between the identity of a nurse species and the relative ontogeny of the beneficiary species (Paterno et al. 2016). They reported that beneficiary identity changed both with nurse species identity as well as with 
ontogenetic shifts. During germination of beneficiary species, all nurse species had a positive effect on growth. In summary, the strength and direction of plant-plant interactions is often dependent on species identity, and this idiosyncrasy currently limits the development of an improved general theory of species interactions over stress gradients.

Plants can be considered to exist in two separate environments; one above ground, and one below ground. Within each environment a tree will experience its own suite of unique selective pressures and ecological forces. While competition for light may be intense in the above ground environment, a plant may be experiencing a strong facilitative effect below ground by interacting with other plants through a mycorrhizal network, resulting in an imbalance between the two environments.

\section{Above ground interactions}

Above-ground interactions are generally created by the volume, density, and proximity of the neighbouring benefactor's canopy (Franco and Nobel 1989, Castanho and Prado 2014). A neighbouring plant can provide benefits by forming a barrier from the wind, diffusing intense solar radiation, protection from herbivory by crypsis, preventing the growth of potential competitors, and buffering soil and air temperature (Callaway 2007).

\section{Below ground interactions.}

A major aspect of plant facilitation is the sharing of resources between two or more individuals using below-ground nutrient transfer pathways. Plants require 14 essential mineral nutrients, along with $\mathrm{CO}_{2}$, and water to carry out photosynthetic processes (Marschner and Rimmington 1988). The access that an individual may have to these resources can be sporadic due to variation in the distribution of mineral nutrients and water in an area. Facilitative interactions occurring below-ground between plants may help ameliorate the effects of resource poor soils by the recycling of the mineral nutrients, or the transferal of nutrients between individuals from areas of high resource availability to the areas of low availability. It is generally accepted that there are three primary mechanisms of below ground nutrient transfer and acquisition amongst plants (Hunter and Aarssen 1988).. (1) Through the soil solution (SS); (2) Mycorrhizal Networks (MN); (3) by the formation of Root Grafts (RG).

\section{(1) Soil solution}


Plants can receive resources directly from the soil solution via root interception, diffusion, and mass flow. Most of the nutrient uptake by roots is due to the effects of mass flow and then diffusion, root interception is the least important driver of nutrient uptake from the soil solution with less than 3\% being attributed to this mechanism (Marschner and Rengel 2012).

(2) Mycorrhizal networks

In its simplest form a mycorrhizal networks is a single fungal individual colonizing the roots of two or more plant individuals and linking them together with its hyphal network. (Simard et al. 2012). The fungal mycelia are able to acquire nutrients and water more efficiently due to the increased surface area created by the hyphal network in comparison to the plant roots. The mycorrhizal networks facilitate the growth and survival of plants through the reciprocal transfer of mineral nutrients acquired by the fungi in exchange for organic carbon created by the plants (Smith and Read 2010, Simard et al. 2012).

(3) Root grafts

Conspecific plants may also form root grafts, creating a direct link between two or more trees by which nutrients and organic carbon may be transported (Fraser et al. 2006). Root-grafting may occur when the roots of two individuals cross, as the roots increase in diameter, the vascular system can fuse at certain points creating a potential pathway for the transfer of resources among plants (Bormann 1966).

\section{Measuring net interaction}

Four approaches have commonly been used by studies measuring interactions; RCI Relative Competition Index (Wilson and Keddy 1986), RNE - Relative Neighbour Effects (Markham and Chanway 1996), $\operatorname{lnRR}$ - Log Response Ratio (Hedges et al. 1999), and RII Relative Interaction Index (Armas et al. 2004). Most of these have been developed after, or derived from, models which are used for assessing competitive interactions. I have elected to use the Relative Interaction Index because it is uniquely useful in assessing the total interaction effects. The index is mathematically symmetrical and can be used to show whether interactions are net facilitative, or net competitive. When calculated, RII will take on a value between +1 and -1 .

In this chapter, I use the Relative Interaction Index to determine net interaction direction and intensity for a target plant, while manipulating the above and below ground interactions. I 
also quantified the effect of interactions on the biomass gain of $D$. dacrydioides and $P$. totara juveniles. The end goal being to partition the contribution of above ground and below ground interactions towards biomass gain in newly established juvenile trees. To my knowledge, this will be the first time that the Relative Interaction Index has been used to measure interactions within a New Zealand context.

\section{Methods.}

This study was conducted was conducted at a research and restoration site in 'Stage 3' of Wairio wetland, which is located on the south-eastern shore of Lake Wairarapa in the southern part of New Zealand's North Island (41²1437.9"S 175¹5'38.6"E) (Figure. 13). Wairio wetland is a 132ha of ephemeral wetland, typically drying out in the summer months and flooding in the winter. It forms one part of a larger complex of ecologically significant wetlands extending along the Wairarapa valley.

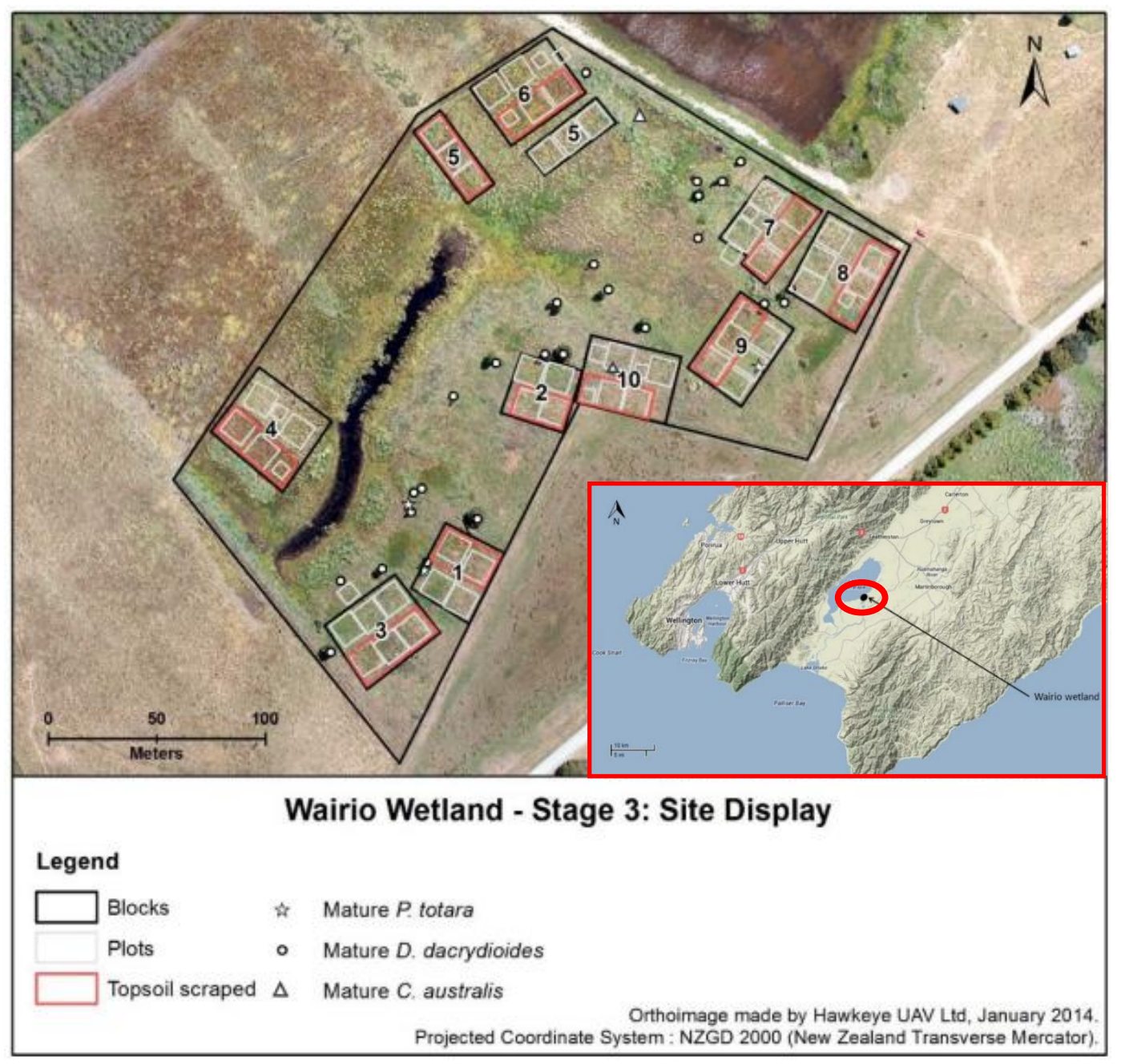

Figure 13. Map of the lower North Island (inset bottom right) showing the location of Wairio wetland (red circle) on the south eastern shore of Lake Wairarapa. Adapted from (Gillon 2014). Map of Stage 3 at Wairio wetland. Blocks 3, 7, and 10 were used. Adapted from (Fanal 2017). 
In July 2011, several blocks of native trees were planted in 'Stage 3' (Figure 13) by Victoria University of Wellington for the purpose of conducting research into wetland restoration (Gillon 2014). These blocks were comprised of multiple plots containing either; (1) a mix of Dacrycarpus dacrydioides (kahikatea), Podocarpus totara (totara), Cordyline australis (cabbage tree), and Olearia virgata (twiggy tree daisy); or (2) Leptospermum scoparium (manuka), and Pittosporum tenuifolium (kohūhū). Additionally, during July 2016, 14 D. dacrydioides and $14 P$. totara juveniles were randomly distributed and planted into gaps within the five-year-old plots of blocks 3,7, and 10, as well as establishing new plots containing only the newly planted juveniles and none of the trees planted in 2011 (Figure 1314). The newly planted $D$. dacrydioides and $P$. totara juveniles had been grown from seed by the Norfolk Road nursery and were $\sim 24$ months old at the time of planting (Pers. Comms). Each juvenile was planted either; (1) directly into the ground, (2) with a grotector, (3) inside a mesh bag and then into the ground, (4) with a grotector and a mesh bag, (5) inside a net pot and mesh bag, (6) with a grotector, net pot, and a mesh bag.

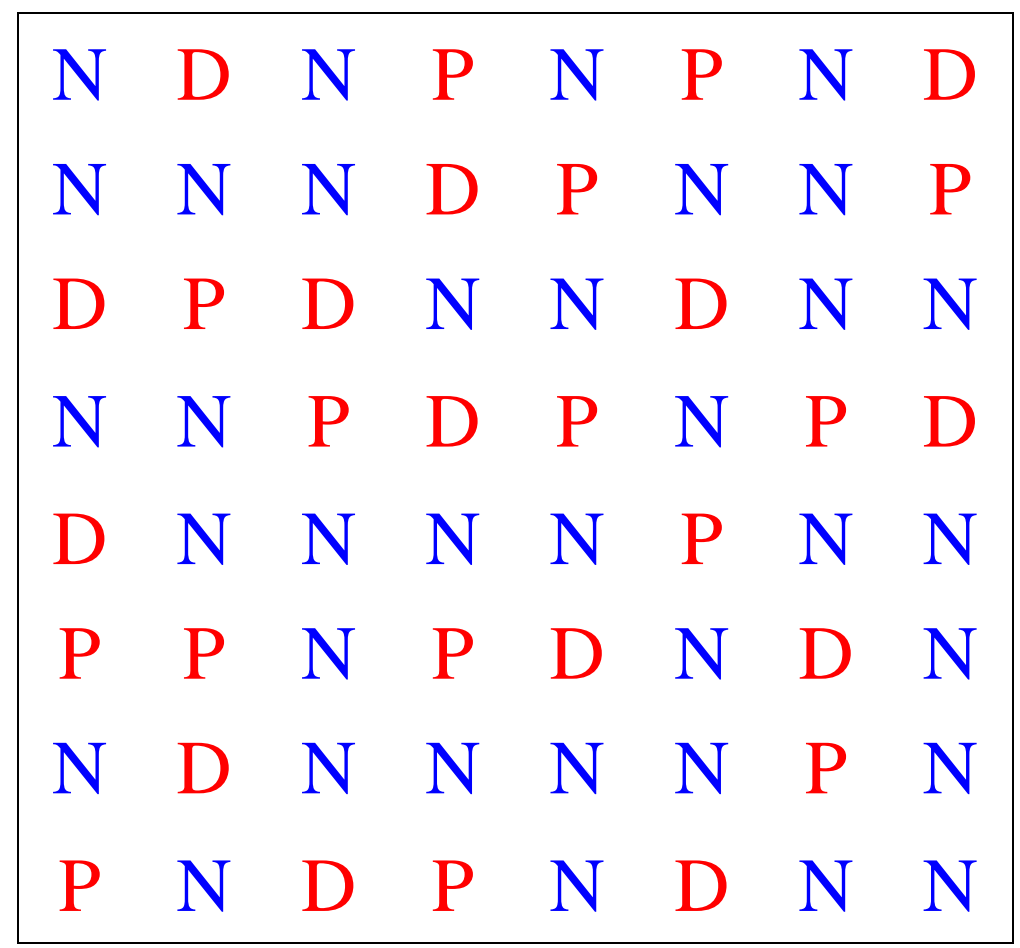

Figure 14. Stylized representation of a plot with $D$. dacrydioides $($ red D, $\mathrm{n}=14)$ and $P$. totara $($ red $\mathrm{P}, \mathrm{n}=14)$ planted in to gaps left within a plot of surviving nurse species (blue $\mathrm{N}$ ) planted in 2011, with spacings of $1.5 \mathrm{~m}$ between plants. 
In addition to the woody tree species planted by the Victoria University of Wellington, much of the ground was occupied by pastural grasses such as Schedonorus arundinaceus (tall fescue), and Holcus lanatus (Yorkshire fog) (Gillon 2014). These grasses were particularly prevalent in the areas between the plots and within the plots containing the $D$. dacrydioides, $P$. totara, C. australis, and O. virgata planted in 2011 (Figure 15). They were less prevalent within the plots containing L. scoparium, and P. tenuifolium.
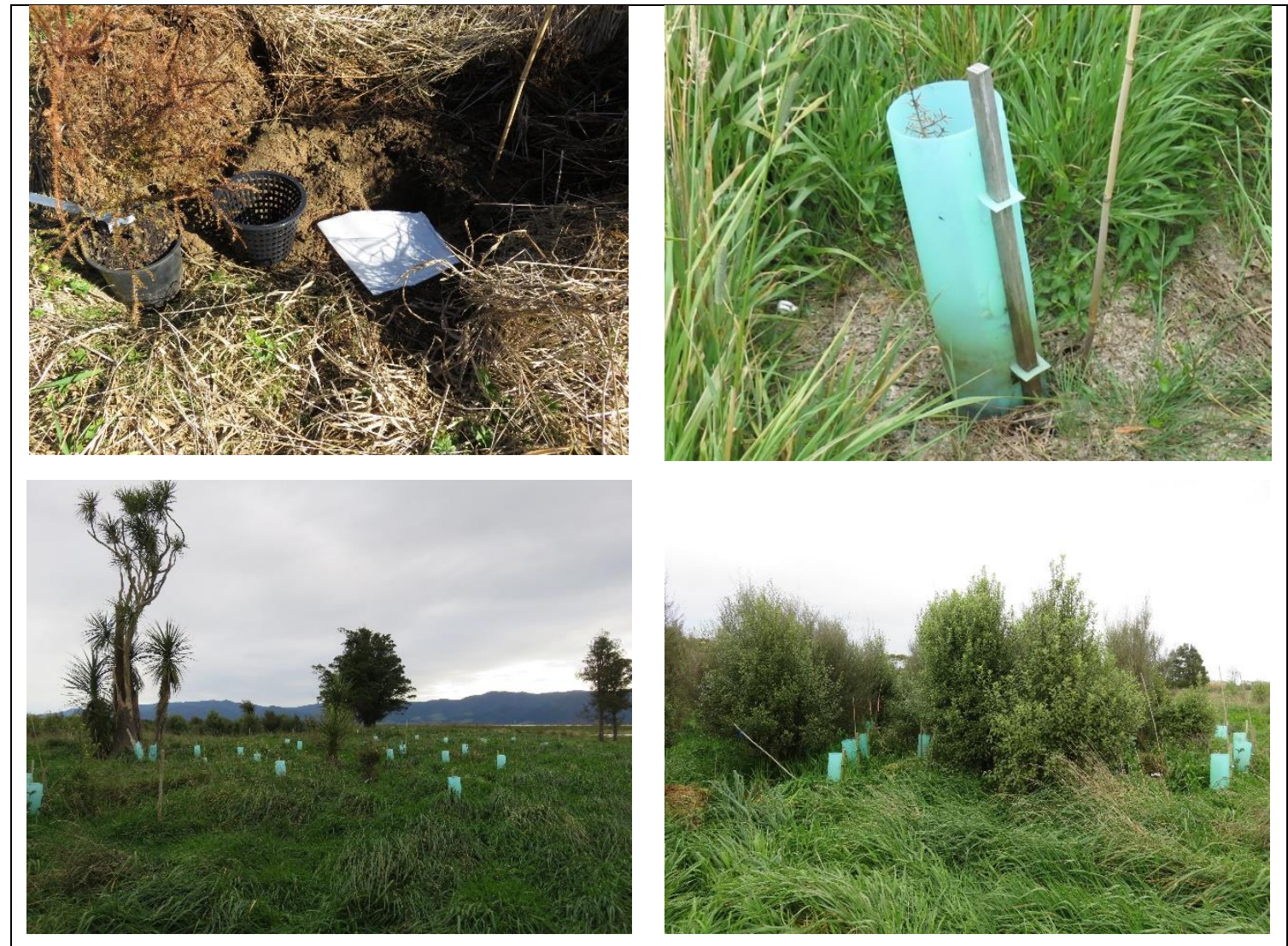

Figure 15. Top left: A D. dacrydioides juvenile prior to being planted with a mesh bag and net pot. Top right: A grotector surrounding a juvenile $P$. totara. Bottom left: In the foreground are plots of $D$. dacrydioides and $P$. totara juveniles, planted with six-year old $D$. dacrydioides, $P$. totara, $C$. australis, and $O$. virgate. In the background can be seen the grotectors from a newly establish plot containing only juvenile $D$. dacrydioides and $P$. totara. Bottom right: A plot containing six-year old $L$. scoparium and $P$. tenuifolium, and juvenile $D$. dacrydioides and P. totara.

\section{Above ground effects}

Half of all the juveniles for each species and planting method were planted within a grotector (shown in Figure 15.). Grotectors have been known to reduce mortality by providing protection from the wind, herbivory, and reduces the likelihood of other plants in the immediate area - such as grass - from overgrowing the juvenile completely (Close et al. 2009). In this study, the protection afforded by the grotector was assumed to be analogous to the physical protections provided by a neighbour without the associated competitive effects. 
Neighbouring species of nurse plants (i.e. trees planted in July 2011) were classified as being either 'conspecific', 'interspecific', unless there was no neighbouring tree in which case it was classified as 'none'. A summary of the classification of each species pairing is shown in Table 2.

Table 7. Classifications of different pairs of neighbours within $1.5 \mathrm{~m}$ of a juvenile tree. Con is a conspecific pairing, Inter is an interspecific pairing, and None is where there was no neighbour next to juvenile.

\section{Juvenile}

\begin{tabular}{l|cc}
$\begin{array}{l}\text { Six-year-old } \\
\text { Neighbour species }\end{array}$ & D. dacrydioides & P. totara \\
\hline D. dacrydioides & Con & Inter \\
P. totara & Inter & Con \\
C. australis & Inter & Inter \\
L. scoparium & Inter & Inter \\
O. virgata & Inter & Inter \\
P. tenuifolium & Inter & Inter \\
No neighbour & None & None
\end{tabular}

In cases where a juvenile was planted next to both a conspecific and interspecific neighbour it was necessary to discriminate under which classification the juvenile's nearest neighbour would fall in order to maintain a respectable sample size in each classification. The inversesquare of the distance from the dripline of each neighbour to the juvenile was multiplied by the area of the neighbour's dripline using the diameter at the widest part of the tree (Figure 16). Giving the following equation:

$$
\text { Nearest neighbour }=\frac{1}{\text { distance }^{2}} \times \frac{1}{4} \pi \times \text { diameter }^{2}
$$

The tree with the highest value was considered to be the nearest neighbour. 


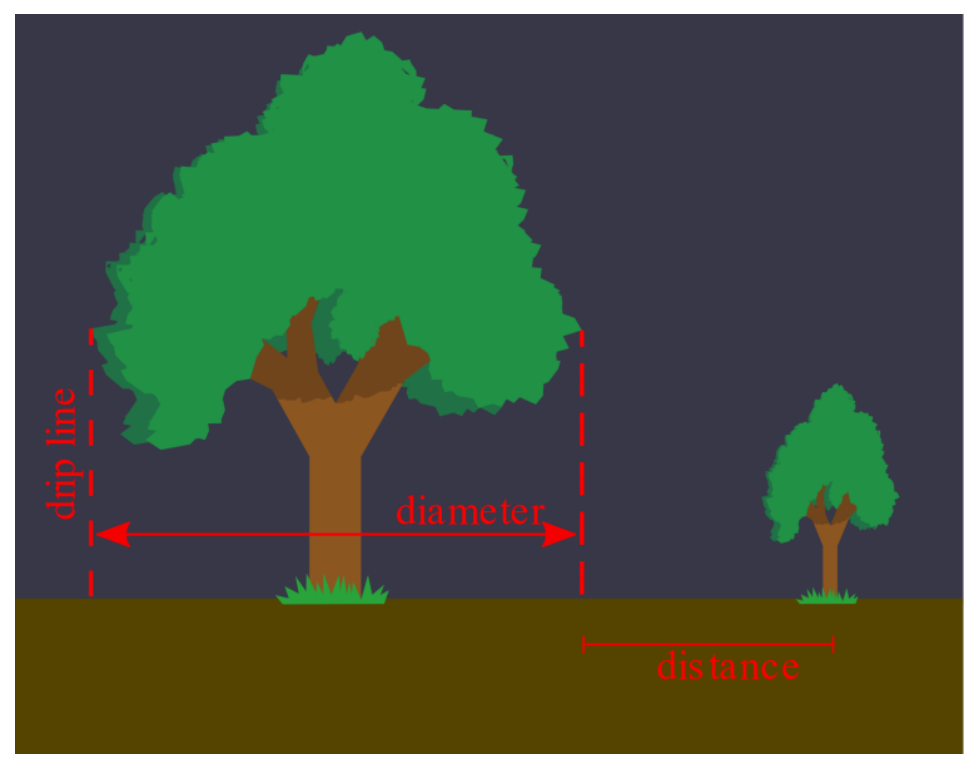

Figure 16. Diagram of the measurements used in calculating the value for determining the nearest neighbouring tree (left) from a focal juvenile tree (right).

It was assumed that a tree's root system would extend to at least the drip line, and that the closer the aerial foliage and root system were to the juvenile, the greater the interaction effect would be relative to a tree with a smaller diameter that was farther away.

\section{Above ground pathways}

While not directly measuring the above ground interactions independently, this study will be able to investigate the net interaction effect that a neighbour provides by comparing the differences between the nearest neighbour groups for plants with no access to the mycorrhizal network (i.e. SS). For example, if there is an above ground interaction effect it will be discernible by a higher RII value in the groups Conspecific, Soil solution and Interspecific, SS and a lower RII value in None, SS.

\section{Below ground pathways}

To measure below ground interactions this experiment used the below-ground access to the three pathways by which interactions were likely to occur; (1) soil solution, (2) mycorrhizal network, and (3) root-grafting.

Access to the below-ground pathways was manipulated using a combination of polyester mesh bags with apertures of $48 \mu \mathrm{m}$ in diameter, plastic net pots, and having the pot twisted $180^{\circ}$ through the horizontal plane every four weeks (Figure 17). 


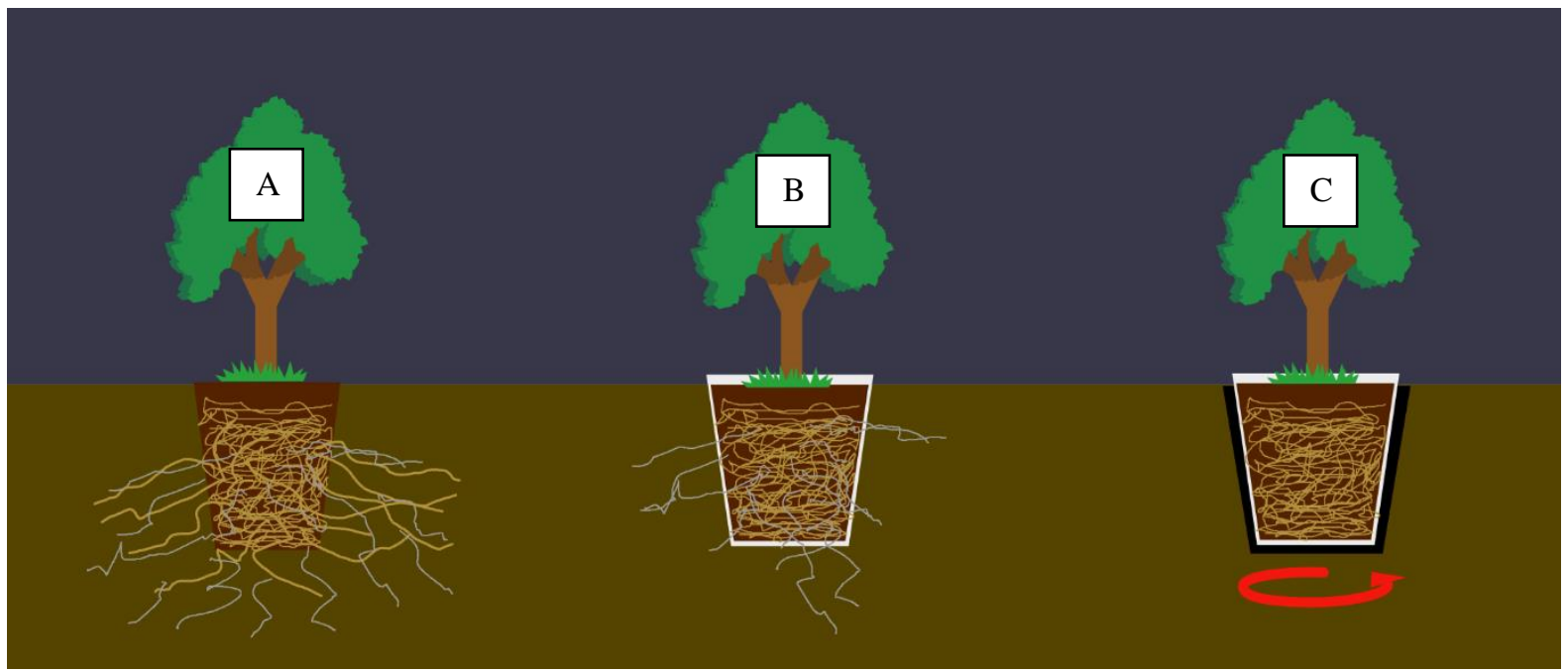

Figure 17. Diagram showing the different planting techniques used to disturb the juvenile's access to belowground nutrient transfer pathways. Tree A has been planted directly in to the ground (Root grafts, Mycorrhizal Network, and Soil Solution). Tree B has been planted with a mesh bag (Mycorrhizal Network and Soil solution). Tree $\mathrm{C}$ has been planted with a mesh bag, pot, and has the pot twisted every four weeks (Soil Solution only). The light brown lines represent the tree roots, while the light grey lines represent the mycorrhizal mycelia.

Juveniles which had access to all three below ground pathways were planted directly in to the ground (Figure 17.A). Juveniles with access to the soil solution and mycorrhizal network were planted with the root mass inside of a mesh bag (Figure 17.B). Juveniles with access to the soil solution only, were planted with the root mass inside a mesh bag and then into a plastic net pot which was twisted $180^{\circ}$ around the horizontal plane every four weeks (Figure 17.C).

Table 8. Summary of how the planting method relates to the access an individual has to the below ground interaction pathways. Planting methods A, B, and C also relate to the diagram shown in Figure 17.

\section{Below-ground pathway access}

\begin{tabular}{l|ccc}
\multicolumn{1}{l|}{$\begin{array}{l}\text { Planting method } \\
\end{array}$} & $\begin{array}{c}\text { Soil solution } \\
\text { (SS) }\end{array}$ & $\begin{array}{c}\text { Mycorrhizal network } \\
\text { (MN) }\end{array}$ & $\begin{array}{c}\text { Root grafts } \\
\text { (RG) }\end{array}$ \\
\cline { 2 - 4 } (A) Directly in to ground & $\checkmark$ & $\checkmark$ & $\checkmark$ \\
(B) Mesh bag only & $\checkmark$ & $\checkmark$ & $\times$ \\
(C) Mesh bag + pot + & $\checkmark$ & & $\times$
\end{tabular}

The aperture size of the mesh prevents the juvenile tree's roots from growing beyond the confines of the bag or another plant's roots from entering, thus stopping the formation of root-grafts between individuals. However, the pores are large enough to allow the hyphae of arbuscular mycorrhizae to pass through and potentially form a network between plants. The 
twisting of the pot can break the connection of the mycorrhizal network to the juvenile by severing the hyphae that extend through the mesh bag and beyond the pot, preventing access to the mycorrhizal network pathway.

\section{Mortality and effect of grotectors}

During the summer of 2016-2017 unseasonably heavy rain caused extensive flooding of the Wairio wetland, with a number of plots being completely inundated and suffering $100 \%$ mortality. Because of the high mortality suffered by juvenile of both species it was necessary to try and pool certain groups to provide a reasonable sample size for statistical tests.

The effect of grotectors on the growth of the juveniles was tested in Chapter 2 and found to have no significant effect on the height gained over a one-year growth period. Further, height was found to be the most important variable in the development of the allometric equations used in estimating juvenile biomass (see Chapter 2). Therefore, it was accepted that juveniles planted with and without grotectors could be pooled together as presence of a grotector was an inconsequential factor in the estimation of biomass gain of juveniles over the one-year growth period.

\section{Relative Interaction Index}

To assess the direction and intensity of the net interaction effect on the juvenile trees at the end of a one-year growth period the Relative Interaction Index was used. RII is calculated from the formula $R I I=\frac{\left(\Delta B_{w}-B_{o}\right)}{\left(\Delta B_{w}+B_{o}\right)}$ developed by Armas et al. (2004). In the context of this study, $\mathrm{B}_{\mathrm{w}}$ is the change in total biomass of a targeted juvenile grown with (Figure 18.A and B), or without a neighbour (Figure 18.C), and with access to one of the three below ground pathways types. Whereas, $\mathrm{B}_{\mathrm{o}}$ is the mean change in total above and below ground biomass of all trees grown without a neighbour and without access to the mycorrhizal network or rootgrafts (Figure 17.8, red dashed box). When calculated, RII will take on a value between 1 and -1 . If RII is $>0$ the direction of the interaction effect is net facilitative, if RII is $<0$ the direction is net competitive. If RII $=0$ then the interaction effect is net neutral. The direction of an interaction is made in comparison to $\mathrm{B}_{\mathrm{o}}$ (i.e. None, $\mathrm{SS}$ - represented by the dashed line in Figure 18).

To calculate the Relative Interaction Index, measurements of total tree biomass are required. Due to time and resource limitations, direct measurements of biomass for all the study trees 
was impractical. Therefore, allometric equations developed in Chapter 2 were used to estimate total biomass for each individual tree. Estimates of total tree biomass were calculated for the initial biomass at planting, and final biomass after a one-year period. $D$. dacrydioides used the formula $B_{\text {Total }}=0.009\left(\text { Height }^{2}\right)^{0.8749}$, and P. totara used $B_{\text {Total }}=$ $0.2635\left((\text { Height } \times \text { Diameter })^{2}\right)^{0.5695}$. Height $(\mathrm{cm})$ was measured from the root collar to the apical meristem, and diameter $(\mathrm{cm})$ was measured at $10 \mathrm{~cm}$ above the root collar. Each plant was measured at the time of planting, and again after the one-year growth period. 

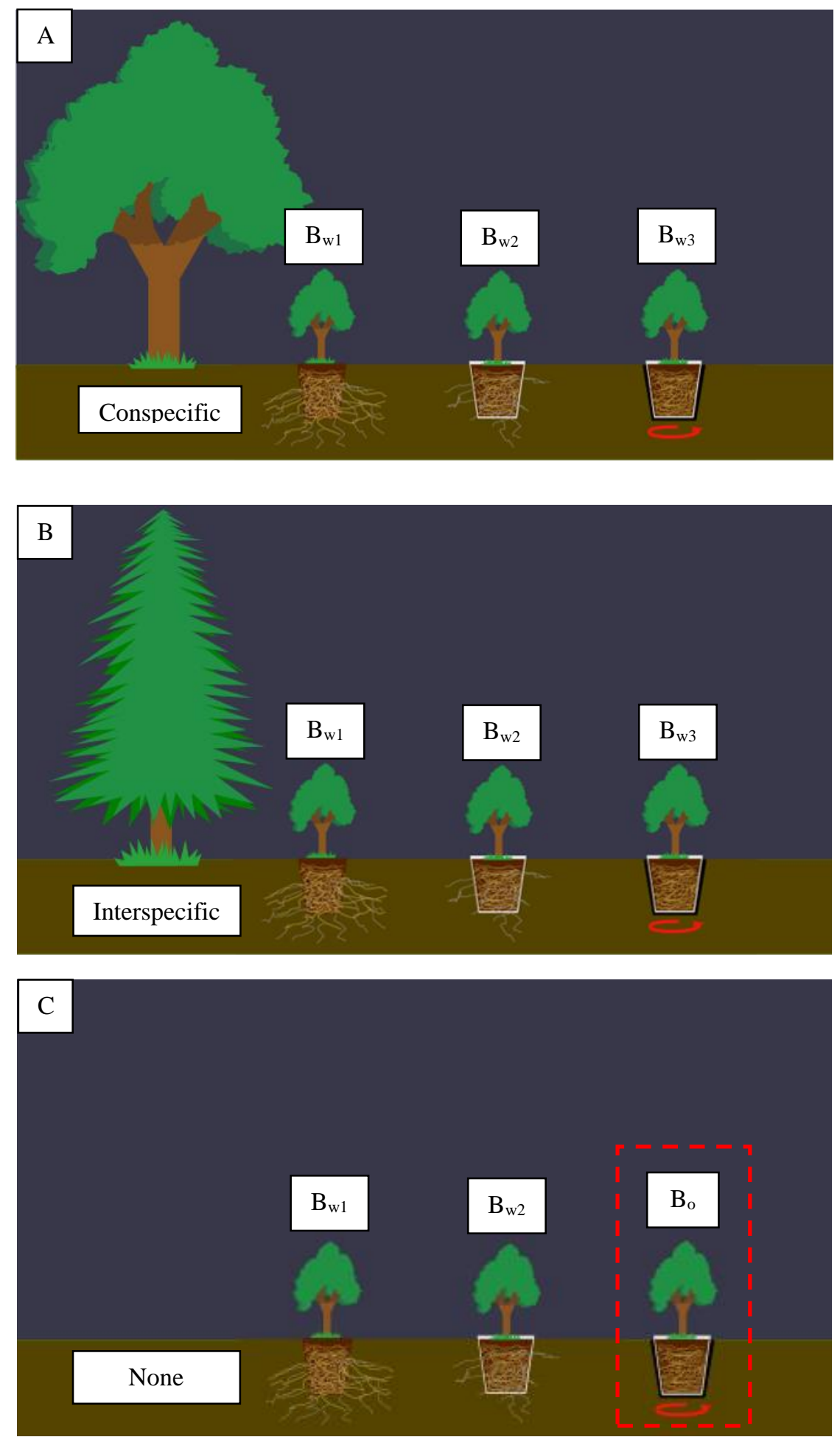

Figure 18. Diagrams showing the different combinations for calculating the relative interaction index (RII) values. Diagram A, B, and C show the nearest six-year old neighbour within $1.5 \mathrm{~m}$ (represented by the larger tree) being Conspecific, Interspecific, or None at all, respectively. Biomass $\left(\mathrm{B}_{\mathrm{w}}\right)$ was estimated for each plant with access to the $R G+M N+S S\left(B_{w 1}\right), M N+S S\left(B_{w 2}\right)$, and $S S\left(B_{w 3}\right)$ below ground pathways. The red dashed box indicates $B_{0}$, a plant with no neighbour and access to only the $S S$. $B_{o}$ is significant as it is indicative of a plant with no, or neutral interaction effects and is used as a comparison against all other combinations. 


\section{Relative Biomass Gain.}

Relative biomass gained over the one-year growth period was used to quantify the net interaction effect that the nearest neighbour, and access to the below ground pathways had on the juvenile trees. Relative biomass gain was calculated as the difference between the final and initial biomass, as a proportion of the initial biomass.

\section{Relative Biomass Gain $=\frac{\text { Final biomass-Initial biomass }}{\text { Initial biomass }}$.}

The assumptions of normality and homogeneity were tested using Shapiro-Wilk tests, and Bartlett tests respectively

For each species, a Type III two-way ANOVA test was used to assess differences in the mean relative biomass gain of each nearest neighbour group. A further One-way ANOVA test was conducted after pooling the nearest neighbour groups together. Post-hoc analyses were conducted when necessary using Tukey-HSD tests.

All statistical analyses were conducted using the ' $R$ ' Statistical Software program ( $R$ Development Core Team 2015). Tests were conducted at the $\alpha=0.05$ level of significance unless otherwise specified.

\section{$\underline{\text { Results }}$}

\section{Mortality}

Overall mortality was evenly distributed between juveniles of the two species. Out of the 168 individuals of each species planted in the winter of 2016, 81 (48\%) D. dacrydioides and 87 (51\%) P. totara were still surviving by winter 2017 . The greatest mortality occurred in the five lowest elevated plots, with mortality for individuals planted in these plots approaching $100 \%$. This was caused by long term water inundation due to a wetter than average year and the construction of a water-retaining bund wall during 2016.

Table 9. Summary of mortality in juveniles of each species over the one-year growth period.

\begin{tabular}{l|ccc} 
Species & Planted 2016 & Surviving 2017 & Mortality \\
\hline D. dacrydioides & 168 & 81 & $52 \%$ \\
P. totara & 168 & 87 & $49 \%$
\end{tabular}




\section{D. dacrydioides}
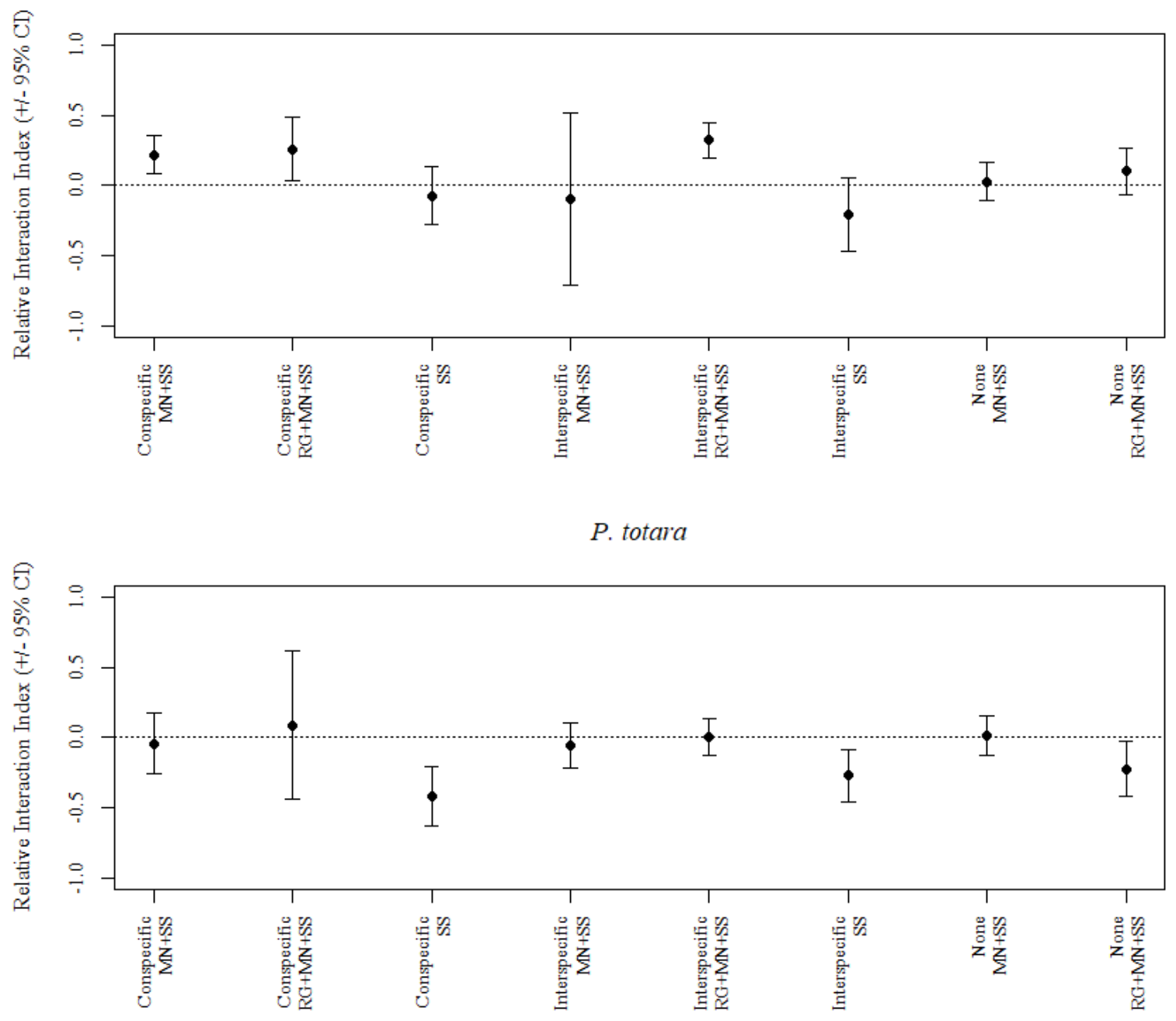

Figure 19. Mean (+/- 95\% CI) Relative Interaction Index values for D. dacrydioides, and P. totara as a function of the effect of nearest neighbouring species type, and nutrient pathway access. The dotted line represents a net neutral interaction, above the dotted line a net facilitative interaction, and below the dotted line a net competitive interaction.

\section{Interaction direction and intensity}

The relative interaction index shows that $D$. dacrydioides juveniles benefitted from having neighbours present and access to root grafting and mycorrhizal networks (Figure 19). In comparison, $P$. totara juveniles received no benefit from having neighbours, and in fact suffered from competition without access to a mycorrhizal network when neighbours were present.

Conspecific and interspecific SS groups for D. dacrydioides all had net neutral interactions of similar intensity. With access to the RG+MN+SS below ground pathway $D$. dacrydioides juveniles showed net facilitative interactions when growing next to conspecific or 
interspecific neighbours. While only juveniles with conspecific neighbours and access to the $\mathrm{MN}+\mathrm{SS}$ below ground pathway had net facilitative interactions. With no neighbours present, net interactions were always neutral regardless of what below ground pathways a juvenile had access to. The intensity of each facilitation interaction was similar for those conditions in which they occurred.

P. totara juveniles were never net facilitative, regardless of access to below ground pathways or nearest neighbour. Net competitive interactions were seen for all P. totara juveniles with no access to mycorrhizal networks or root grafting (SS), regardless of whether the nearest neighbour was conspecific, or interspecific. Interestingly, there was also a competitive effect when $P$. totara had access to $\mathrm{RG}+\mathrm{MN}+\mathrm{SS}$ pathway while growing with no neighbour.

\section{D. dacrydioides}

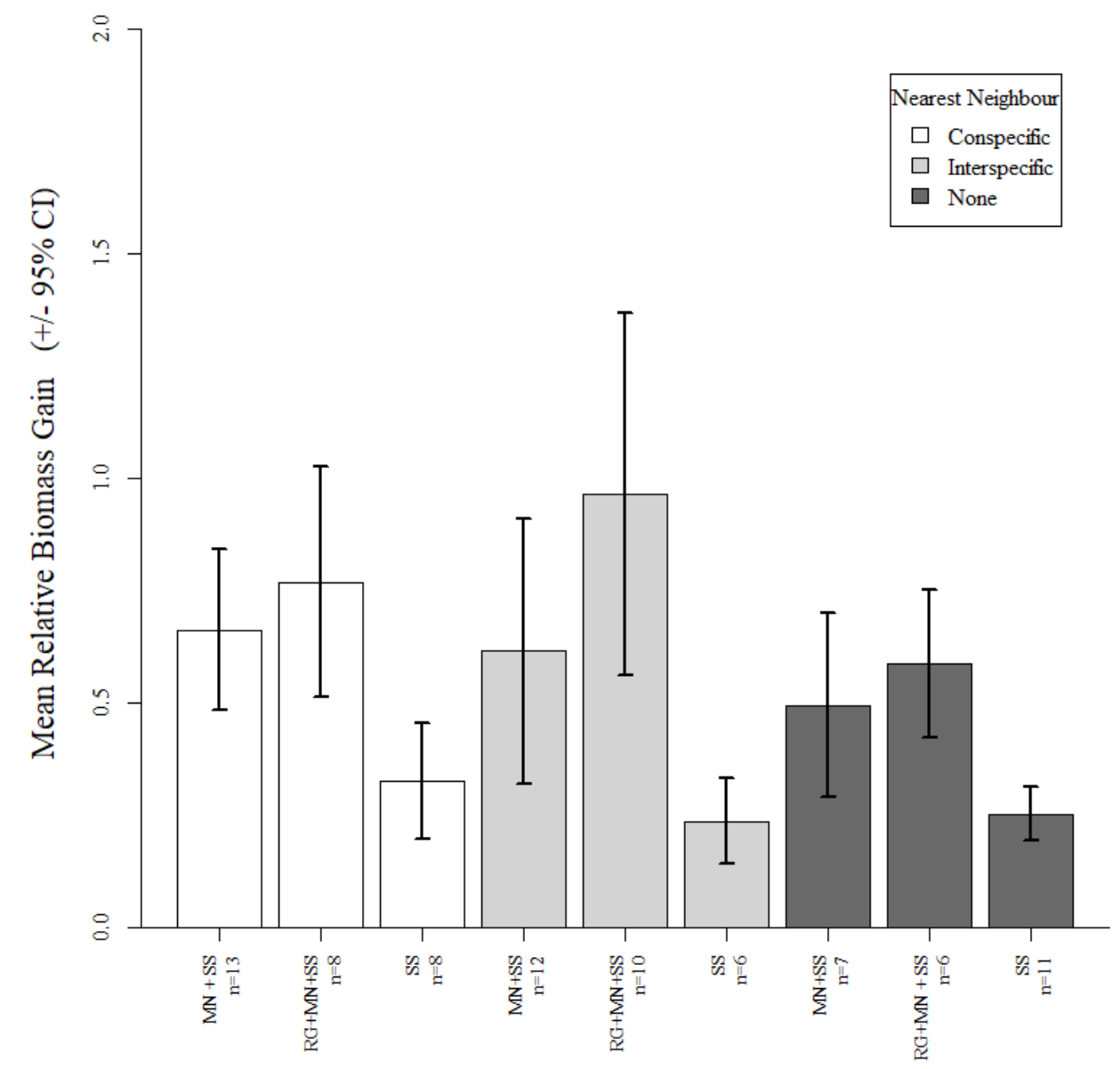

Figure 20. Mean (+/- 95\% Confidence Interval) relative total biomass gain of juvenile $D$. dacrydioides over a one-year growth period at Wairio wetland. Conspecific neighbours are shown by the white bars, Interspecific neighbour by the light grey bar, and no neighbour (None) by the dark gray bars. The three bars of each Nearest neighbour group represent access to different nutrient pathways. From left to right; Mycorrhizal Network \& Soil Solution (MN+SS), Root-grafts \& Mycorrhizal network \& Soil Solution (RG+MN+SS), and Soil Solution only (SS). 
Table 10. Result of the Two-way ANOVA test for $D$. dacrydioides. * denotes a significant result

$\underline{\text { Relative biomass gain } D \text {. dacrydioides }}$

\begin{tabular}{lccc} 
& F-value & df & p-value \\
\hline Nearest Neighbour & 1.285 & 2 & 0.283 \\
Below ground Pathway Access & 10.71 & 2 & $8.476 \mathrm{e}-05^{*}$ \\
Interaction & 0.655 & 4 & 0.625
\end{tabular}

\section{Relative total biomass gain}

D. dacrydioides juveniles showed a greater total biomass gain when an individual was able to access a mycorrhizal network, regardless of whether the juvenile was planted alone or next to either a conspecific neighbour, or an interspecific neighbour (Figure 19). Mean relative biomass gain caused by differences in access to the below-ground facilitative pathways in $D$. dacrydioides juveniles showed similar patterns when separated in to groups classed by their nearest neighbour (Conspecific, Interspecific, and None). There is an apparent trend across all the nearest neighbour groups of increased biomass gain in juveniles when below-ground facilitative pathways were left intact ( $\mathrm{MN}+\mathrm{SS}$, and $\mathrm{RG}+\mathrm{MN}+\mathrm{SS})$, compared to when the pathway access is disrupted (SS). Two-way ANOVA analysis revealed that there was indeed a similar trend with no statistical significance in the differences between the nearest neighbour groups $(\mathrm{p}$-value $=0.283)$, but differences in mean relative biomass gain due to below ground facilitative pathways access were highly significant $\left(\mathrm{p}\right.$-value $=8.48 \mathrm{e}^{-05}$ ). No significant interaction effect was found between Nearest neighbour and Below-ground facilitative pathway $(\mathrm{p}$-value $=0.625)($ Table 10$)$.

The results of the Two-way ANOVA analyses suggest that effect of the nearest neighbour was not be having an impact on mean relative biomass gain, while below ground pathway access was. It was therefore decided to pool the nearest neighbour groups together for further analysis of the below ground pathway effects using a One-way ANOVA (Figure 22). 


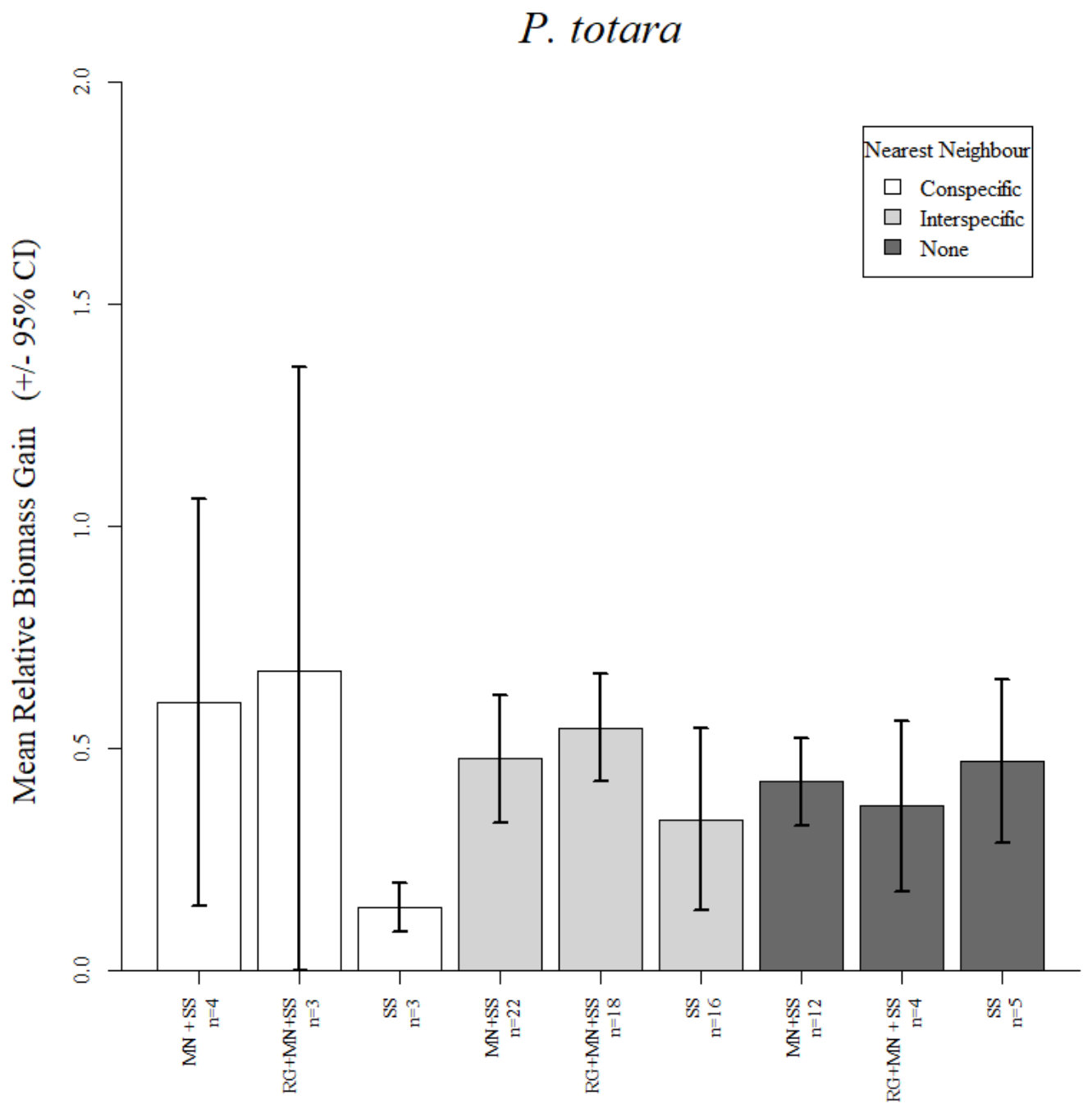

Figure 21. Mean (+/- 95\% Confidence Interval) relative total biomass gain of juvenile $P$. totara over a one-year growth period at Wairio wetland. Conspecific neighbours are shown by the white bars, Interspecific neighbour by the light grey bar, and no neighbour (None) by the dark gray bars. The three bars of each Nearest Neighbour group represent access to different nutrient pathways. From left to right; Mycorrhizal Network, and Soil Solution (MN+SS); Root-grafts, Mycorrhizal network, and Soil Solution (RG+MN+SS); Soil Solution only (SS).

Table 11 Result of the Two-way ANOVA test for $P$. totara

\section{$\underline{\text { Relative biomass gain } P \text {. totara }}$}

F-value df $\quad$ P-value

$\begin{array}{llll}\text { Nearest Neighbour } & 0.0915 & 2 & 0.9127 \\ \text { Below ground Pathway Access } & 1.9706 & 2 & 0.1462 \\ \text { Interaction } & 1.0389 & 4 & 0.3926\end{array}$


Mean biomass gain in P. totara juveniles showed an apparent decrease in mean biomass when a neighbour was present and there was no access to root grafting or a mycorrhizal network (SS) (Figure 21). However, when analysed using a Two-way ANOVA test the differences in mean relative biomass were found to be highly non-significant differences between the gain between the nearest neighbour groups ( $\mathrm{p}$-value $=0.9127$ ). Relative mean biomass were also not significantly different when considering differences between below ground pathway groups ( $\mathrm{p}$-value $=0.1462)$. No significant interaction between the nearest neighbour and the access to below ground pathway was found (p-value $=0.3926)($ Table 11$)$.

A One-way ANOVA was also conducted on the $P$. totara mean relative biomass data once the nearest neighbour groups had been pooled together, similar to what was conducted on $D$. dacrydioides.

D. dacrydioides

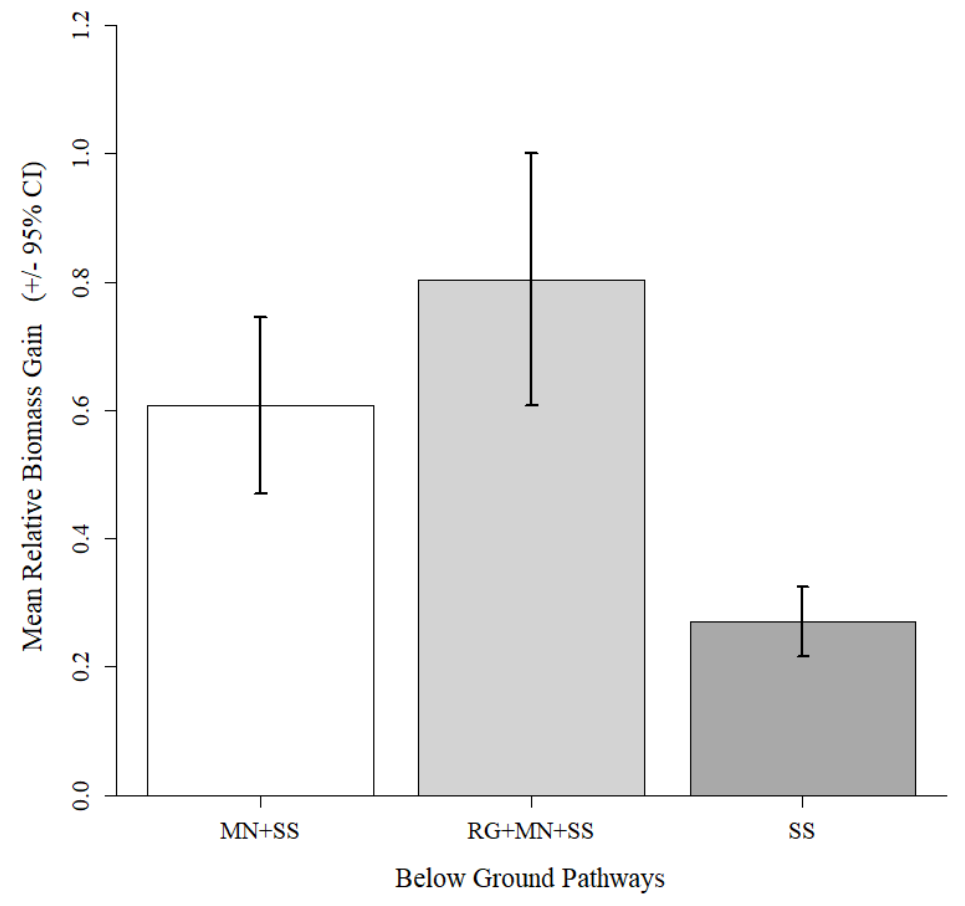

P. totara

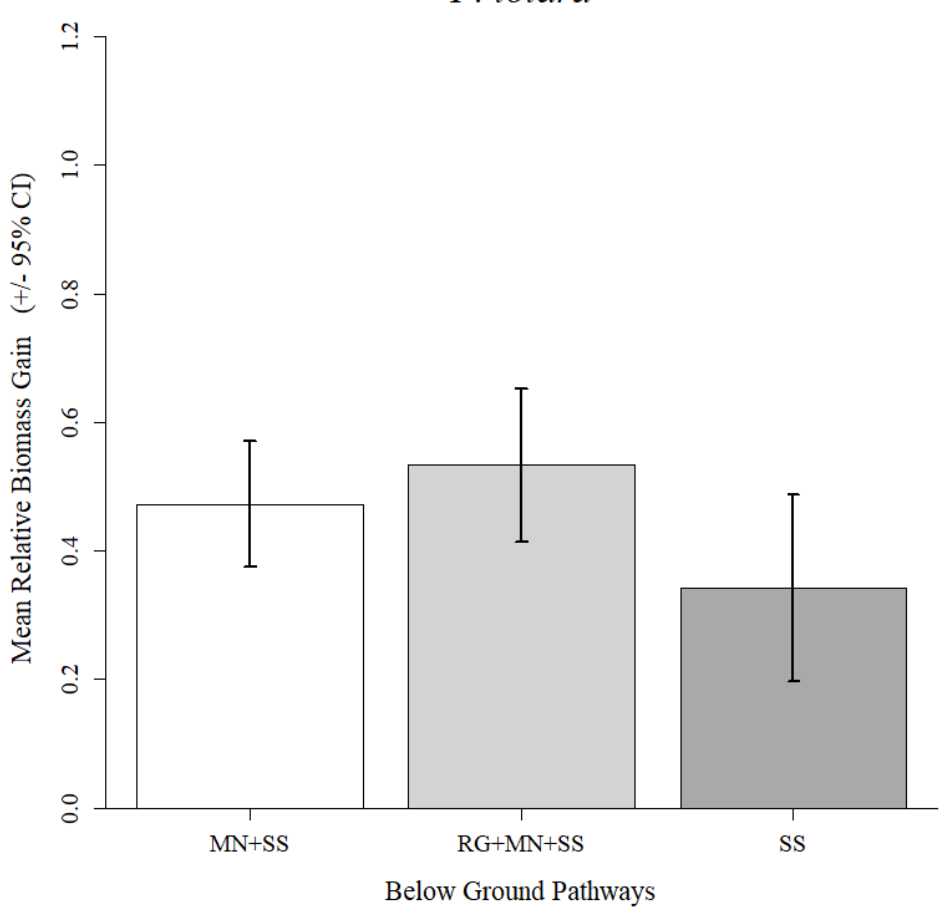

Figure 22. Mean relative biomass gain (+/- 95\% confidence interval) in $D$. dacrydioides (left) and $P$. totara when nearest neighbour groups were pooled together. Access to the mycorrhizal network and soil solution $(\mathrm{MN}+\mathrm{SS})$ below ground pathways is represented by the white bars. Access to root grafts, mycorrhizal network and soil solution (RG+MN+SS) below ground pathways are represented by the light grey bars. Access to the soil solution (SS) below-ground pathway only is represented by the dark grey bar.

The results of the Two-way ANOVA analyses were supported by further investigation in to each nearest neighbour group independently using a One-way ANOVA (Figure 22). When 
nearest neighbour groups were pooled, there was a significant difference in mean relative biomass gain for $D$. dacrydiodes due to the below ground pathways $\left(\mathrm{F}_{2,78}=12.88 \mathrm{p}\right.$-value $=$ 1.47e-05), but no significant difference for P. totara $\left(\mathrm{F}_{2,84}=2.268 \mathrm{p}\right.$-value $\left.=0.11\right)$. Post hoc analysis of the effect of the below ground pathways on the mean relative biomass of $D$. dacrydioides showed that access to the soil solution only (SS) resulted in a smaller relative biomass gain than either having access to the mychorrizal network and soil solution $(\mathrm{MN}+\mathrm{SS}, \mathrm{p}$-value $=0.003)$, or having access to root grafts, mycorrhizal network and soil solution $(\mathrm{RG}+\mathrm{MN}+\mathrm{SS}, \mathrm{p}$-value $=1.03 \mathrm{e}-05)$. There was no significant difference between the two pathways with mycorrizal network access $(\mathrm{p}$-value $=0.13)$.

\section{$\underline{\text { Discussion }}$}

My overall assessment of the relative interaction index and mean relative biomass gain for $D$. dacrydioides and $P$. totara juveniles is that facilitative interaction effects are primarily being driven by the below ground pathways. However, below ground interactions do change depending if there is a neighbour present or not, as well as what access a juvenile has to the below ground pathways. Access to a mycorrhizal network results in a greater relative total biomass gain over a one-year growth period for D. dacrydioides, but not for P. totara. There is no difference between a conspecific and an interspecific neighbour in their below ground effects. It is not clear how the above-ground effects of a neighbour are affecting the juveniles, although $D$. dacrydioides had net neutral interactions and $P$. totara competitive interactions.

\section{Mortality}

The high proportion of mortality observed across both species was due to extensive flooding in the summer of 2016-2017. It was estimated that $62 \%$ of 'Stage 3' at Wairio wetland was under standing water in January 2017 (Fanal 2017). Unfortunately, this caused the entirety of five out of the 12 plots (140 plants total) of $D$. dacrydioides and P. totara juveniles to die, masking any effects of above or below ground interactions on survival.

\section{Above-ground pathways}

D. dacrydioides juveniles showed net neutral interactions with no difference in the RII values in groups where below ground access was limited to the soil solution only (SS). In contrast $P$. totara had net competitive effects, suggesting that it is being negatively impacted by the 
above ground effects of a neighbour. However, relative total biomass gain was not different from if it had no neighbour. This could be partly because of the small sample size in each group did not provide the statistical analyses enough power to detect any changers. However, when nearest neighbour data was pooled the relative biomass gain due to below-ground processes was still not different.

Another possibility is that the effect observed is due to the surrounding grasses. Grass species were ubiquitous throughout the Wairio wetland and could be as much as $\sim 1 \mathrm{~m}$ high. When plants were transplanted into a grass dominated community, Peltzer and Köchy (2001) found that growth was supressed twofold in comparison to when they were planted away from the grasses. It is possible that the competitive effect is masking any facilitative effects provided by a neighbouring nurse plant.

\section{Below -ground pathways}

$\mathrm{RG}+\mathrm{MN}+\mathrm{SS}$ had similar effects to $\mathrm{MN}+\mathrm{SS}$ for both $D$. dacrydioides and P. totara. This is not surprising as it is likely that no root grafts were able form, given the age of the juveniles and the length of time they were planted for. Tarroux and Desrochers (2010) found that the length of time taken for root grafts to form between individual Pinus banksiana trees ranged between 2.43 and 2.97 years depending on soil type. Well over the period of time the juveniles were growing for. Examining the roots during harvest also failed to find any evidence of root grafts being formed between the juveniles and any other plants. If this is true, then is expected that $\mathrm{RG}+\mathrm{MN}+\mathrm{SS}$ pathway should act in the same manner as the $\mathrm{MN}+\mathrm{SS}$ pathway.

The effect of access to a mycorrhizal network was an increase in the relative total biomass gained for $D$. dacrydioides regardless of whether the neighbour was interspecific or conspecific. Whereas for $P$. totara relative total biomass did not increase. Waring (2017) reported comparable results in an experiment also conducted at Wairio wetland. She postulated that there may be species differences in the AMF community that caused the mycorrhization of $D$. dacrydioides roots, but not $P$. totara.

P. totara juveniles with no access to the mycorrhizal network and planted next to either a conspecific or interspecific neighbour showed net competitive interactions. However, when 
planted alone with access to the mycorrhizal network net interaction effect shifted towards neutral. This suggests that the $P$. totara is competing with its neighbour for some resource.

Here, I investigated how ecological interactions changed direction, and intensity in response to differences in access to below-ground pathways and nearest neighbours. $D$. dacrydioides and $P$. totara responded differently even though they received the same treatments and were grown with the same temporal and environmental conditions suggesting a degree of species specific interaction. D. dacrydioides interactions were net facilitative when it has access to the mycorrhizal network and either a conspecific or interspecific neighbour. Whereas, $P$. totara was net neutral in the same situation. The interactions were asymmetrical about the above-ground and below-ground environment, with interactions primarily being driven by below-ground processes. These results provide some insight in to how the plant community may develop at Wairio wetland. 


\section{Implications for the reforestation of a New Zealand wetland.}

\section{$\underline{\text { Introduction }}$}

One of the objectives of this thesis was to provide insight in to how the reforestation of Wairio wetland might progress given the findings from the previous chapters. In this chapter I will use the information gained from my chapter 3 to discuss their implication for the reforestation of New Zealand wetlands, using Wairio wetland as a case study.

In chapter 3, I found that my two study species $D$. dacrydioides and $P$. totara showed different responses to the treatments that they received. $D$. dacrydioides showed net facilitation and gained biomass when it had access to the mycorrhizal network and a neighbour. Whereas, $P$. totara showed net neutral interactions and did not gain biomass. $P$. totara also showed net competition when it did not have access to the mycorrhizal network and was grown next to neighbours. Above ground interactions were found to be less important than below ground interactions, overall. In general, these results mean that $D$. dacrydioides juveniles should be expected to have higher growth, reproductive, and survival rates when grown next to nurse species in comparison to $P$. totara.

\section{Wetlands}

Wetlands are ecologically important, biologically rich and unique habitats that support a vast range of habitats for plants, animals and soil microbes. Swamps are a category of wetland that are dominated by flood-tolerant trees, which thrive in soils that are nutrient-rich, but occasionally boggy or flooded. Historically, New Zealand's swamps were dominated by large podocarp trees, especially D. dacrydioides and P. totara (Beadel et al. 2000), but these were targeted as valuable timber species throughout the $19^{\text {th }}$ century. Thereafter, land conversions for urban expansion and agriculture continued to degrade swamps. Today, $90 \%$ of New Zealand's original swamplands have been lost (Robertson 2016). It is only relatively recently that wetlands have been appreciated for the wide range of economic, social, environmental and cultural benefits they provide to people (Zedler and Kercher 2005). Swamps and other wetlands protect shorelines, sustain biodiversity, store carbon, reduce damage from floods, and store and filter water (Zedler and Kercher 2005). 


\section{Wetland restoration}

Wetland restoration is the purposeful enhancement of a wetland habitat to beautify a site and regain its ecological functions (Clewell et al. 2002). Currently, hundreds of wetland restoration projects exist across New Zealand. A primary goal of these projects is to revegetate sites with native tree species. However, this goal is often difficult to achieve, because up to $38 \%$ of juvenile trees can die within the first year of planting (Anton et al. 2015). The death of trees increases the financial costs of wetland restoration while reducing the benefits to nature. Utilizing techniques which promote tree survival is therefore of great importance in restoration

The survival and growth of juvenile trees planted in wetland restoration projects depends on the interplay of many site factors including water levels, soil biology and fertility, wind exposure, herbivores and locations of nearby trees and plants. Nearby plants can matter a lot during the earlier years of a juvenile's life. Neighbouring plants can alter the environment that a juvenile experiences. For example, highly competitive perennial grasses can shade and outcompete the newly planted juveniles for light and soil resources (Peltzer and Köchy 2001). Conversely, having neighbours may benefit the juvenile. Nurse effects are positive interactions between plant species whereby an older 'nurse' tree facilitates the establishment of a younger juvenile. Nurse trees can help juveniles in a variety of ways; a nurse tree may ameliorate local conditions by forming a barrier from the wind, diffusing intense solar radiation, creating protection from herbivory by crypsis, preventing the growth of potential competitors, buffering soil and air temperature, increasing hydraulic lift, soil aeration, and through the transfer of resources between individual plants(Callaway 2007)

The deep root systems of nurse trees can draw up nutrient-rich water from deeper soil, enhancing water availability to the shallow root systems of the juveniles (Caldwell et al. 1998, Zou et al. 2005). Nurse trees can also provide a source of beneficial fungal spores (Clark and Zeto 2000). Arbuscular mycorrhizal fungi (AMF) form mutually beneficial relationships with trees. In exchange for sugars made by the plant in photosynthesis, AMF provide the plant with soil nutrients. Root grafts can also form between trees allowing the direct transfer of sugars from one plant to another through their conjoint vascular system. Because juvenile establishment in restoration projects is influenced by nurse trees over such a wide range of site conditions, nurse effects may be particularly important for trees. 


\section{Wairio wetland}

Wairio wetland is located on the south-eastern shore of Lake Wairarapa in the southern part of New Zealand's North Island $\left(41^{\circ} 14^{\prime} 37.9^{\prime \prime S} 175^{\circ} 15^{\prime} 38.6^{\prime \prime E}\right)$. Wairio is a 132 ha of ephemeral wetland, typically drying out in the summer months and flooding in the winter. It forms one part of a larger complex of ecologically significant wetlands extending along the Wairarapa valley. Historically the wetland was thought to be dominated by podocarp species, such as $D$. dacrydioides and $P$. totara, remnants of which still exist at Wairio today (Beadel et al. 2000). However, the drainage and clearance of the wetland for conversion into pastoral farmland has resulted in the degradation and disruption of the ecosystem.

Ecological restoration aims to assist in the accelerated recovery of a damaged ecosystem back on to its historical trajectory (Clewell et al. 2002). As such, one of the aims at Wairio wetland is to restore it back to the $D$. dacrydioides and $P$. totara dominated community. One way that it can do this is by using our knowledge of secondary succession.

In secondary succession, a previously occupied area is re-occupied in a series of recolonization events following a disturbance which removed the previously established community. As new plants become established they alter the environmental conditions in the habitat such as amount of light, water, and soil mineral composition. These changes allow other species which may not have been able to establish before, to become established under the new range of conditions. In turn, the newly arrived species may alter conditions again, making the local environment unsuitable for the older established species, and more suitable for a new suite of species.

The restoration project at Wairio has been trying to accelerate the process of succession by planting and maintaining 'nurse' species in order allow greater success in the establishment of D. dacrydioides and P. totara. Current practice at Wairio is for D. Dacrycarpus and $P$. totara to be planted in amongst the nurse species so that beneficial interactions between the nurse species and the newly planted juveniles can occur. The findings of my study suggest that under these conditions $D$. dacrydioides is more likely to become established than $P$. totara. Resulting in a possible future community where $D$. dacrydioides is more abundant than P. totara.

Below ground competition with neighbours was reducing the facilitative effect of access to the mycorrhizal network on P. totara. If the goal of the restoration project is to have the maximum potential survival for the juvenile podocarps, then there may be some benefit in 
planting $P$. totara farther away from the nurse plants than it currently is, in order to reduce the amount of root competition with other woody tree species. 


\section{Appendix 1}

Table 12. Values of RII for D. dacrydioides and $P$. totara in response to changes in nearest neighbour (Conspecific, Interspecific, None) and below ground pathways (MN+SS, RG+MN+SS, SS).

$$
\begin{gathered}
\text { RII } \\
(+/-95 \% \mathrm{CI})
\end{gathered}
$$

Neighbour/Below ground

$\underline{\text { D. dacrydioides }}$

$\underline{\text { P. totara }}$

\begin{tabular}{|c|c|c|}
\hline Conspecific / MN+SS & $\begin{array}{c}0.22 \\
(+/-0.137)\end{array}$ & $\begin{array}{c}-0.044 \\
(+/-0.216)\end{array}$ \\
\hline Conspecific / RG+ MN+SS & $\begin{array}{c}0.258 \\
(+/-0.226)\end{array}$ & $\begin{array}{c}0.086 \\
(+/-0.53)\end{array}$ \\
\hline Conspecific / SS & $\begin{array}{c}-0.072 \\
(+/-0.205)\end{array}$ & $\begin{array}{c}-0.421 \\
(+/-0.215)\end{array}$ \\
\hline Interspecific / MN+SS & $\begin{array}{c}-0.1 \\
(+/-0.616)\end{array}$ & $\begin{array}{c}-0.06 \\
(+/-0.162)\end{array}$ \\
\hline Interspecific / RG+ MN+SS & $\begin{array}{c}0.322 \\
(+/-0.124)\end{array}$ & $\begin{array}{c}0.006 \\
(+/-0.132)\end{array}$ \\
\hline Interspecific / SS & $\begin{array}{c}-0.208 \\
(+/-0.26)\end{array}$ & $\begin{array}{c}-0.272 \\
(+/-0.189)\end{array}$ \\
\hline None / MN+SS & $\begin{array}{c}0.028 \\
(+/-0.139)\end{array}$ & $\begin{array}{c}0.014 \\
(+/-0.145)\end{array}$ \\
\hline None / RG+MN+SS & $\begin{array}{c}0.103 \\
(+/-0.165)\end{array}$ & $\begin{array}{l}-0.223 \\
(+/-0.2)\end{array}$ \\
\hline
\end{tabular}

pathway 


\section{$\underline{\text { References }}$}

Agrawal, A. A., D. D. Ackerly, F. Adler, A. E. Arnold, C. Cáceres, D. F. Doak, E. Post, P. J. Hudson, J. Maron, and K. A. Mooney. 2007. Filling key gaps in population and community ecology. Frontiers in Ecology and the Environment 5:145-152.

Anton, V., S. Hartley, and H. U. Wittmer. 2015. Survival and growth of planted seedlings of three native tree species in urban forest restoration in Wellington, New Zealand. New Zealand Journal of Ecology 39:170-178.

Armas, C., R. Ordiales, and F. I. Pugnaire. 2004. Measuring plant interactions: A new comparative index. Ecology 85:2682-2686.

Beadel, S., A. Perfect, A. Rebergen, and J. Sawyer. 2000. Wairarapa plains ecological district: Survey report for the protected natural areas programme. New Zealand Protected Natural Areas Programme.

Beets, P. N., M. O. Kimberley, G. R. Oliver, S. H. Pearce, J. D. Graham, and A. Brandon. 2012. Allometric equations for estimating carbon stocks in natural forest in NewZealand. Forests 3:818-839.

Berkowitz, A. R., C. D. Canham, and V. R. Kelly. 1995a. Competition vs facilitation of tree seedling growth and survival in early successional communities. Ecology 76:1156-1168. 
Berkowitz, A. R., C. D. Canham, and V. R. Kelly. 1995b. Competition vs. Facilitation of tree seedling growth and survival in early successional communities. Ecology 76:1156-1168.

Bertness, M. D., and R. Callaway. 1994. Positive interactions in communities. Trends in Ecology \& Evolution 9:191-193.

Bertness, M. D., G. H. Leonard, J. M. Levine, P. R. Schmidt, and A. O. Ingraham. 1999. Testing the relative contribution of positive and negative interactions in rocky intertidal communities. Ecology 80:2711-2726.

Bertness, M. D., and S. W. Shumway. 1993. Competition and facilitation in marsh plants. American Naturalist 142:718-724.

Bever, J. D. 2003. Soil community feedback and the coexistence of competitors: Conceptual frameworks and empirical tests. New Phytologist 157:465473.

Blom, C., and L. Voesenek. 1996. Flooding: The survival strategies of plants. Trends in Ecology \& Evolution 11:290-295.

Bormann, F. 1966. The structure, function, and ecological significance of root grafts in pinus strobus L. Ecological Monographs 36:1-26.

Bormann, F., and B. F. Graham. 1959. The occurrence of natural root grafting in eastern white pine, pinus strobus 1., and its ecological implications. Ecology 40:677-691. 
Briggs, D. 2010. Enhancing forest value productivity through fiber quality. Journal of Forestry 108:174-182.

Briggs, D., L. Ingaramo, and E. Turnblom. 2007. Number and diameter of breast-height region branches in a douglas-fir spacing trial and linkage to $\log$ quality. Forest Products Journal 57:28.

Bruno, J. F., J. J. Stachowicz, and M. D. Bertness. 2003. Inclusion of facilitation into ecological theory. Trends in Ecology \& Evolution 18:119-125.

Burnham, K. P., and D. R. Anderson. 2003. Model selection and multimodel inference: A practical information-theoretic approach. Springer Science \& Business Media.

Butterfield, B. J. 2009. Effects of facilitation on community stability and dynamics: Synthesis and future directions. Journal of Ecology 97:11921201.

Butterfield, B. J., J. B. Bradford, C. Armas, I. Prieto, and F. I. Pugnaire. 2016. Does the stress-gradient hypothesis hold water? Disentangling spatial and temporal variation in plant effects on soil moisture in dryland systems. Functional Ecology 30:10-19.

Caldwell, M. M., T. E. Dawson, and J. H. Richards. 1998. Hydraulic lift: Consequences of water efflux from the roots of plants. Oecologia 113:151-161.

Callaway, R. M. 1998. Are positive interactions species-specific? Oikos:202207. 
Callaway, R. M. 2007. Interaction between competition and facilitation. Pages 179-254 Positive interactions and interdependence in plant communities. Springer.

Callaway, R. M., R. W. Brooker, P. Choler, Z. Kikvidze, C. J. Lortie, R. Michalet, L. Paolini, F. I. Pugnaire, B. Newingham, E. T. Aschehoug, C. Armas, D. Kikodze, and B. J. Cook. 2002. Positive interactions among alpine plants increase with stress. Nature 417:844-848.

Callaway, R. M., and L. King. 1996. Temperature-driven variation in substrate oxygenation and the balance of competition and facilitation. Ecology 77:1189-1195.

Castanho, C. d. T., and P. I. Prado. 2014. Benefit of shading by nurse plant does not change along a stress gradient in a coastal dune. Plos One 9:e105082.

Chapagain, T. R., R. P. Sharma, and S. K. Bhandari. 2014. Modeling aboveground biomass for three tropical tree species at their juvenile stage. Forest Science and Technology 10:51-60.

Choler, P., R. Michalet, and R. M. Callaway. 2001. Facilitation and competition on gradients in alpine plant communities. Ecology 82:3295-3308.

Clark, D. A., S. Brown, D. W. Kicklighter, J. Q. Chambers, J. R. Thomlinson, and J. Ni. 2001. Measuring net primary production in forests: Concepts and field methods. Ecological Applications 11:356-370.

Clark, R. B., and S. K. Zeto. 2000. Mineral acquisition by arbuscular mycorrhizal plants. Journal of Plant Nutrition 23:867-902. 
Clements, F. E. 1916. Plant succession: An analysis of the development of vegetation. Carnegie Institution of Washington.

Clewell, A., J. Aronson, and K. Winterhalder. 2002. The ser international primer on ecological restoration.

Close, D. C., K. X. Ruthrof, S. Turner, D. P. Rokich, and K. W. Dixon. 2009. Ecophysiology of species with distinct leaf morphologies: Effects of plastic and shadecloth tree guards. Restoration Ecology 17:33-41.

Connell, J. H., and R. O. Slatyer. 1977. Mechanisms of succession in natural communities and their role in community stability and organization. American Naturalist 111:1119-1144.

Cook, J., A. Mark, and B. Shore. 1980. Responses of leptospermum scoparium and 1. Ericoides (myrtaceae) to waterlogging. New Zealand journal of botany 18:233-246.

Craine, J. M., and R. Dybzinski. 2013. Mechanisms of plant competition for nutrients, water and light. Functional Ecology 27:833-840.

Drew, M. C. 1983. Plant injury and adaptation to oxygen deficiency in the root environment: A review. Plant and soil 75:179-199.

Fanal, A. 2017. Ecological restoration of wairio wetland, new zealand: Effect of flooding on woody vegetation, carbon sequestration and recommendations for future plantings. Unpublished master's thesis. 
Flores, J., and E. Jurado. 2003. Are nurse-protégé interactions more common among plants from arid environments? Journal of Vegetation Science 14:911-916.

Fortier, J., B. Truax, D. Gagnon, and F. Lambert. 2017. Allometric equations for estimating compartment biomass and stem volume in mature hybrid poplars: General or site-specific? Forests 8:309.

Franco, A., and P. Nobel. 1989. Effect of nurse plants on the microhabitat and growth of cacti. The Journal of Ecology:870-886.

Fraser, E. C., V. J. Lieffers, and S. M. Landhäusser. 2006. Carbohydrate transfer through root grafts to support shaded trees. Tree physiology 26:1019-1023.

Gambrell, R., and W. Patrick Jr. 1978. Chemical and microbiological properties of anaerobic soils and sediments. Plant life in anaerobic environments:375-423.

Gerdol, R., L. Brancaleoni, M. Menghini, and R. Marchesini. 2000. Response of dwarf shrubs to neighbour removal and nutrient addition and their influence on community structure in a subalpine heath. Journal of Ecology 88:256-266.

Gillon, A. K. 2014. Ecological restoration of wairio wetland, lake wairarapa: The response of native wetland vegetation to eutrophication and revegetation management strategies. Unpublished doctoral thesis. 
Gleason, H. A. 1926. The individualistic concept of the plant association. Bulletin of the Torrey Botanical Club:7-26.

Gomez-Aparicio, L. 2009. The role of plant interactions in the restoration of degraded ecosystems: A meta-analysis across life-forms and ecosystems. Journal of Ecology 97:1202-1214.

Gomez-Aparicio, L., R. Zamora, J. M. Gomez, J. A. Hodar, J. Castro, and E. Baraza. 2004. Applying plant facilitation to forest restoration: A metaanalysis of the use of shrubs as nurse plants. Ecological Applications 14:1128-1138.

Graham, B. F. 1960. Transfer of dye through natural root grafts of Pinus strobus L. Ecology 41:56-64.

Grime, J. P. 1973. Competitive exclusion in herbaceous vegetation. Nature 242:344-347.

Grime, J. P. 1977. Evidence for existence of three primary strategies in plants and its relevance to ecological and evolutionary theory. American Naturalist 111:1169-1194.

Hedges, L. V., J. Gurevitch, and P. S. Curtis. 1999. The meta-analysis of response ratios in experimental ecology. Ecology 80:1150-1156.

Herault, B., B. Bachelot, L. Poorter, V. Rossi, F. Bongers, J. Chave, C. Paine, F. Wagner, and C. Baraloto. 2011. Functional traits shape ontogenetic growth trajectories of rain forest tree species. Journal of Ecology 99:1431-1440. 
Holmgren, M., M. Scheffer, and M. A. Huston. 1997. The interplay of facilitation and competition in plant communities. Ecology 78:19661975.

Hunter, A., and L. Aarssen. 1988. Plants helping plants. Bioscience 38:34-40.

Huxley, J. S. 1924. Constant differential growth-ratios and their significance. Nature 114:895.

Johnson, N., J. H. Graham, and F. Smith. 1997. Functioning of mycorrhizal associations along the mutualism-parasitism continuum. New Phytologist 135:575-585.

Johnson, N. C., D. Tilman, and D. Wedin. 1992. Plant and soil controls on mycorrhizal fungal communities. Ecology 73:2034-2042.

Ketterings, Q. M., R. Coe, M. van Noordwijk, Y. Ambagau', and C. A. Palm. 2001. Reducing uncertainty in the use of allometric biomass equations for predicting above-ground tree biomass in mixed secondary forests. Forest Ecology and Management 146:199-209.

Kozak, A., and R. Kozak. 2003. Does cross validation provide additional information in the evaluation of regression models? Canadian Journal of Forest Research 33:976-987.

Kozlowski, T. T. 1984. Plant responses to flooding of soil. Bioscience 34:162167. 
Lamb, E. G., S. W. Kembel, and J. F. Cahill. 2009. Shoot, but not root, competition reduces community diversity in experimental mesocosms. Journal of Ecology 97:155-163.

Lerat, S., R. Gauci, J. G. Catford, H. Vierheilig, Y. Piché, and L. Lapointe. 2002. $14 \mathrm{c}$ transfer between the spring ephemeral erythronium americanum and sugar maple saplings via arbuscular mycorrhizal fungi in natural stands. Oecologia 132:181-187.

Lidicker, W. Z. 2008. Levels of organization in biology: On the nature and nomenclature of ecology's fourth level. Biological Reviews 83:71-78.

Lortie, C. J., R. W. Brooker, P. Choler, Z. Kikvidze, R. Michalet, F. I. Pugnaire, and R. M. Callaway. 2004. Rethinking plant community theory. Oikos 107:433-438.

Louthan, A. M., D. F. Doak, J. R. Goheen, T. M. Palmer, and R. M. Pringle. 2014. Mechanisms of plant-plant interactions: Concealment from herbivores is more important than abiotic-stress mediation in an african savannah. Proceedings of the Royal Society of London B: Biological Sciences 281:20132647.

MacArthur, R., and R. Levins. 1967. The limiting similarity, convergence, and divergence of coexisting species. The American Naturalist 101:377-385.

Maestre, F. T., R. M. Callaway, F. Valladares, and C. J. Lortie. 2009. Refining the stress-gradient hypothesis for competition and facilitation in plant communities. Journal of Ecology 97:199-205. 
Markham, J. H., and C. P. Chanway. 1996. Measuring plant neighbour effects. Functional Ecology 10:548-549.

Marschner, H., and G. Rimmington. 1988. Mineral nutrition of higher plants. Plant Cell Environ 11:147-148.

Marschner, P., and Z. Rengel. 2012. Nutrient availability in soils. Pages 315330 Marschner's mineral nutrition of higher plants (third edition). Elsevier.

Mathews, R. W., T. A. R. Jenkins, E. D. Mackie, and E. C. Dick. 2016. Forest yield: A handbook on forest growth and yield tables for british forestry. Pages 1-92 in F. Commission, editor., Edinburgh.

Mencuccini, M., J. Martínez-Vilalta, D. Vanderklein, H. Hamid, E. Korakaki, S. Lee, and B. Michiels. 2005. Size-mediated ageing reduces vigour in trees. Ecology Letters 8:1183-1190.

Menge, B. A. 2000. Testing the relative importance of positive and negative effects on community structure. Trends in Ecology \& Evolution 15:4647.

Mesquita, R. C., K. Ickes, G. Ganade, and G. B. Williamson. 2001. Alternative successional pathways in the amazon basin. Journal of Ecology 89:528537.

Michalet, R., R. W. Brooker, L. A. Cavieres, Z. Kikvidze, C. J. Lortie, F. I. Pugnaire, A. Valiente-Banuet, and R. M. Callaway. 2006. Do biotic 
interactions shape both sides of the humped-back model of species richness in plant communities? Ecology Letters 9:767-773.

Mitsch, W. J., and J. G. Gosselink. 2007. Wetlands. John Willey \& Sons Inc. NY. USA.

Mougi, A., and M. Kondoh. 2012. Diversity of interaction types and ecological community stability. Science 337:349-351.

Nam, V. T., M. van Kuijk, and N. P. R. Anten. 2016. Allometric equations for aboveground and belowground biomass estimations in an evergreen forest in vietnam. PLoS One 11:e0156827.

Paterno, G. B., J. A. Siqueira, and G. Ganade. 2016. Species-specific facilitation, ontogenetic shifts and consequences for plant community succession. Journal of Vegetation Science 27:606-615.

Paul, K. I., S. H. Roxburgh, J. R. England, P. Ritson, T. Hobbs, K. Brooksbank, R. J. Raison, J. S. Larmour, S. Murphy, and J. Norris. 2013. Development and testing of allometric equations for estimating above-ground biomass of mixed-species environmental plantings. Forest Ecology and Management 310:483-494.

Peltzer, D. A., and M. Köchy. 2001. Competitive effects of grasses and woody plants in mixed-grass prairie. Journal of Ecology 89:519-527.

Pfeffer, P. E., D. D. Douds, G. Bécard, and Y. Shachar-Hill. 1999. Carbon uptake and the metabolism and transport of lipids in an arbuscular mycorrhiza. Plant Physiology 120:587-598. 
Picard, N., L. Saint-André, and M. Henry. 2012. Manual for building tree volume and biomass allometric equations: From field measurement to prediction., FAO; Food and Agricultural Organization of the United Nations (2012).

Pringle, E. G. 2016. Orienting the interaction compass: Resource availability as a major driver of context dependence. PLoS biology 14:e2000891.

R Development Core Team. 2015. R: A language and environment for statistical computing. R Foundation for Statistical Computing, Vienna, Austria.

Robertson, H. A. 2016. Wetland reserves in new zealand: The status of protected areas between 1990 and 2013. New Zealand Journal of Ecology 40:1-11.

Rodriguez-Echeverria, S., C. Armas, N. Piston, S. Hortal, and F. I. Pugnaire. 2013. A role for below-ground biota in plant-plant facilitation. Journal of Ecology 101:1420-1428.

Rodriguez-Echeverria, S., Y. M. Lozano, and R. D. Bardgett. 2016. Influence of soil microbiota in nurse plant systems. Functional Ecology 30:30-40.

Rozendaal, D. M., H. J. During, F. J. Sterck, D. Asscheman, J. Wiegeraad, and P. A. Zuidema. 2015. Long-term growth patterns of juvenile trees from a bolivian tropical moist forest: Shifting investments in diameter growth and height growth. Journal of Tropical Ecology 31:519-529. 
Sato, T., M. Saito, D. Ramirez, L. F. P. DE MOLAS, J. Toriyama, Y. Monda, Y. Kiyono, E. Herebia, N. Dubie, and E. D. VERA. 2015. Development of allometric equations for tree biomass in forest ecosystems in Paraguay. Japan Agricultural Research Quarterly: JARQ 49:281-291.

Sieber, Y., R. Holderegger, N. M. Waser, V. F. Thomas, S. Braun, A. Erhardt, H.-U. Reyer, and L. R. Wirth. 2011. Do alpine plants facilitate each other's pollination? Experiments at a small spatial scale. Acta oecologica 37:369-374.

Simard, S. W., K. J. Beiler, M. A. Bingham, J. R. Deslippe, L. J. Philip, and F. P. Teste. 2012. Mycorrhizal networks: Mechanisms, ecology and modelling. Fungal Biology Reviews 26:39-60.

Smith, S. E., and D. J. Read. 2010. Mycorrhizal symbiosis. Academic Press.

Sprugel, D. 1983. Correcting for bias in log-transformed allometric equations. Ecology 64:209-210.

Stankova, T., V. Gyuleva, E. Popov, K. Velinova, E. Velizarova, D. N. Dimitrov, K. Kalmukov, M. Glushkova, P. Dimitrova, and H. Hristova. 2015. Allometric relationships for aboveground biomass of juvenile black poplar hybrids. Silva Balcanica 16:5-28.

Stephens, J., P. C. Molan, and B. D. Clarkson. 2005. A review of Leptospermum Scoparium (myrtaceae) in New Zealand. New Zealand Journal of Botany 43:431-449. 
Sthultz, C. M., C. A. Gehring, and T. G. Whitham. 2007. Shifts from competition to facilitation between a foundation tree and a pioneer shrub across spatial and temporal scales in a semiarid woodland. New Phytologist 173:135-145.

Sullivan, M. J., S. L. Lewis, W. Hubau, L. Qie, T. R. Baker, L. F. Banin, J. Chave, A. Cuni Sanchez, T. R. Feldpausch, and G. Lopez-Gonzalez. 2018. Field methods for sampling tree height for tropical forest biomass estimation. Methods in Ecology and Evolution.

Tarroux, E., and A. Desrochers. 2010. Frequency of root grafting in naturally and artificially regenerated stands of pinus banksiana: Influence of site characteristics.

Tarroux, E., and A. DesRochers. 2011. Effect of natural root grafting on growth response of jack pine (pinus banksiana; pinaceae). American Journal of botany 98:967-974.

Tewksbury, J. J., and J. D. Lloyd. 2001. Positive interactions under nurseplants: Spatial scale, stress gradients and benefactor size. Oecologia 127:425-434.

Tielbörger, K., and R. Kadmon. 2000. Temporal environmental variation tips the balance between facilitation and interference in desert plants. Ecology 81:1544-1553.

Tilman, D. 1982. Resource competition and community structure. Princeton university press. 
Truax, B., D. Gagnon, J. Fortier, and F. Lambert. 2014. Biomass and volume yield in mature hybrid poplar plantations on temperate abandoned farmland. Forests 5:3107-3130.

Vetaas, O. R. 1992. Micro-site effects of trees and shrubs in dry savannas. Journal of Vegetation Science 3:337-344.

Visser, E., L. Voesenek, B. Vartapetian, and M. Jackson. 2003. Flooding and plant growth. Annals of Botany 91:107-109.

Walker, L. R., J. Walker, and R. J. Hobbs. 2007. Linking restoration and ecological succession. Springer.

Wang, B., M. Li, W. Fan, Y. Yu, and J. M. Chen. 2018. Relationship between net primary productivity and forest stand age under different site conditions and its implications for regional carbon cycle study. Forests 9:5.

Waring, S. 2017. The factors that influence the reestablishment of Podocarpus Totara (totara) and Dacrycarpus dacrydioides (kahikatea) in a freshwater new zealand wetland. Unpublished master's thesis. Victoria University of Wellington

Whittaker, R. H. 1956. Vegetation of the great smoky mountains. Ecological Monographs 26:1-69.

Wilson, S. D., and P. A. Keddy. 1986. Measuring diffuse competition along an environmental gradient: Results from a shoreline plant community. The American Naturalist 127:862-869. 
Zedler, J. B., and S. Kercher. 2005. Wetland resources: Status, trends, ecosystem services, and restorability. Annu. Rev. Environ. Resour. 30:3974.

Zhang, W. P., X. Jia, C. Damgaard, E. C. Morris, Y. Y. Bai, S. Pan, and G. X. Wang. 2013. The interplay between above- and below-ground plant-plant interactions along an environmental gradient: Insights from two-layer zone-of-influence models. Oikos 122:1147-1156.

Zhou, X., C. Peng, and Q.-L. Dang. 2006. Formulating and parameterizing the allocation of net primary productivity for modeling overmature stands in boreal forest ecosystems. Ecological Modelling 195:264-272.

Zou, C., P. Barnes, S. Archer, and C. McMurtry. 2005. Soil moisture redistribution as a mechanism of facilitation in savanna tree-shrub clusters. Oecologia 145:32-40. 